\title{
Psychological therapies for the treatment of post-traumatic stress disorder in children and adolescents (Review)
}

Gillies D, Taylor F, Gray C, O'Brien L, D'Abrew N

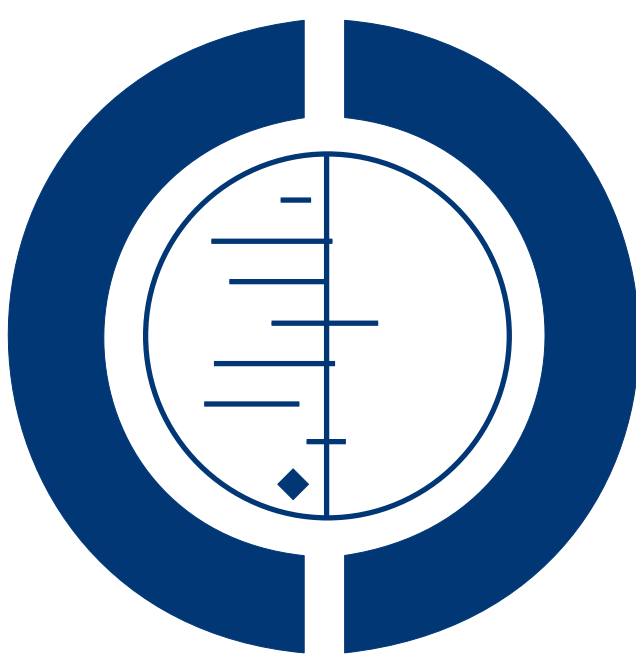

\section{THE COCHRANE COLLABORATION $^{\circledR}$}

This is a reprint of a Cochrane review, prepared and maintained by The Cochrane Collaboration and published in The Cochrane Library 2012, Issue 12

http://www.thecochranelibrary.com

\section{WILEY}

Psychological therapies for the treatment of post-traumatic stress disorder in children and adolescents (Review)

Copyright @ 2012 The Cochrane Collaboration. Published by John Wiley \& Sons, Ltd. 
TABLE OF CONTENTS

HEADER . . . . . . . . . . . . . . . . . . . . . . . . . . . . . . . . . . . . . . . . . . . . . . . . . . . . .

ABSTRACT . . . . . . . . . . . . . . . . . . . . . . . . . . . . . . . . . . . . . . . . . . . . . . . . . . . . .

PLAIN LANGUAGE SUMMARY . . . . . . . . . . . . . . . . . . . . . . . . . . . . . . . . . . . . . . . . . . . .

BACKGROUND . . . . . . . . . . . . . . . . . . . . . . . . . . . . . . . . . . . . . 3

OBJECTIVES . . . . . . . . . . . . . . . . . . . . . . . . . . . . . . . . . . . . . . . . . . . . . . . . . . . . .

METHODS . . . . . . . . . . . . . . . . . . . . . . . . . . . . . . . . . . . . . . 4

RESUlTS . . . . . . . . . . . . . . . . . . . . . . . . . . . . . . . . . . . . . . . . . . . . . . . . .

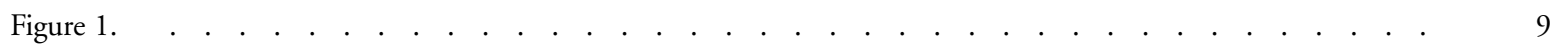

Figure 2. . . . . . . . . . . . . . . . . . . . . . . . . . . . . . . . . . . . . . . .

DISCUSSION . . . . . . . . . . . . . . . . . . . . . . . . . . . . . . . . . . . . . . . . . . . .

AUTHORS' CONCLUSIONS . . . . . . . . . . . . . . . . . . . . . . . . . . . . . . . . . . . . . . . .

ACKNOWLEDGEMENTS . . . . . . . . . . . . . . . . . . . . . . . . . . . . . . . . . . . . . . . . . . .

REFERENCES . . . . . . . . . . . . . . . . . . . . . . . . . . . . . . . . . . . . . . . . . . . . . .

CHARACTERISTICS OF STUDIES . . . . . . . . . . . . . . . . . . . . . . . . . . . . . . . . . . . . . . . . . . . .

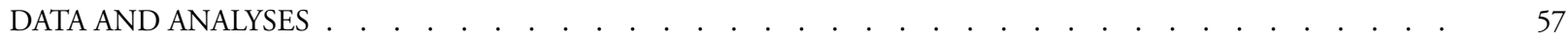

Analysis 1.1. Comparison 1 All psychological therapies versus control, Outcome 1 Improvement. . . . . . . . . 63

Analysis 1.2. Comparison 1 All psychological therapies versus control, Outcome 2 PTSD total. . . . . . . . . . 64

Analysis 1.3. Comparison 1 All psychological therapies versus control, Outcome 3 Anxiety. . . . . . . . . . . 65

Analysis 1.4. Comparison 1 All psychological therapies versus control, Outcome 4 Depression. . . . . . . . . . 66

Analysis 1.5. Comparison 1 All psychological therapies versus control, Outcome 5 Loss to follow-up. . . . . . . . 67

Analysis 2.1. Comparison 2 CBT versus control, Outcome 1 Improvement. . . . . . . . . . . . . . . . . . . 68

Analysis 2.2. Comparison 2 CBT versus control, Outcome 2 PTSD total. . . . . . . . . . . . . . . . . . . . . . . 69

Analysis 2.3. Comparison 2 CBT versus control, Outcome 3 PTSD avoidance. . . . . . . . . . . . . . . . . . . . . 70

Analysis 2.4. Comparison 2 CBT versus control, Outcome 4 PTSD hyperarousal. . . . . . . . . . . . . . . . . . 70

Analysis 2.5. Comparison 2 CBT versus control, Outcome 5 PTSD re-experiencing. . . . . . . . . . . . . . . 71

Analysis 2.6. Comparison 2 CBT versus control, Outcome 6 Anxiety. . . . . . . . . . . . . . . . . . . . . . . . 72

Analysis 2.7. Comparison 2 CBT versus control, Outcome 7 Depression. $\quad . \quad$. . . . . . . . . . . . . . . . . . . . . 73

Analysis 2.8. Comparison 2 CBT versus control, Outcome 8 Loss to follow-up. . . . . . . . . . . . . . . . . . 74

Analysis 3.1. Comparison 3 Narrative versus control, Outcome 1 Improvement. . . . . . . . . . . . . . . . 74

Analysis 3.2. Comparison 3 Narrative versus control, Outcome 2 PTSD total. . . . . . . . . . . . . . . . . . . . . 75

Analysis 3.3. Comparison 3 Narrative versus control, Outcome 3 PTSD avoidance. . . . . . . . . . . . . . . . . . . 76

Analysis 3.4. Comparison 3 Narrative versus control, Outcome 4 PTSD hyperarousal. . . . . . . . . . . . . . . . 76

Analysis 3.5. Comparison 3 Narrative versus control, Outcome 5 PTSD re-experiencing. . . . . . . . . . . . . . . 77

Analysis 3.6. Comparison 3 Narrative versus control, Outcome 6 Depression. . . . . . . . . . . . . . . . . . . . . 77

Analysis 3.7. Comparison 3 Narrative versus control, Outcome 7 Loss to follow-up. . . . . . . . . . . . . . . . . 78

Analysis 4.1. Comparison 4 EMDR versus control, Outcome 1 PTSD. . . . . . . . . . . . . . . . . . . . . . . . . 79

Analysis 4.2. Comparison 4 EMDR versus control, Outcome 2 PTSD avoidance. $\quad . \quad$. . . . . . . . . . . . . . . 79

Analysis 4.3. Comparison 4 EMDR versus control, Outcome 3 PTSD hyperarousal. . . . . . . . . . . . . . . . . . $\quad 80$

Analysis 4.4. Comparison 4 EMDR versus control, Outcome 4 PTSD re-experiencing. . . . . . . . . . . . . . . . . 80

Analysis 4.5. Comparison 4 EMDR versus control, Outcome 5 Anxiety. . . . . . . . . . . . . . . . . . . . . . . 81

Analysis 4.6. Comparison 4 EMDR versus control, Outcome 6 Depression. $\quad . \quad$. . . . . . . . . . . . . . . . . . . $\quad 81$

Analysis 4.7. Comparison 4 EMDR versus control, Outcome 7 Loss to follow-up. . . . . . . . . . . . . . . . . $\quad$. 82

Analysis 5.1. Comparison 5 Other psychological therapies versus control, Outcome 1 PTSD total. . . . . . . . . . $\quad 82$

Analysis 5.2. Comparison 5 Other psychological therapies versus control, Outcome 2 PTSD avoidance. . . . . . . . $\quad 83$

Analysis 5.3. Comparison 5 Other psychological therapies versus control, Outcome 3 PTSD hyperarousal. . . . . . 83

Analysis 5.4. Comparison 5 Other psychological therapies versus control, Outcome 4 PTSD re-experiencing. . . . . 84

Analysis 5.5. Comparison 5 Other psychological therapies versus control, Outcome 5 Depression. . . . . . . . . 84

Analysis 5.6. Comparison 5 Other psychological therapies versus control, Outcome 6 Loss to follow-up. . . . . . . 85

Analysis 6.1. Comparison 6 CBT versus supportive counselling, Outcome 1 Improvement. . . . . . . . . . . . . $\quad$. 86

Analysis 6.2. Comparison 6 CBT versus supportive counselling, Outcome 2 PTSD avoidance. . . . . . . . . . . . . $\quad$. 87

Analysis 6.3. Comparison 6 CBT versus supportive counselling, Outcome 3 PTSD hyperarousal. $\quad . \quad$. . . . . $\quad . \quad$. $\quad$. $\quad 87$

Psychological therapies for the treatment of post-traumatic stress disorder in children and adolescents (Review)

Copyright @ 2012 The Cochrane Collaboration. Published by John Wiley \& Sons, Ltd. 
Analysis 6.4. Comparison 6 CBT versus supportive counselling, Outcome 4 PTSD re-experiencing. $\quad . \quad$. . . . $\quad . \quad$. 88

Analysis 6.5. Comparison 6 CBT versus supportive counselling, Outcome 5 Anxiety state. . . . . . . . . . . . . . . 89

Analysis 6.6. Comparison 6 CBT versus supportive counselling, Outcome 6 Anxiety trait. . . . . . . . . . . . . . . 90

Analysis 6.7. Comparison 6 CBT versus supportive counselling, Outcome 7 Depression. . . . . . . . . . . . . . . . 90

Analysis 6.8. Comparison 6 CBT versus supportive counselling, Outcome 8 Behaviour. . . . . . . . . . . . . . . 91

Analysis 6.9. Comparison 6 CBT versus supportive counselling, Outcome 9 Loss to follow-up. . . . . . . . . . . . 92

Analysis 7.1. Comparison 7 Narrative versus supportive counselling, Outcome 1 Improvement. . . . . . . . . . . . 92

Analysis 7.2. Comparison 7 Narrative versus supportive counselling, Outcome 2 PTSD total. . . . . . . . . . . . 93

Analysis 7.3. Comparison 7 Narrative versus supportive counselling, Outcome 3 Depression. . . . . . . . . . . . 93

Analysis 7.4. Comparison 7 Narrative versus supportive counselling, Outcome 4 Loss to follow-up. . . . . . . . . 94

Analysis 8.1. Comparison 8 Narrative versus meditation/relaxation, Outcome 1 Improvement. . . . . . . . . . . . 95

Analysis 8.2. Comparison 8 Narrative versus meditation/relaxation, Outcome 2 PTSD total. . . . . . . . . . . . 96

Analysis 8.3. Comparison 8 Narrative versus meditation/relaxation, Outcome 3 Loss to follow-up. . . . . . . . .97

Analysis 9.1. Comparison 9 Exposure versus interpersonal therapy, Outcome 1 Improvement. . . . . . . . . . . . . 98

Analysis 9.2. Comparison 9 Exposure versus interpersonal therapy, Outcome 2 PTSD total. . . . . . . . . . . . . 98

Analysis 9.3. Comparison 9 Exposure versus interpersonal therapy, Outcome 3 Depression. . . . . . . . . . . . . 99

Analysis 9.4. Comparison 9 Exposure versus interpersonal therapy, Outcome 4 Loss to follow-up. . . . . . . . . 99

Analysis 10.1. Comparison 10 Sensitivity analysis: types of therapy, Outcome 1 Improvement. . . . . . . . . . 100

Analysis 10.2. Comparison 10 Sensitivity analysis: types of therapy, Outcome 2 PTSD total. . . . . . . . . . . . 101

Analysis 11.1. Comparison 11 Sensitivity analysis: types of trauma, Outcome 1 Improvement. . . . . . . . . . 102

Analysis 11.2. Comparison 11 Sensitivity analysis: types of trauma, Outcome 2 PTSD total. . . . . . . . . . . . 103

Analysis 12.1. Comparison 12 Sensitivity analysis: allocation concealment, Outcome 1 PTSD total. . . . . . . 104

Analysis 13.1. Comparison 13 Sensitivity analysis: blinding, Outcome 1 Improvement. . . . . . . . . . . . 105

Analysis 13.2. Comparison 13 Sensitivity analysis: blinding, Outcome 2 PTSD total. . . . . . . . . . . . . . . 106

Analysis 14.1. Comparison 14 Sensitivity analysis: skewed and non-skewed data, Outcome 1 PTSD total. $\quad . \quad$. $\quad . \quad 107$

Analysis 15.1. Comparison 15 ITT analysis, Outcome 1 Improvement. . . . . . . . . . . . . . . . . 108

HISTORY . . . . . . . . . . . . . . . . . . . . . . . . . . . . . . . . . . . . . . . 108

CONTRIBUTIONS OF AUTHORS . . . . . . . . . . . . . . . . . . . . . . . . . . . . . . . . . . . . . . . . 108

DECLARATIONS OF INTEREST . . . . . . . . . . . . . . . . . . . . . . . . . . . . . . . . . . . . . . . . . . .

SOURCES OF SUPPORT . . . . . . . . . . . . . . . . . . . . . . . . . . . . . . . . . . . . . . . . . . . . . . . . . .

DIFFERENCES BETWEEN PROTOCOL AND REVIEW . . . . . . . . . . . . . . . . . . . . . . . . . . . . . . 109

INDEX TERMS . . . . . . . . . . . . . . . . . . . . . . . . . . . . . . . . . . . . . . . . . . . . . . . 110

Psychological therapies for the treatment of post-traumatic stress disorder in children and adolescents (Review) 


\title{
[Intervention Review] \\ Psychological therapies for the treatment of post-traumatic stress disorder in children and adolescents
}

\author{
Donna Gillies ${ }^{1}$, Fiona Taylor ${ }^{2}$, Carl Gray ${ }^{3}$, Louise O’Brien ${ }^{4}$, Natalie D’Abrew ${ }^{5}$ \\ ${ }^{1}$ Western Sydney and Nepean Blue Mountains Local Health Districts - Mental Health, Parramatta, Australia. ${ }^{2}$ Prevention, Early \\ Intervention and Recovery Service, Sydney West Area Mental Health Service, Parramatta, Australia. ${ }^{3}$ Department of Child and \\ Adolescent Psychiatry, Western Sydney Local Health Network, New South Wales Health Service, Westmead, Australia. ${ }^{4}$ School of \\ Nursing and Midwifery, University of Newcastle and Greater Western Area Health Service, New South Wales Health Service, Orange, \\ Australia. ${ }^{5}$ Cancer Nursing Research Unit, Sydney School of Nursing, University of Sydney and Sydney Cancer Centre, Royal Prince \\ Alfred Hospital, Camperdown, Australia \\ Contact address: Donna Gillies, Western Sydney and Nepean Blue Mountains Local Health Districts - Mental Health, Cumberland \\ Hospital, Locked Bag 7118, Parramatta, NSW, 2150, Australia. Donna_Gillies@wsahs.nsw.gov.au.
}

Editorial group: Cochrane Common Mental Disorders Group.

Publication status and date: New, published in Issue 12, 2012.

Review content assessed as up-to-date: 30 December 2011.

Citation: Gillies D, Taylor F, Gray C, O'Brien L, D'Abrew N. Psychological therapies for the treatment of post-traumatic stress disorder in children and adolescents. Cochrane Database of Systematic Reviews 2012, Issue 12. Art. No.: CD006726. DOI: 10.1002/14651858.CD006726.pub2.

Copyright (C) 2012 The Cochrane Collaboration. Published by John Wiley \& Sons, Ltd.

\begin{abstract}
A B S T R AC T
Background

Post-traumatic stress disorder (PTSD) is highly prevalent in children and adolescents who have experienced trauma and has high personal and health costs. Although a wide range of psychological therapies have been used in the treatment of PTSD there are no systematic reviews of these therapies in children and adolescents.
\end{abstract}

\section{Objectives}

To examine the effectiveness of psychological therapies in treating children and adolescents who have been diagnosed with PTSD.

Search methods

We searched the Cochrane Depression, Anxiety and Neurosis Review Group's Specialised Register (CCDANCTR) to December 2011. The CCDANCTR includes relevant randomised controlled trials from the following bibliographic databases: CENTRAL (the Cochrane Central Register of Controlled Trials) (all years), EMBASE (1974 -), MEDLINE (1950 -) and PsycINFO (1967 -). We also checked reference lists of relevant studies and reviews. We applied no date or language restrictions.

\section{Selection criteria}

All randomised controlled trials of psychological therapies compared to a control, pharmacological therapy or other treatments in children or adolescents exposed to a traumatic event or diagnosed with PTSD.

\section{Data collection and analysis}

Two members of the review group independently extracted data. If differences were identified, they were resolved by consensus, or referral to the review team.

We calculated the odds ratio (OR) for binary outcomes, the standardised mean difference (SMD) for continuous outcomes, and $95 \%$ confidence intervals (CI) for both, using a fixed-effect model. If heterogeneity was found we used a random-effects model.

Psychological therapies for the treatment of post-traumatic stress disorder in children and adolescents (Review)

Copyright @ 2012 The Cochrane Collaboration. Published by John Wiley \& Sons, Ltd. 


\section{Main results}

Fourteen studies including 758 participants were included in this review. The types of trauma participants had been exposed to included sexual abuse, civil violence, natural disaster, domestic violence and motor vehicle accidents. Most participants were clients of a traumarelated support service.

The psychological therapies used in these studies were cognitive behavioural therapy (CBT), exposure-based, psychodynamic, narrative, supportive counselling, and eye movement desensitisation and reprocessing (EMDR). Most compared a psychological therapy to a control group. No study compared psychological therapies to pharmacological therapies alone or as an adjunct to a psychological therapy.

Across all psychological therapies, improvement was significantly better (three studies, $\mathrm{n}=80$, OR 4.21, 95\% CI 1.12 to 15.85 ) and symptoms of PTSD (seven studies, $\mathrm{n}=271$, SMD $-0.90,95 \% \mathrm{CI}-1.24$ to -0.42 ), anxiety (three studies, $\mathrm{n}=91, \mathrm{SMD}-0.57,95 \% \mathrm{CI}$ -1.00 to -0.13 ) and depression (five studies, $\mathrm{n}=156$, SMD $-0.74,95 \% \mathrm{CI}-1.11$ to -0.36 ) were significantly lower within a month of completing psychological therapy compared to a control group.

The psychological therapy for which there was the best evidence of effectiveness was CBT. Improvement was significantly better for up to a year following treatment (up to one month: two studies, $\mathrm{n}=49$, OR 8.64, 95\% CI 2.01 to 37.14; up to one year: one study, $\mathrm{n}=25$, OR $8.00,95 \%$ CI 1.21 to 52.69). PTSD symptom scores were also significantly lower for up to one year (up to one month: three studies, $\mathrm{n}=98$, SMD $-1.34,95 \% \mathrm{CI}-1.79$ to -0.89 ; up to one year: one study, $\mathrm{n}=36$, SMD $-0.73,95 \%$ CI -1.44 to -0.01 ), and depression scores were lower for up to a month (three studies, $\mathrm{n}=98, \mathrm{SMD}-0.80,95 \% \mathrm{CI}-1.47$ to -0.13 ) in the CBT group compared to a control. No adverse effects were identified.

No study was rated as a high risk for selection or detection bias but a minority were rated as a high risk for attrition, reporting and other bias. Most included studies were rated as an unclear risk for selection, detection and attrition bias.

\section{Authors' conclusions}

There is evidence for the effectiveness of psychological therapies, particularly CBT, for treating PTSD in children and adolescents for up to a month following treatment. At this stage, there is no clear evidence for the effectiveness of one psychological therapy compared to others. There is also not enough evidence to conclude that children and adolescents with particular types of trauma are more or less likely to respond to psychological therapies than others.

The findings of this review are limited by the potential for methodological biases, and the small number and generally small size of identified studies. In addition, there was evidence of substantial heterogeneity in some analyses which could not be explained by subgroup or sensitivity analyses.

More evidence is required for the effectiveness of all psychological therapies more than one month after treatment. Much more evidence is needed to demonstrate the relative effectiveness of different psychological therapies or the effectiveness of psychological therapies compared to other treatments. More details are required in future trials in regards to the types of trauma that preceded the diagnosis of PTSD and whether the traumas are single event or ongoing. Future studies should also aim to identify the most valid and reliable measures of PTSD symptoms and ensure that all scores, total and sub-scores, are consistently reported.

\section{PLAIN LANGUAGESUMMARY}

\section{Psychological therapies for the treatment of post-traumatic stress disorder in children and adolescents}

Post-traumatic stress disorder (PTSD) is highly prevalent in children and adolescents who have experienced trauma and has high personal and health costs. The aim of this review was to examine the effectiveness of all psychological therapies for the treatment of PTSD in children and adolescents.

We searched for all randomised controlled trials comparing psychological therapies to a control, other psychological therapies or other therapies for the treatment of PTSD in children and adolescents aged 3 to 18 years. We identified 14 studies with a total of 758 participants. The types of trauma related to the PTSD were sexual abuse, civil violence, natural disaster, domestic violence and motor vehicle accidents. Most participants were clients of a trauma-related support service.

The psychological therapies used in the included studies were cognitive behavioural therapy (CBT), exposure-based, psychodynamic, narrative, supportive counselling, and eye movement desensitisation and reprocessing (EMDR). Most included studies compared a

Psychological therapies for the treatment of post-traumatic stress disorder in children and adolescents (Review)

Copyright @ 2012 The Cochrane Collaboration. Published by John Wiley \& Sons, Ltd. 
psychological therapy to a control group. No study compared psychological therapies to medications or medications in combination with a psychological therapy.

There was fair evidence for the effectiveness of psychological therapies, particularly CBT, for the treatment of PTSD in children and adolescents for up to a month following treatment. More evidence is required for the effectiveness of psychological therapies in the longer term and to be able to compare the effectiveness of one psychological therapy to another.

The findings of this review are limited by the potential for bias in the included studies, possible differences between studies which could not be identified, the small number of identified studies and the low number of participants in most studies.

\section{B A C K G R O U N D}

\section{Description of the condition}

Post-traumatic stress disorder (PTSD) is the development of characteristic symptoms following exposure to an extreme traumatic event. The characteristic symptoms of PTSD are re-experiencing the trauma, avoidance of stimuli associated with the trauma, and increased arousal (APA 2000; WHO 1990). Developmental factors can play a strong role in the presentation of PTSD (AACAP 1998; Carr 2004; Yule 1994). Children and adolescents may display symptoms of PTSD which are not seen in adults, such as behavioural problems, developmental regression, physical symptoms and more generalised fears (APA 2000; Schwarz 1994; Yule 2001). Under the Fourth Edition Diagnostic and Statistical Manual of Mental Disorders text revision (DSM-IV-TR) criteria for a PTSD diagnosis, symptoms must be present for at least a month and cause clinically significant distress or impairment in social, occupational or other important areas of functioning (APA 2000). However, these criteria may require amendment for the diagnosis of PTSD in young children (AACAP 2010; Scheeringa 1995). The types of traumatic events that may cause PTSD include natural and man-made disasters, war, physical or sexual abuse, violence to self or others, exposure to suicidal acts, serious injury and lifethreatening illness such as cancer or severe burns (AACAP 1998; APA 2000; Parry-Jones 1995).

Post-traumatic stress disorder has a high prevalence and results in high personal and public health costs (Vickers 2005). Social and welfare costs for severe stress and PTSD were estimated to have been GBP 103,000,000 in the UK between 2003 and 2004 (NICE 2005). Although personal cost has not been quantified, multiple studies have noted the co-morbidity between PTSD and other psychiatric disorders, including depression and anxiety disorders, externalising disorders and substance use (APA 2000; Donnelly 2002; Perrin 2000; WHO 1990). In addition, anxiety and depression associated with PTSD are commonly associated with suicidal ideation (AACAP 1998; Donnelly 2002; WHO 1990). It is im- portant, therefore, that negative outcomes such as emotional distress or mental health problems associated with PTSD are reduced in children diagnosed with PTSD.

Estimates of the prevalence of PTSD in children and adolescents who have experienced trauma vary widely. Estimates ranging from $2 \%$ to $100 \%$ have been cited in reviews of the literature, although most estimates are around 30\% to 40\% (AACAP 1998; Fletcher 2003; McNally 1996; Saigh 1996). This is consistent with an estimated prevalence of $36 \%$ based on a meta-analysis of 34 studies of 2697 children and adolescents who had been exposed to traumatic events (Fletcher 2003). The prevalence of PTSD appears to vary with a number of factors such as the gender and age of the child or adolescent, type of trauma, frequency and severity of exposure, and the amount of time since the traumatic event (Carr 2004; Donnelly 2002; Fletcher 2003; Foy 1996; Terr 1991; Yule 1994). Children and adolescents who have undergone complex trauma defined by repeated or chronic trauma, which is often of an interpersonal nature and begins early in life (Spinazzola 2005), may demonstrate different responses to children and adolescents who have undergone other forms of trauma (Ford 2009; van der Kolk 2005) and therefore may respond differently to different therapies for PTSD (Amaya-Jackson 2007).

\section{Description of the intervention}

Most of the literature for the effectiveness of psychological treatments for PTSD is based on preventive therapies in children and adolescents who have experienced trauma rather than the treatment of PTSD (e.g. Carr 2004; Fletcher 2003; Yule 1994; Yule 2001). A number of trauma-specific and generic psychological therapy approaches have been used in the treatment of PTSD for children and adolescents. Cognitive behavioural therapy (CBT) challenges the distorted, negative thinking patterns associated with the trauma in order to help people develop more adaptive cognitions and behaviours (Robertson 2004; Sones 2011). Because people who have undergone trauma often have impaired social and interpersonal responses, interpersonal therapy is used to im- 
prove their social and interpersonal function (Robertson 2004). The aim of exposure therapy is to help patients overcome PTSD symptoms through exposure to specific or non-specific cues or memories related to the trauma (Neuner 2004; Robertson 2004). Because the fragmentation and distortion of memories and cognitions associated with trauma are thought to prevent symptom resolution, narrative therapy is used to help someone reconstruct a consistent narrative about the trauma (Neuner 2004). In psychodynamic psychotherapy an individual works with a therapist to develop a better understanding of their responses to the trauma and how it impacts on their feelings, behaviour and relationships (AACAP 2010; BluePages 2012; Foa 1997). In eye movement desensitisation and reprocessing (EMDR) the individual focuses on a disturbing image, memory, emotion or cognition associated with the trauma while the therapist initiates rapid voluntary eye movements (Bryant 2001; Robertson 2004). Other therapies include supportive counselling where counsellors give support, listen to people and help them talk over their problems (BluePages 2012). The major alternative to psychological therapies is pharmacological treatments (AACAP 1998; Donnelly 2002) but at the present time there is not enough evidence to recommend their use for the treatment of PTSD in children and adolescents, either as an alternative or adjunct treatment (NICE 2005). Other alternative treatments include relaxation, massage, hypnosis, attention control and behaviour reinforcement (AACAP 1998; Perrin 2000).

\section{How the intervention might work}

Despite the number of trauma therapy models, they are frequently difficult to characterise as a singular therapy as most include common elements. These may include psychoeducation elements which may help the traumatised child or adolescent to normalise PTSD reactions, psychodynamic elements which can help them to emotionally process the trauma and gain a better understanding of its meaning to them, exposure elements to desensitise them to trauma-related memories, cognitive behavioural elements to help them rethink assumptions and reactions to the traumatic event, and coping skills such as problem-solving, safety planning and anxiety management (AACAP 2010; Carr 2004; Robertson 2004; Sones 2011). Inclusion of the parent may enhance the effectiveness of these therapies with children and adolescents by improving parental recognition of trauma symptoms, their ability to help with their child's emotional distress and management of related behaviour problems (AACAP 2010).

\section{Why it is important to do this review}

This systematic review on the effectiveness of psychological therapies for the treatment of PTSD in children and adolescents is needed as a systematic review and meta-analysis of this topic has not yet been done. A review of psychological therapies for PTSD in adults published in The Cochrane Library (Bisson 2007) found that individual trauma-focused CBT and stress management were effective in the treatment of PTSD. However, the findings of this review may not readily extend to children.

\section{O B JE C T IVES}

To examine the effectiveness of psychological therapies in reducing PTSD and its associated negative emotional, behavioural and mental health outcomes in children and adolescents diagnosed with PTSD.

\section{METHODS}

\section{Criteria for considering studies for this review}

\section{Types of studies}

All relevant parallel, cross-over and cluster-randomised and quasirandomised controlled trials. Quasi-randomised studies included studies that used allocation methods with no apparent association with participant characteristics. For example, allocation based on the last number of medical identifier numbers or last number of the date of birth could be included.

\section{Types of participants}

Children or adolescents, aged 3 to 18 years, diagnosed with posttraumatic stress disorder (PTSD). PTSD was defined as a clinician diagnosis based on DSM-III, III-R, IV or IV-TR or International Classification of Diseases (ICD-10) criteria or other validated scales for PTSD based on these criteria. Children with comorbid conditions such as depression, substance abuse or behavioural disorders were included.

\section{Types of interventions}

\section{Experimental intervention}

- All psychological therapies including but not restricted to: cognitive behavioural therapy (CBT), exposure-based therapy, psychodynamic therapy, narrative therapy, supportive counselling, family-based therapy and EMDR 


\section{Comparator intervention}

- Control (treatment as usual, waiting list controls or no treatment)

- Another psychological therapy

- Pharmacological therapy

- Other treatments

\section{Types of outcome measures}

\section{Primary outcomes}

1. Improvement from a diagnosis of post-traumatic stress disorder determined by accepted clinical diagnostic criteria such as the ICD-10 or DSM-IV TR.

2. PTSD symptoms measured using scales which are based on diagnostic criteria such as the ICD-10 or DSM-IV-TR and have published reliability and validity, e.g. the Children's PTSD Inventory (Saigh 2000).

\section{Secondary outcomes}

3. Quality of life, e.g. Pediatric Quality of Life Inventory Version 4.0 (Varni 2001).

4. Severity or incidence of depressive symptoms, e.g. Children's Depression Inventory (Kovacs 1992).

5. Severity or incidence of anxiety symptoms, e.g. State-Trait Anxiety Inventory for Children (Spielberger 1973).

6. Severity or incidence of behavioural problems, e.g. Child Behavior Checklist (Achenbach 1983).

7. Any adverse events including self harm or suicidal behaviour.

8. Loss to follow-up.

9. Cost.

\section{Outcome scales}

Improvement from a previous diagnosis of PTSD would only be included if the clinician making the diagnosis was blinded to the participant's treatment group membership or it was not clear whether they were blinded. However, no study reported that improvement was determined by an unblinded rater. Other outcome data were only included if the scale or questionnaire had been reported to be valid and reliable in a peer-reviewed journal.

\section{Search methods for identification of studies}

\section{CCDAN's Specialised Register (CCDANCTR)}

The Cochrane Depression, Anxiety and Neurosis Group (CCDAN) maintain two clinical trials registers at their editorial base in Bristol, UK, a references register and a studies-based register.
The CCDANCTR-References Register contains over 30,000 reports of randomised controlled trials in depression, anxiety and neurosis. Approximately $65 \%$ of these references have been tagged to individual, coded trials. The coded trials are held in the CCDANCTR-Studies Register and records are linked between the two registers through the use of unique Study ID tags. Coding of trials is based on the EU-Psi coding manual. Please contact the CCDAN Trials Search Co-ordinator for further details.

Reports of trials for inclusion in the Group's registers are collated from routine (weekly), generic searches of MEDLINE (1950 -), EMBASE (1974 -) and PsycINFO (1967 -); quarterly searches of the Cochrane Central Register of Controlled Trials (CENTRAL) and review-specific searches of additional databases. Reports of trials are also sourced from international trials registers c/o the World Health Organization's trials portal (ICTRP), ClinicalTrials.gov, drug companies, the handsearching of key journals, conference proceedings and other (non-Cochrane) systematic reviews and meta-analyses. Details of CCDAN's generic search strategies can be found on the Group's website.

\section{Electronic searches}

\section{CCDANCTR-Studies Register}

We searched the Studies Register using the following terms:

Diagnosis $=$ ("post-traumatic stress disorders" or "acute stress disorder" or stress)

And

Age-Group = (child or adolescent $)$

And

Intervention $=\left(\right.$ counsel $^{*}$ or ${ }^{*}$ therapy or intervention or training or *education)

\section{CCDANCTR-References Register}

We searched he References Register using a more sensitive set of free-text terms to identify additional untagged/uncoded references:

Title/Abstract/Keywords $=(($ PTSD or "post trauma*" or posttrauma* or posttrauma* or trauma* or stress) And (adolesc* or preadolesc* ${ }^{*}$ or pre-adolesc* ${ }^{*}$ or boy* or girl* or child* or infant* or juvenil* or minors or school* or pediatri* or paediatri* or pubescen* or puberty or student* or teen* or young or youth* or school* or high-school or "high school" or college or undergrad*))

\section{Searching other resources}

\section{Reference lists}


We checked reference lists of relevant studies and reviews for additional references to potentially relevant studies. Non-English language studies were included.

\section{Data collection and analysis}

\section{Selection of studies}

The principal review author checked the results of the database searches to exclude references that were clearly not relevant to the review. Two review authors then assessed the titles, abstracts (or both) of the remaining studies, and any studies identified by other methods, for eligibility for the review. Where there was still doubt, we obtained and reviewed the full article. Any disagreements regarding the selection of studies were resolved through consensus or, if necessary, by consultation with a third member of the review team. Where there was still doubt, we obtained and reviewed the full article. Where further clarification was needed from study authors in order to make a decision, we made all reasonable attempts to contact authors.

\section{Data extraction and management}

All members of the review team developed and piloted a data extraction form. Two members of the review group extracted methodological and outcome data from each study independently. Each pair then compared their results for any differences. If differences were identified, they were resolved, either by consensus, or referral to a third member of the team. Where further clarification or missing data were needed from study authors, we made all reasonable attempts to contact the authors.

\section{Assessment of risk of bias in included studies}

We independently assessed trials as 'low', 'high' or 'unclear' risk of bias according to the following quality criteria.

1. Adequate sequence generation: e.g. computer-generated allocation sequence.

2. Allocation concealment: where an independent party allocated participants to groups.

3. Blinding: of outcome assessors as it was not possible to blind participants.

4. Incomplete outcome data addressed: i.e. if intention-totreat analyses were reported or there was zero loss to follow-up.

5. Free of selective reporting: this was considered high risk if it appeared some outcomes had not been reported.

6. Free of any other bias: i.e. if no other potential biases were identified.

We also collected information on any other sources of bias (for example, baseline imbalance, cross-over design, differential loss to follow-up, inappropriate administration of an intervention or cointervention, early stopping and selective reporting of subgroups). If there was any disagreement about whether or not a trial fulfilled a particular quality criteria, these differences were resolved by consensus or referral to a third member of the review team. All quality criteria ratings and supporting information are listed in the 'Risk of bias' table (Characteristics of included studies).

\section{Measures of treatment effect}

\section{Binary data}

For binary outcomes we calculated the odds ratio (OR) and 95\% confidence interval $(95 \% \mathrm{CI})$ using a random-effects model.

\section{Continuous data}

We calculated the standardised mean difference (SMD) and 95\% confidence interval of continuous outcomes using a random-effects model. The major reason for using SMDs is to pool continuous outcomes when different measures are used. However, to ensure consistency of reporting in this review, we used SMDs throughout.

To calculate SMDs, means and standard deviations (SDs) were needed. If SDs were not reported, we calculated them from reported measures of variance such as standard errors or $95 \%$ confidence intervals.

\section{Skewed data}

As a meta-analysis is based on assumptions of normality, we checked all continuous data for skew before inclusion. For a scale which starts from zero, a standard deviation which is more than half the mean suggests skew, while a standard deviation which is more than the mean is considered strong evidence of a skewed distribution (Altman 1996). Therefore, if the standard deviation was greater than the mean, these data were not included. If the standard deviation was more than half the mean, these data were included but a sensitivity analysis of the effects of including these data was done.

\section{Unit of analysis issues}

If multiple treatment arms described different comparisons we analysed these separately. For example, in the three-arm trial by Ertl 2011 which incorporated a narrative therapy, supportive counselling and control treatment arm, these data were used in the narrative versus control, supportive therapy versus control and narrative therapy versus supportive therapy comparisons. However, where studies reported more than one arm of the same therapy, e.g. King 2000 which reported individual and individual plus parent CBT, we calculated and used pooled means and SDs in the meta- 
analysis. If cluster-randomised trials had been identified, appropriate corrections for the cluster design would have been made and these data incorporated into the meta-analyses. If any cross-over trials which reported first interval data had been identified, these would also have been incorporated. However, no relevant crossover or cluster-randomised trials were identified.

\section{Dealing with missing data}

We used intention-to-treat analysis in all studies where these data were available. However, we also carried out analyses based on best and worst-case data (Higgins 2008 16.2.2) as described in Sensitivity analysis to assess the potential effects of loss to followup on results. We also contacted authors for missing data or if the reporting of data was unclear. While the authors of the study by Schauer 2008 provided us with additional information, we were unable to make contact with the authors of Chemtob 2002a.

\section{Assessment of heterogeneity}

We used a Mantel-Haenszel $\mathrm{Chi}^{2}$ test and the $\mathrm{I}^{2}$ statistic to test for heterogeneity using a fixed-effect model.

Higgins 2008 (9.5.2) gives a rough guide to the interpretation of heterogeneity as:

- $0 \%$ to $40 \%$ : might not be important;

- $30 \%$ to $60 \%$ : may represent moderate heterogeneity;

- $50 \%$ to $90 \%$ : may represent substantial heterogeneity;

- $75 \%$ to $100 \%$ : considerable heterogeneity.

\section{Assessment of reporting biases}

We entered primary outcome data from all included studies into a funnel plot (trial effect against trial size) to investigate the possibility of publication bias (Egger 1997).

\section{Data synthesis}

\section{Main comparisons}

1. Psychological therapies versus a control

2. Psychological therapies versus other psychological therapies

3. Psychological therapies versus pharmacological therapies

4. Psychological therapies versus other treatments

The majority of interventions employed a variety of psychotherapeutic elements, so we categorised interventions on the primary description of the intervention, the primary objectives of the therapy, or both. However, as it became apparent to us during the review that some of the psychological therapies described in included studies were not based on any clear theoretical domain, we made the decision to include these under the heading of 'Other psychological therapies'.
We organised data under the following categories of psychological therapies.

1. Cognitive behavioural therapy (CBT)

2. Behavioural therapy (BT) (including exposure-based therapy and narrative therapy)

3. Psychodynamic psychotherapy

4. Supportive counselling

5. EMDR

6. Interpersonal therapy (IPT)

7. Other psychological therapy

We collected data for all follow-up periods as long as the loss to follow-up did not exceed $40 \%$ for either group. There is little to inform what loss to follow-up is too much (Altman 2000; Fewtrell 2008 ) with overall rates of between $50 \%$ to $80 \%$ considered acceptable and no recommendations for differential loss to followup. Therefore, we decided a priori to accept a loss to follow-up of no more than $40 \%$ for either group. We analysed data as shortterm (up to and including one month following completion of the therapy), medium-term (one month to one year following completion) and long-term (one year or more). If there was more than one set of data for any of these periods, we used the first data set. For example, in Ertl 2011 follow-up data at three and six months were reported, therefore we used data for the three-month followup period. Where data from multiple PTSD symptom scales were reported (e.g. Cohen 2011), we used clinician scales in preference because these were based on clinician interview with the child and parent which is considered by expert groups as the most valid form of assessment (AACAP 1998).

If the standard deviation (SD) was greater than the mean this would have been considered strong evidence of skewed data (Higgins 2008), therefore if data for both groups showed strong evidence of skew, these would not have been included in a metaanalysis. Where there was a suggestion of skew, i.e. a SD more than half the mean (Altman 1996), we included these data but carried out a sensitivity analyses for the inclusion of these data. If there was strong evidence of skew in one group these data would have been included but would have been considered skewed.

\section{Subgroup analysis and investigation of heterogeneity}

Subgroup analyses compared potential sources of heterogeneity.

- Type of therapy: CBT, narrative therapy, supportive counselling, interpersonal therapy, EMDR

- Type of trauma: sexual abuse, civil or social violence, physical trauma, natural disasters

We used a $\mathrm{Chi}^{2}$ test to test for subgroup differences.

It was also proposed that subgroup analysis based on whether therapies were individual, parent, family or group-based would be done but insufficient data were available.

We considered interpersonal versus non-interpersonal trauma as an additional source of heterogeneity for investigation in a post 
hoc subgroup analysis, but insufficient information was provided in each study to be able to conduct this analysis.

\section{Sensitivity analysis}

We carried out sensitivity analyses based on allocation concealment and blinding of outcome measurement as these factors are most associated with a bias in effect size (Moher 1998). If any quasi-randomised trials had been identified these would have been considered to have a high risk of allocation bias.

We also carried out a sensitivity analysis to assess whether including data that may have been skewed had an effect on the analysis. Studies were considered skewed if they reported data for at least one group where the SD was more than half the mean.

We also conducted sensitivity analysis for loss to follow-up using best-case and worst-case analyses of the primary binary outcome, improvement. For the best-case analysis, participants lost to follow-up in the treatment group were considered to have improved while those lost to follow-up in the control group were considered not improved. In the worst-case analysis, participants lost to follow-up in the treatment group were considered not to have improved while those lost to follow-up in the control group were considered improved. Those studies which did not report loss to follow-up could not be included in this analysis.

Therefore the sensitivity analyses were as follows.

- Allocation concealment: low versus unclear risk (no high risk studies were identified)

- Blinding: low versus unclear versus high risk

- Skewed versus non-skewed data

- Best versus worst-case data

\section{RES U L T S}

\section{Description of studies}

\section{Results of the search}

There were 18 randomised trials identified for review; 14 (20 publications) with 758 participants were included and four were excluded. No quasi-randomised trials were identified (Figure 1). A further 52 studies of children and adolescents exposed to trauma have been assessed for a companion Cochrane review 'Psychological therapies for the prevention of post-traumatic stress disorder in children and adolescents' (Berger 2007; Berger 2009; Berkowitz 2011; Berliner 1996; Bolton 2007; Brown 2003; Celano 1996; Chapman 2001; Chemtob 2002; Cohen 1997; Cohen 1998; Cohen 2005; Cohen 2007; Cooley-Strickland 2011; Cox 2010; Deblinger 1996; Deblinger 2001; Deblinger 2011; Dominguez 2001; Ehntholt 2005; Ensink 2004; Farkas 2010; Gelkopf 2009; Goenjian 1997; Jaberghaderi 2004; Jeffres 2004; Jordans 2010; Kassam-Adams 2011; Kataoka 2003; Kazak 2004; Kemp 2010; Layne 2008; Lieberman 2005; Lyshak-Stelzer 2007; McWhirter 2011; Pfeffer 2002; Raider 2008; Salloum 2008; Scheeringa 2011; Shechtman 2010; Shelby 1995; Shooshtary 2008; Stallard 2006; Stein 2003; Taussig 2010; Thabet 2005; Tol 2010; Trowell 2002; Wang 2011; Wolmer 2011a; Wolmer 2011b; Zehnder 2010). Data from Cohen 2011 were used in both reviews. 
Figure I. Study flow diagram.

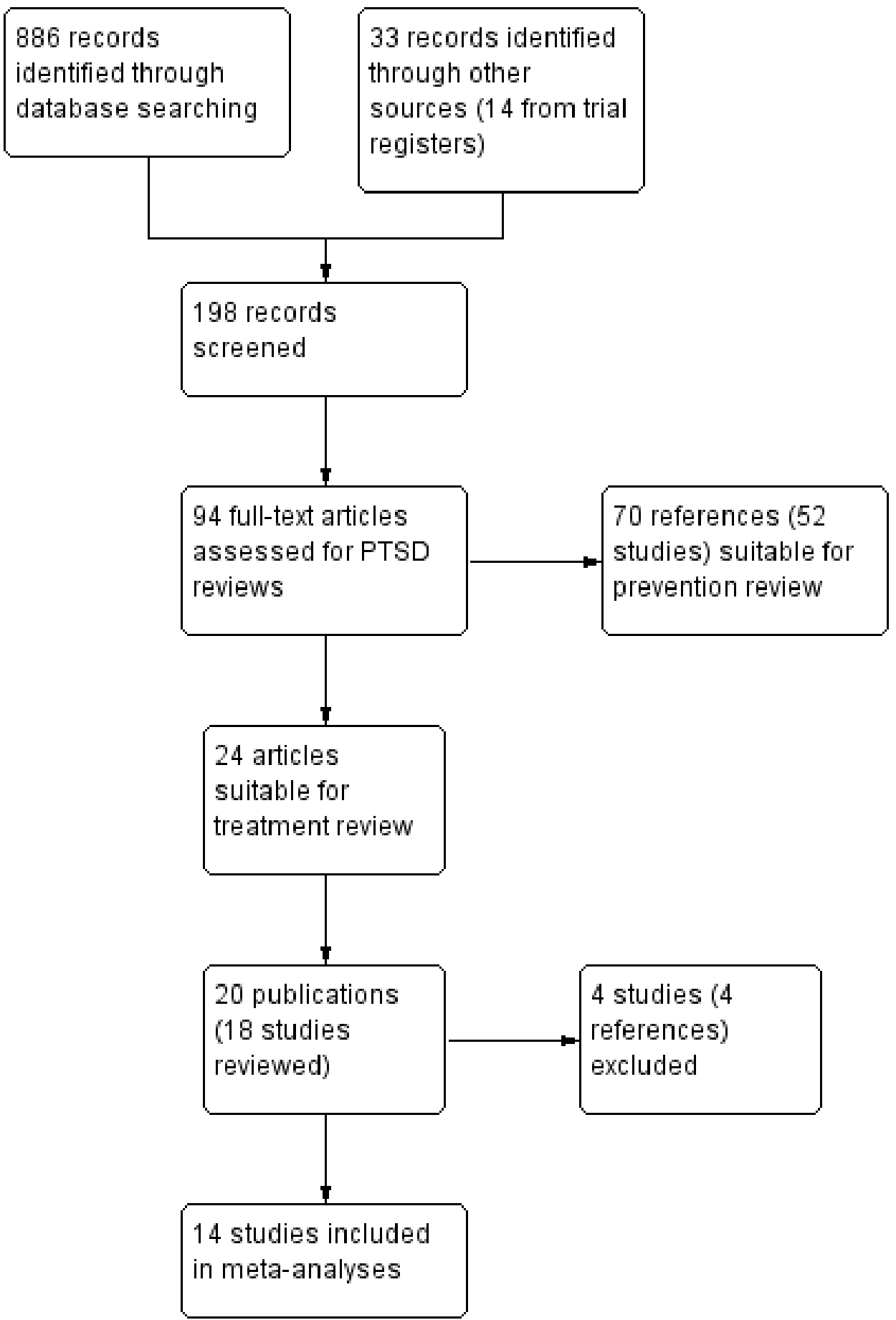


Most included studies were carried out in the US (Ahrens 2002; Chemtob 2002a; Cohen 2004; Cohen 2011; Najavits 2006); two in Sri Lanka (Catani 2009; Schauer 2008) and one study each in Australia (King 2000), Germany (Ruf 2010), Israel (GilboaSchechtman 2010), Kosovo (Gordon 2008), Uganda (Ertl 2011), the UK (Smith 2007) and Sweden (Ahmad 2007).

\section{Included studies}

\section{Participants}

In all but two studies, all participants had to meet diagnostic criteria for PTSD. King 2000 was also included because the majority of participants (25/36) were diagnosed with PTSD and a subset of data from the 50 participants diagnosed with PTSD in Cohen 2011 was also used in this review.

The number of participants ranged from 24 (Smith 2007) to 203 (Cohen 2004). The majority of participants were female in all studies except Catani 2009, Ruf 2010, Smith 2007 and Ahrens 2002, which only included males.

In all but one study the age of participants ranged from 6 to 18 years, although Ahmad 2007, Gilboa-Schechtman 2010, Gordon 2008 and Najavits 2006 only included adolescents. Although the age of participants in Ertl 2011 ranged from 12 to 25 years, this study was included because their average age was 18 years.

The study populations included covered a range of trauma exposures. The types of trauma related to the PTSD were sexual abuse (Cohen 2004; King 2000), civil violence (Catani 2009; Ertl 2011; Schauer 2008; Ruf 2010), natural disaster (Catani 2009; Chemtob 2002a), exposure to domestic violence (Cohen 2011) or mixed traumas (Ahmad 2007; Gilboa-Schechtman 2010; Najavits 2006; Smith 2007), although the predominant trauma in the studies by Gilboa-Schechtman 2010 and Smith 2007 was a motor vehicle accident. The types of trauma participants were exposed to was not described in Ahrens 2002 and Gordon 2008.

Baseline symptom scores were measured using a range of measures. However, baseline symptom scores on the UCLA PTSD index of 36.5 to 43.3 were reported by Catani 2009, Chemtob 2002a and Ruf 2010. The Clinician-Administered PTSD Scale (CAPS) (Ertl 2011) and the CAPS for children and adolescents (CAPS-CA) (Schauer 2008; Smith 2007) baseline scores were between 54.7 and 71.2, and the Child PTSD Symptoms Scale scores (Ahrens 2002; Gilboa-Schechtman 2010; Smith 2007) were between 16.89 and 28.3 at baseline.

Most participants were clients of a trauma-related support service (Cohen 2004; Cohen 2011; King 2000; Ruf 2010, Smith 2007). In two studies participants were identified in refugee camps (Catani 2009; Ertl 2011) and two studies took place in schools in trauma-affected areas (Gordon 2008; Schauer 2008). Participants were incarcerated in a youth correctional facility in Ahrens
2002, attended a medical centre in Gilboa-Schechtman 2010, and a mental health clinic in Ahmad 2007. The setting of Chemtob 2002a and Najavits 2006 was not clear.

The major exclusion criteria were developmental disorder (Cohen 2004; Cohen 2011; Gilboa-Schechtman 2010; Smith 2007) or psychosis (Catani 2009; Cohen 2004; Cohen 2011; Ertl 2011; Najavits 2006; Ruf 2010). Substance abuse was also excluded in Cohen 2004 and Gilboa-Schechtman 2010. However, several studies did not report explicit exclusion criteria (Ahrens 2002; Chemtob 2002a; Gordon 2008; King 2000). Najavits 2006 specifically included adolescent girls with co-existing substance use disorder and Ahrens 2002 included incarcerated adolescent males.

\section{Interventions}

Most (11) included studies compared a psychological therapy to a control group. The interventions were delivered over four to 25 sessions of 45 minutes to two hours duration. Most were delivered on a weekly basis.

Three studies compared narrative therapy to control groups (Catani 2009; Ertl 2011; Ruf 2010; Schauer 2008), three studies compared CBT to controls (Ahrens 2002; King 2000; Smith 2007), two compared EMDR to controls (Ahmad 2007; Chemtob 2002a), and two studies compared other psychological therapies to controls (Gordon 2008; Najavits 2006). CBT was compared to supportive therapy in Cohen 2004 and Cohen 2011; narrative therapy was compared to supportive counselling in Ertl 2011 and a combination of meditation and relaxation in Catani 2009 and Schauer 2008; and exposure therapy was compared to interpersonal therapy in Gilboa-Schechtman 2010.

All studies with a control group used a waiting list control (Ahmad 2007; Ahrens 2002; Chemtob 2002a; Ertl 2011; Gordon 2008; King 2000; Ruf 2010; Smith 2007) except for Najavits 2006 which used treatment as usual as a control.

No study compared psychological therapies to pharmacological interventions either alone or as an adjunct to psychological therapy.

\section{Outcomes}

Data for the dichotomous outcomes of improvement and loss to follow-up and the continuous outcomes of PTSD, anxiety and depression symptoms, and scales for behaviour were extracted from the included studies.

\section{Primary outcomes}

\section{Improvement}


Improvement from a diagnosis of PTSD was reported by Catani 2009; Cohen 2004; Ertl 2011; Gilboa-Schechtman 2010; King 2000; Ruf 2010; Schauer 2008 and Smith 2007. Improvement was assessed using the Clinician-Administered PTSD Scale (CAPS; Ertl 2011) and the CAPS for children and adolescents (CAPSCA; Schauer 2008; Smith 2007), the Anxiety Disorders Interview Schedule for children (ADIS; King 2000), the UCLA PTSD Index (Catani 2009; Ruf 2010) and the Kiddie Schedule for Affective Disorders and Schizophrenia for school-aged children - Present and Lifetime version (K-SADS-PL; Cohen 2004; Gilboa-Schechtman 2010).

\section{PTSD symptoms}

The most frequently used measures for PTSD symptoms were the UCLA PTSD Index (Catani 2009; Chemtob 2002a; Cohen 2011; Ruf 2010), the K-SADS-PL (Cohen 2004; Cohen 2011; Gilboa-Schechtman 2010), the CAPS (Ertl 2011) and CAPS-CA (Schauer 2008; Smith 2007), and Child PTSD Symptoms Scale (Ahrens 2002; Gilboa-Schechtman 2010; Smith 2007). Other studies used the ADIS (King 2000), Harvard Trauma Questionnaire (Gordon 2008), Impact of Events Scale (Ahrens 2002), Post traumatic Stress Symptom Scale for Children (Ahmad 2007), and Trauma Symptom Checklist for Children (Najavits 2006).

\section{Secondary outcomes}

\section{Quality of life}

No data were reported.

\section{Anxiety}

Anxiety was reported by Chemtob 2002a, Cohen 2004, Cohen 2011 and King 2000. The scales used to measure anxiety were the Revised Children's Manifest Anxiety Scale (Chemtob 2002a; King 2000), the State-trait Anxiety Inventory for Children (Cohen 2004) and the Screen for Child Anxiety Related Emotional Disorders (SCARED; Cohen 2011).

\section{Depression}

Ahrens 2002; Chemtob 2002a; Cohen 2004; Cohen 2011; Ertl 2011; Gilboa-Schechtman 2010; King 2000; Najavits 2006;
Schauer 2008 and Smith 2007 reported depression. The Children's Depression Inventory was used by Chemtob 2002a; Cohen 2004; Cohen 2011; Deblinger 2011 and King 2000. Ahrens 2002 and Gilboa-Schechtman 2010 used the Beck Depression Inventory, Najavits 2006 the Adolescent Psychopathology Scale, Smith 2007 the Depression Self Rating Scale, Ertl 2011 the Mini-International Neuropsychiatric Interview (MINI), Schauer 2008 the MINI-KID, and Smith 2007 the Depression Self-rating Scale.

\section{Behaviour}

The Child Behaviour Checklist was used in all studies that reported behaviour as an outcome (Cohen 2004; Cohen 2004; Cohen 2011; King 2000).

\section{Adverse events}

No data were reported.

\section{Loss to follow-up}

Loss to follow-up, or data from which it could be calculated, was reported in all studies except Ahrens 2002.

\section{Cost}

No data were reported.

\section{Data that could not be added to the meta-analysis}

Because the SD for depression and PTSD re-experiencing scores in Cohen 2004 were larger than the mean, these data were not included in the meta-analyses.

\section{Excluded studies}

Four studies were excluded. Allocation was not randomised in two studies (Lesmana 2009; March 1998), the average age of participants was 19 years in Schaal 2010, and Cohen 2007 compared $\mathrm{CBT}$ in combination with sertraline to CBT with placebo.

\section{Risk of bias in included studies}

See Figure 2. 
Figure 2. 'Risk of bias' summary: review authors' judgements about each risk of bias item for each included study.

\begin{tabular}{|c|c|c|c|c|c|c|}
\hline & 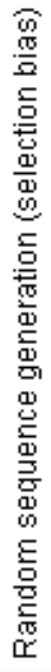 & 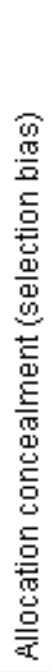 & 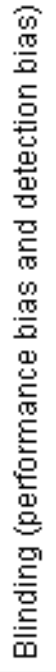 & 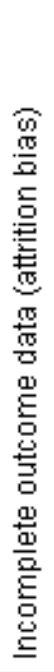 & 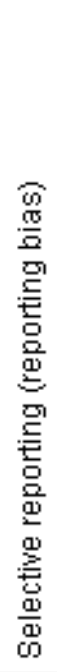 & 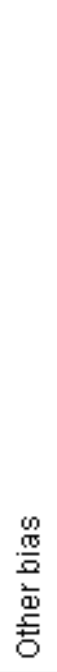 \\
\hline Ahmad 2007 & $?$ & $?$ & + & + & & $?$ \\
\hline Ahrens 2002 & $?$ & $?$ & $?$ & $?$ & & \\
\hline Catani 2009 & + & $?$ & + & + & & \\
\hline Chemtob 2002a & $?$ & $?$ & + & $?$ & & \\
\hline Cohen 2004 & $?$ & $?$ & ? & & & \\
\hline Cohen 2011 & + & + & + & $?$ & & $?$ \\
\hline Ertl 2011 & $?$ & $?$ & $?$ & & & \\
\hline Gilboa-Schechtman 2010 & $\Omega$ & $?$ & $?$ & $?$ & & \\
\hline Gordon 2008 & + & + & $?$ & $?$ & 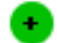 & $?$ \\
\hline King 2000 & $?$ & $?$ & $?$ & $?$ & $?$ & \\
\hline Najavits 2006 & $?$ & $?$ & $?$ & & & \\
\hline Ruf 2010 & + & $?$ & + & & & \\
\hline Schauer 2008 & + & + & $?$ & $?$ & +1 & $?$ \\
\hline Smith 2007 & + & $?$ & + & + & & \\
\hline
\end{tabular}




\section{Allocation}

We rated the generation of the randomisation sequence as a low risk of bias in Catani 2009, Gilboa-Schechtman 2010, Gordon 2008, Ruf 2010, Schauer 2008 and Smith 2007. We considered all other studies to have an unclear risk of bias because the randomisation sequence was not described. Because allocation concealment was described adequately in Cohen 2011, Gordon 2008 and Schauer 2008, we rated these as a low risk of bias due to allocation concealment. Allocation concealment was not described in the remaining studies which we therefore rated as having an unclear risk of bias.

\section{Blinding}

Blinded outcome assessment was described in Ahmad 2007, Catani 2009, Chemtob 2002a, Cohen 2011, Ruf 2010 and Smith 2007 which we therefore rated as having a low risk of detection bias. Because blinding of outcome measurement was not described in the remaining studies we rated these as having an unclear risk of detection bias.

\section{Incomplete outcome data}

The loss to follow-up was reported in all studies but Ahrens 2002 and for the subset of children diagnosed with PTSD in Cohen 2011 included in this review. Therefore we rated these studies as having an unclear risk of attrition bias. There was no loss to followup in Smith 2007, which we therefore rated as having a low risk of attrition bias. Ahmad 2007, Cohen 2011, Gilboa-Schechtman 2010 and King 2000 reported intention-to-treat (ITT) data. We rated Ahmad 2007 as having a low risk of attrition bias because ITT analyses were reported and there was a low loss to follow-up. We considered Gilboa-Schechtman 2010 and King 2000 to have an unclear risk even though ITT analyses were reported because there was a high loss to follow-up. Catani 2009, Cohen 2004 and Ertl 2011 also used ITT analyses but reported data for participants available at follow-up. We rated Catani 2009 as having a low risk of bias because the loss to follow-up was small, while we rated Cohen 2004 and Ertl 2011 as having a high risk because the loss to follow-up was high. The remaining studies also reported data for participants who completed assessment. We rated Gordon 2008, Ruf 2010 and Schauer 2008 as having an unclear risk of bias because the loss to follow-up was low but we rated Najavits 2006 as having a high risk of attrition bias because of the high loss to follow-up.

\section{Selective reporting}

Outcomes appear to have been completely reported in all studies except Najavits 2006 which did not report improvement or PTSD symptoms and King 2000 which did not report behaviour.

\section{Other potential sources of bias}

There were potential biases identified in Ahmad 2007, Cohen 2011, Gordon 2008, Najavits 2006 and Schauer 2008. There were more children of Swedish ethnicity in the EMDR group in Ahmad 2007. The data for a subset of children diagnosed with PTSD in Cohen 2011 were used for this review. It was not clear how the cut-off values for the PTSD domains were determined in the study by Gordon 2008. In Najavits 2006, the baseline levels of anorexia, loss of control, sexual concerns and sexual distress were higher in the control group. Also, although not statistically significant, the baseline trauma score was higher in the meditation/relaxation group (71.2) compared to the KIDNET group (63.2) in Schauer 2008.

\section{Effects of interventions}

The outcomes collected over these studies were: improvement of post-traumatic stress disorder (PTSD); PTSD symptoms (total and sub-scores for arousal, avoidance and intrusion); anxiety (total, state and trait); depression; behaviour (total, internalising and externalising); and loss to follow-up.

No studies reported psychosocial function or cost.

\section{All psychological therapies versus controls}

\section{Primary outcomes}

\section{Improvement}

Over all studies that compared a psychological therapy to a control group, there was a significantly smaller proportion of children and adolescents who were still diagnosed with PTSD at the end of the study compared to the control group in the short term (two studies, $\mathrm{n}=49$, odds ratio (OR) 8.64, 95\% confidence interval (CI) 2.01 to $37.14, \mathrm{I}^{2}=0 \%$, Analysis 1.1 ) and medium term (two studies, $\mathrm{n}=50$, OR 9.46, 95\% CI 2.46 to $36.32, \mathrm{I}^{2}=57 \%$, Analysis 1.1) but there was no significant difference in the long term (one study, $\mathrm{n}=53$, OR $1.84,95 \%$ CI 0.60 to 5.65, Analysis 1.1).

Psychological therapies for the treatment of post-traumatic stress disorder in children and adolescents (Review) 


\section{PTSD symptoms}

Scores for PTSD symptoms were also significantly lower in the psychological therapy group in the short term (six studies, $\mathrm{n}=$ 241, standardised mean difference (SMD) $-1.05,95 \%$ CI -1.52 to $-0.58, \mathrm{I}^{2}=62 \%$, Analysis 1.2 ) and medium term (three studies, $\mathrm{n}=115$, SMD $-0.58,95 \%$ CI -0.97 to $-0.18, \mathrm{I}^{2}=42 \%$, Analysis 1.2) but there was no significant difference in the long term (one study, $\mathrm{n}=53, \mathrm{SMD}-0.44,95 \% \mathrm{CI}-0.98$ to 0.11 , Analysis 1.2 ).

\section{Secondary outcomes}

\section{Quality of life}

No data were reported.

\section{Anxiety}

Anxiety scores were also significantly reduced in the short term (three studies, $\mathrm{n}=91$, SMD $-0.57,95 \% \mathrm{CI}-1.00$ to $-0.13, \mathrm{I}^{2}=$ $0 \%$, Analysis 1.3) but not the medium term (one study, $\mathrm{n}=36$, SMD $-0.63,95 \%$ CI -1.34 to 0.08 , Analysis 1.3 ).

\section{Depression}

Depression was significantly lower in the psychological therapytreated group over the five studies that reported this outcome in the short term ( $\mathrm{n}=156, \mathrm{SMD}-0.74,95 \%-1.11$ to $-0.36, \mathrm{I}^{2}=$ $21 \%$, Analysis 1.4 ) but not the three studies that reported it in the medium term ( $\mathrm{n}=110$, SMD $0.02,95 \%-0.36$ to $0.40, \mathrm{I}^{2}=0 \%$, Analysis 1.4) or the one study that reported long-term outcomes $(\mathrm{n}=53$, SMD 0.02, $95 \%-0.52$ to 0.56 , Analysis 1.4$)$.

\section{Behaviour}

No data were reported.

\section{Adverse events}

No data were reported.

\section{Loss to follow-up}

There was no difference between psychological therapy and control groups in the loss to follow-up (short term: five studies, $\mathrm{n}=$ 208, OR $1.59,95 \%$ CI 0.56 to $4.49, \mathrm{I}^{2}=0 \%$; medium term: three studies, $\mathrm{n}=116$, OR $1.54,95 \%$ CI 0.47 to $5.04, \mathrm{I}^{2}=0 \%$; long term: one study, $\mathrm{n}=57$, OR $10.06,95 \%$ CI 0.52 to 196.10 , $\mathrm{I}^{2}=33 \%$, Analysis 1.5 ).

\section{Cost}

No data were reported.

\section{CBT versus controls}

\section{Primary outcomes}

\section{Improvement}

There was significantly more improvement in the CBT groups over the two studies that reported this outcome in the short term ( $\mathrm{n}=49$, OR 8.64, 95\% CI 2.01 to $37.14, \mathrm{I}^{2}=0 \%$, Analysis 2.1 ) and one study ( $\mathrm{n}=25$, OR $8.00,95 \%$ CI 1.21 to 52.69) reporting medium-term data.

\section{PTSD symptoms}

There was also a significant decrease in PTSD scores in the short and medium term (short term: three studies, $\mathrm{n}=98, \mathrm{SMD}-1.34$, $95 \%$ CI -1.79 to -0.89 ; medium term: one study, $\mathrm{n}=36$, SMD $0.73,95 \%$ CI -1.44 to $-0.01, \mathrm{I}^{2}=0 \%$, Analysis 2.2 ). The PTSD sub-scores were reported by one study with 36 participants. There was significant improvement in scores for medium-term avoidance (SMD -0.68, 95\% CI - 1.56 to -0.11, Analysis 2.3) and short-term hyperarousal (SMD -1.30, 95\% CI -2.06 to -0.53, Analysis 2.4) and re-experiencing (SMD -0.72, 95\% CI - 1.44 to -0.01, Analysis 2.5).

\section{Secondary outcomes}

\section{Anxiety}

Anxiety scores were not significantly different in the two studies that compared CBT to controls in the short term or the one medium-term study (short term: two studies, $\mathrm{n}=59$, SMD -0.66, $95 \% \mathrm{CI}-1.33$ to $0.01, \mathrm{I}^{2}=31 \%$; medium term: one study, $\mathrm{n}=$ 36, SMD -0.63, 95\% CI -1.34 to 0.08, Analysis 2.6).

\section{Depression}

Depression scores were significantly lower in the three studies that reported this outcome in the short term $(\mathrm{n}=98$, SMD - $0.80,95 \%$ CI -1.47 to $-0.13, \mathrm{I}^{2}=59 \%$, Analysis 2.7 ) but not the one study that reported depression in the medium term (one study, $\mathrm{n}=36$, SMD $-0.19,95 \%$ CI -0.88 to 0.31 , Analysis 2.7$)$.

\section{Behaviour}

No data were reported. 


\section{Adverse events}

No data were reported.

\section{Loss to follow-up}

There was no difference between CBT and control groups in the two studies which reported loss to follow-up (short term: two studies, $\mathrm{n}=60$, not estimable, Analysis 2.8).

\section{Cost}

No data were reported.

\section{Narrative therapy versus controls}

\section{Primary outcomes}

\section{Improvement}

There was a significant difference in improvement when narrative therapy was compared to a control in the medium term (one study, $\mathrm{n}=25$, OR $11.25,95 \%$ CI 1.65 to 76.85 , Analysis 3.1) but not the long term (one study, $\mathrm{n}=53$, OR $1.84,95 \%$ CI 0.60 to 5.65 , Analysis 3.1).

\section{PTSD symptoms}

There was a no difference between the narrative therapy and control groups in PTSD symptom scores (Analysis 3.2) at any follow-up interval. One study reported sub-scores for avoidance, hyperarousal and re-experiencing in the short term. Avoidance $(\mathrm{n}=$ 25, SMD -1.13, 95\% CI -1.99 to -0.27 , Analysis 3.3) and hyperarousal ( $\mathrm{n}=25$, SMD $-0.84,95 \% \mathrm{CI}-1.67$ to -0.02 , Analysis 3.4) scores were significantly lower in the narrative therapy group but there was no statistical difference in re-experiencing sub-scores (Analysis 3.5).

\section{Secondary outcomes}

\section{Quality of life}

No data were reported.

\section{Anxiety}

No data were reported.

\section{Depression}

There was no difference between groups in depression scores (short term: one study, $\mathrm{n}=54$, SMD $0.10,95 \% \mathrm{CI}-0.44$ to 0.63 ; medium term: one study, $\mathrm{n}=43$, SMD $0.02,95 \% \mathrm{CI}-0.52$ to 0.56 , Analysis 3.6).

\section{Behaviour}

No data were reported.

\section{Adverse events}

No data were reported.

\section{Loss to follow-up}

There was no difference between groups in the loss to follow-up in the medium or long term (medium term: two studies, $\mathrm{n}=83$, OR 5.13, $95 \%$ CI 0.56 to $47.28, \mathrm{I}^{2}=0 \%$; long term: one study, $\mathrm{n}=57$, OR 10.06, 95\% CI 0.52 to 196.10 , Analysis 3.7).

\section{Cost}

No data were reported.

\section{EMDR versus controls}

Apart from the two studies which reported PTSD total scores, data for all comparisons of EMDR to a control came from one study.

\section{Primary outcomes}

\section{Improvement}

No data were reported.

\section{PTSD symptoms}

There was no significant difference between participants receiving EMDR compared to controls for PTSD total scores (short term: two studies, $\mathrm{n}=65$, SMD $-0.61,95 \% \mathrm{CI}-1.96$ to $0.74, \mathrm{I}^{2}=$ $85 \%$, Analysis 4.1, or avoidance (short term: one study, $\mathrm{n}=33$, SMD - $0.12,95 \%$ CI -0.80 to 0.56 , Analysis 4.2 ), and hyperarousal (short term: one study, $\mathrm{n}=33$, SMD $0.39,95 \% \mathrm{CI}-0.30$ to 1.08 , Analysis 4.3) sub-scores. However, re-experiencing sub-scores were significantly lower in the EMDR group (short term: $\mathrm{n}=33$, SMD $-0.75,95 \%$ CI -1.46 to -0.04 , Analysis 4.4). 


\section{Quality of life}

No data were reported.

\section{Anxiety}

There was no statistical difference between EMDR and control groups in scores for anxiety (short term: one study, $\mathrm{n}=32$, SMD $-0.45,95 \%$ CI -1.15 to 0.26 , Analysis 4.5 ).

\section{Depression}

Depression scores were not statistically different (short term: one study, $\mathrm{n}=32$, SMD $-0.65,95 \% \mathrm{CI}-1.36$ to 0.07 , Analysis 4.6).

\section{Behaviour}

No data were reported.

\section{Adverse events}

No data were reported.

\section{Loss to follow-up}

There was no difference between groups in the loss to follow-up (short term: one study, $\mathrm{n}=33$, OR 3.00, 95\% CI 0.11 to 79.13 , Analysis 4.7).

\section{Cost}

No data were reported.

\section{Other psychological therapies versus controls}

Two studies compared other psychological therapies with a control but because these data could not be pooled all results were from one study only.

\section{Primary outcomes}

\section{Improvement}

No data were reported.

\section{PTSD symptoms}

The short-term PTSD total scores ( $\mathrm{n}=78$, SMD -1.12, 95\% CI 1.64 to -0.64 , Analysis 5.1), frequency of medium-term avoidance ( $\mathrm{n}=78$, OR 0.13 , 95\% CI 0.05 to 0.36 , Analysis 5.2 ) and reexperiencing symptoms $(\mathrm{n}=78$, OR $0.19,95 \%$ CI 0.07 to 0.54 , Analysis 5.4) were significantly decreased in the other psychological therapy group. However, there was no significant difference in the frequency of hyperarousal symptoms (medium term: one study, $\mathrm{n}=78$, OR $0.54,95 \%$ CI 0.19 to 1.52 , Analysis 5.3).

\section{Secondary outcomes}

\section{Quality of life}

No data were reported.

\section{Anxiety}

No data were reported.

\section{Depression}

There was no significant difference between groups in depression scores (short term: one study, $\mathrm{n}=26, \mathrm{SMD}-0.63,95 \% \mathrm{CI}-1.43$ to 0.16 ; medium term: one study, $\mathrm{n}=20$, SMD $0.13,95 \% \mathrm{CI}$ 0.75 to 1.01 , Analysis 5.5).

\section{Behaviour}

No data were reported.

\section{Adverse events}

No data were reported.

\section{Loss to follow-up}

There was no significant difference in loss to follow-up (short term: two studies, $\mathrm{n}=115$, OR $1.38,95 \%$ CI 0.35 to $5.52, \mathrm{I}^{2}=0 \%$; medium term: one study, $\mathrm{n}=33$, OR $0.95,95 \%$ CI 0.23 to 3.38 , Analysis 5.6).

\section{Cost}

No data were reported.

\section{CBT versus supportive therapy}

Two studies compared CBT to supportive therapy. 


\section{Primary outcomes}

\section{Improvement}

The short-term improvement rate was significantly higher in the CBT group compared to the supportive therapy group (two studies, $\mathrm{n}=208$, OR $3.18,95 \%$ CI 1.76 to $5.74, \mathrm{I}^{2}=0 \%$, Analysis 6.1).

\section{PTSD symptoms}

All data for PTSD symptom scores came from only one study. PTSD avoidance ( $\mathrm{n}=180$, SMD $-0.72,95 \% \mathrm{CI}-1.02$ to -0.42 , Analysis 6.2) and hyperarousal ( $\mathrm{n}=180, \mathrm{SMD}-0.37,95 \% \mathrm{CI}$ -0.67 to -0.08 , Analysis 6.3) scores in the short term; and reexperiencing scores in the short and medium term $(\mathrm{n}=180$, SMD $-0.49,95 \%$ CI -0.78 to -0.19 ; medium-term: $\mathrm{n}=147$, SMD $0.48,95 \%$ CI -0.81 to -0.15 , Analysis 6.4 ) were all significantly better in the CBT group.

\section{Secondary outcomes}

\section{Quality of life}

No data were reported.

\section{Anxiety}

There was no statistical difference between groups in anxiety-state scores in the one study that reported these data (short term: $\mathrm{n}=$ 183, SMD $-0.25,95 \%$ CI -0.54 to 0.04 ; medium term: $\mathrm{n}=151$, SMD $-0.24,95 \%$ CI -0.56 to 0.08 ; long term: $n=155$, SMD $-0.19,95 \%$ CI -0.51 to 0.12 , Analysis 6.5 ). Anxiety-trait scores were significantly lower in the short term ( $\mathrm{n}=183$, SMD -0.37 , $95 \%$ CI -0.66 to -0.07 , Analysis 6.6) but not the medium ( $\mathrm{n}=$ 150, SMD -0.22 , $95 \%$ CI -0.54 to 0.11 , Analysis 6.6) or long term $(\mathrm{n}=155$, SMD $-0.28,95 \%$ CI -0.59 to 0.04 , Analysis 6.6).

\section{Depression}

Depression scores were significantly better in the CBT group in the one study that reported these data (short term: $\mathrm{n}=183$, SMD $-0.40,95 \%$ CI -0.69 to -0.11 , Analysis 6.7 ).

\section{Behaviour}

There was a significant reduction in behaviour scores in the CBT group compared to the supportive therapy group in the short term ( $\mathrm{n}=179$, SMD $-0.38,95 \%$ CI -0.67 to- 0.08 , Analysis 6.8 ) in the one study that reported these data; however, there were no statistical differences between groups in the medium $(n=142$,
SMD $-0.07,95 \%$ CI -0.40 to 0.25 , Analysis 6.8 ) or long term (n $=156$, SMD $-0.08,95 \%$ CI -0.40 to 0.25 , Analysis 6.8).

\section{Adverse events}

No data were reported.

\section{Loss to follow-up}

There was no difference in the one study which reported loss to follow-up (short term: $\mathrm{n}=229$, OR $1.07,95 \%$ CI 0.57 to 2.00 ; medium term: $\mathrm{n}=229$, OR $0.69,95 \%$ CI 0.40 to 1.19 ; long term: $\mathrm{n}=229$, OR $0.68,95 \%$ CI 0.39 to 1.18 , Analysis 6.9).

\section{Cost}

No data were reported.

\section{Narrative therapy versus supportive counselling}

One study compared narrative therapy to supportive counselling.

\section{Improvement}

There was no statistical difference between groups in improvement (short term: one study, $\mathrm{n}=48$, OR $1.95,95 \%$ CI 0.60 to 6.29 , Analysis 7.1).

\section{PTSD symptoms}

There was no statistical difference between groups in PTSD symptoms (medium term: one study, $\mathrm{n}=50$, SMD $0.05,95 \% \mathrm{CI}-0.50$ to 0.61 ; long term: one study, $\mathrm{n}=48$, SMD $-0.40,95 \% \mathrm{CI}-0.97$ to 0.17 , Analysis 7.2).

\section{Secondary outcomes}

\section{Quality of life}

No data were reported.

\section{Anxiety}

No data were reported.

\section{Depression}

There was no difference between the narrative therapy and supportive counselling groups in depression scores (Analysis 7.3). 


\section{Behaviour}

No data were reported.

\section{Adverse events}

No data were reported.

\section{Loss to follow-up}

There was no statistical difference between groups in the one study which reported loss to follow-up (medium term: $\mathrm{n}=57$, OR 0.69 , $95 \%$ CI 0.14 to 3.42 ; long term: $\mathrm{n}=57$, OR $0.74,95 \%$ CI 0.18 to 3.08 , Analysis 7.4).

\section{Cost}

No data were reported.

\section{Narrative therapy versus other therapies (meditation/relaxation)}

\section{Primary outcomes}

\section{Improvement}

There was no difference in the proportion of children and adolescents still diagnosed with PTSD in the short (one study, $\mathrm{n}=31$, OR $1.50,95 \%$ CI 0.32 to 7.14 , Analysis 8.1 ) or medium term (two studies, $\mathrm{n}=76$, OR 1.09 , 95\% CI 0.41 to 2.88 , I ${ }^{2}=0 \%$, Analysis 8.1) when narrative therapy was compared to meditationrelaxation.

\section{PTSD symptoms}

There was no difference in PTSD symptoms in the short (one study, $\mathrm{n}=30$, SMD $-0.01,95 \% \mathrm{CI}-0.73$ to 0.70 , Analysis 8.2 ) or medium term (two studies, $\mathrm{n}=76$, SMD $0.06,95 \% \mathrm{CI}-0.39$ to $0.51, \mathrm{I}^{2}=0 \%$, Analysis 8.2 ).

\section{Depression}

No data were reported.

\section{Behaviour}

No data were reported.

\section{Adverse events}

No data were reported.

\section{Loss to follow-up}

There was no difference between therapies in the loss to followup (short term: one study, $\mathrm{n}=31$, not estimable; medium term: two studies, $\mathrm{n}=78$, OR $0.29,95 \%$ CI 0.03 to $2.89, \mathrm{I}^{2}=0 \%$, Analysis 8.3).

\section{Cost}

No data were reported.

\section{Exposure versus interpersonal therapy}

One study compared exposure to interpersonal therapy.

\section{Improvement}

There was significantly more short and medium-term improvement in the exposure therapy group (short term: $\mathrm{n}=30$, OR 7.43, $95 \%$ CI 1.23 to 45.01 ; medium term: $\mathrm{n}=27$, OR 9.60, 95\% CI 1.48 to 62.16 , Analysis 9.1).

\section{PTSD symptoms}

There was no statistical difference in PTSD symptoms when exposure and interpersonal therapy groups were compared (short term: $\mathrm{n}=38, \mathrm{SMD}-0.48,95 \% \mathrm{CI}-1.12$ to 0.17 ; medium term: $\mathrm{n}=$ 38 , SMD $-0.53,95 \%$ CI -1.17 to 0.12 ; long term: $\mathrm{n}=38$, SMD $-0.22,95 \%$ CI -0.86 to 0.42 , Analysis 9.2 ).

\section{Secondary outcomes}

\section{Quality of life}

No data were reported.

\section{Anxiety}

No data were reported. 


\section{Depression}

There was no statistical difference between the exposure and interpersonal therapy groups in scores for depression (short term: $\mathrm{n}$ $=38$, SMD $-0.08,95 \% \mathrm{CI}-0.71$ to 0.56 ; medium term: $\mathrm{n}=38$, SMD -0.19, 95\% CI -0.83 to 0.44; long term: $\mathrm{n}=38$, SMD 0.02, $95 \%$ CI -0.62 to 0.65 , Analysis 9.3).

\section{Behaviour}

No data were reported.

\section{Adverse events}

No data were reported.

\section{Loss to follow-up}

There was no statistical difference between groups in the loss to follow-up (short term: $\mathrm{n}=38$, OR $1.00,95 \%$ CI 0.21 to 4.76 : medium term: $\mathrm{n}=38$, OR $0.77,95 \%$ CI 0.19 to 3.16; long term: one study, $\mathrm{n}=38$, OR $0.53,95 \%$ CI 0.14 to 1.92 , Analysis 9.4).

\section{Cost}

No data were reported.

\section{Subgroup analyses}

\section{Type of therapy}

We carried out subgroup analyses of the different psychological therapies compared to controls for the primary outcomes of improvement and PTSD symptoms. Improvement was reported in studies which had used CBT and narrative therapies. There was no difference between these subgroups $\left(\mathrm{Chi}^{2}=0.49, \mathrm{df}=1, \mathrm{P}=\right.$ $0.48, \mathrm{I}^{2}=0 \%$, Analysis 10.1 ). There was also no difference between CBT, narrative, EMDR and other psychological therapies subgroups for symptoms of PTSD $\left(\mathrm{Chi}^{2}=4.03, \mathrm{df}=3, \mathrm{P}=0.26\right.$, $\mathrm{I}^{2}=25.5 \%$, Analysis 10.2)

\section{Type of trauma}

We compared the type of trauma (sexual abuse, civil or social violence, physical trauma, natural disaster) in a subgroup analyses. There was no significant difference between subgroups in improvement $\left(\mathrm{Chi}^{2}=0.88, \mathrm{df}=2, \mathrm{P}=0.65, \mathrm{I}^{2}=0 \%\right.$, Analysis 11.1) or PTSD symptoms $\left(\mathrm{Chi}^{2}=3.36, \mathrm{df}=3, \mathrm{P}=0.24, \mathrm{I}^{2}=10.6 \%\right.$, Analysis 11.2).

\section{Sensitivity analyses}

\section{Allocation concealment}

As most studies did not report allocation concealment a sensitivity analysis could only be conducted for PTSD symptoms where the one study at low risk of bias for allocation concealment was compared to studies where the risk was unclear. There was no difference between these two groups of studies $\left(\mathrm{Chi}^{2}=0.38, \mathrm{df}=1\right.$, $\mathrm{P}=0.54, \mathrm{I}^{2}=0 \%$, Analysis 12.1).

\section{Blinding}

There was no difference between studies with a low, high or unclear risk of detection bias in improvement $\left(\mathrm{Chi}^{2}=4.36, \mathrm{df}=2, \mathrm{P}=\right.$ $0.11, \mathrm{I}^{2}=54.1 \%$, Analysis 13.1$)$ or PTSD symptoms $\left(\mathrm{Chi}^{2}=\right.$ $0.01, \mathrm{df}=1, \mathrm{P}=0.91, \mathrm{I}^{2}=0 \%$, Analysis 13.2).

\section{Skewed data}

There was no difference between studies which reported skewed data and those that did not $\left(\mathrm{Chi}^{2}=0.22, \mathrm{df}=1, \mathrm{P}=0.84, \mathrm{I}^{2}=\right.$ $0 \%$, Analysis 14.1).

\section{Intention-to-treat analysis}

There was no difference between best and worst-case estimates of improvement when all psychological therapies were compare to a control $\left(\mathrm{Chi}^{2}=1.67, \mathrm{df}=1, \mathrm{P}=0.20, \mathrm{I}^{2}=40.0 \%\right.$, Analysis 15.1$)$.

\section{Funnel plot}

A funnel plot could not be produced because there were not enough studies reporting the primary outcome of PTSD symptoms or improvement.

\section{DISCUSSION}

\section{Summary of main results}

Overall, there is fair evidence for the role of psychological therapies in decreasing the number of children and adolescents who continue to be diagnosed with post-traumatic stress disorder (PTSD) and reducing the scores of PTSD symptoms for up to a month following treatment. In addition, there is some evidence that psychological therapies can decrease the symptoms of anxiety and depression in children and adolescents diagnosed with PTSD.

When each of the psychological therapies were compared to a control, the only therapy for which there was evidence of effectiveness 
was cognitive behavioural therapy (CBT). There was greater improvement and decreased PTSD and depression scores in the CBT group compared to a control for up to a year following treatment. In addition, CBT was shown to be superior to supportive therapy.

\section{Overall completeness and applicability of evidence}

Although subgroup analyses showed that there was a significant difference between psychological therapies and CBT was the only therapy shown to be effective, there is not enough data to conclude whether one psychological therapy is more effective than another. Therefore these analyses can be considered hypothesis generating and warrant investigation in future trials. Also, there were no data which could provide information on the relative benefits of pharmacological and psychological therapies for the treatment of PTSD in children and adolescents.

There is little evidence to conclude that the benefits of psychological therapies last beyond a month after treatment. The majority of studies reported short-term outcomes and in those studies which did report longer follow-up, the loss to follow-up was markedly increased over time.

There were not enough data to make any conclusions about the effectiveness of psychological therapies with different types of trauma and no data that could allow us to differentiate between complex and non-complex trauma. The lack of any significant difference between the different types of PTSD may be because of the limited number of studies available for this review.

There were not enough data to be able to make any comparisons between individual, group and individual plus parent therapies. None of the identified studies compared psychological therapies to pharmacological therapies or other forms of treatment for PTSD in children or adolescents.

\section{Quality of the evidence}

The evidence that psychological therapies are effective in the treatment of PTSD across a range of psychological therapies is limited by the fairly small number of identified studies, low participant numbers and short-term follow-up.

The findings of this review are also limited by the potential for methodological biases. Although no study was rated as a high risk for selection or detection bias, and a minority were rated as a high risk for attrition, reporting and other bias, most studies were rated as having an unclear risk of selection, detection and attrition bias. Therefore, the potential for a high risk remains in those studies where the methods were not adequately described for a decision to be made.

The quality of the evidence is also limited by the small number and generally small size of the identified studies. Therefore, a negative finding with many of these analyses may well be due to a lack of power.

There was evidence of substantial heterogeneity in the analyses of PTSD and depression symptom scores when psychological therapies were compared to controls. As per our protocol we explored potential sources of heterogeneity by performing subgroup analyses for 'type of therapy' and 'type of trauma'. However, there was no evidence that these subgroups could account for the heterogeneity in these outcomes. We also considered whether type of control may have introduced heterogeneity but again there was no evidence for this as all control groups in these analyses were waiting list controls.

\section{Potential biases in the review process}

A large proportion of the 'Risk of bias' ratings in this review were unclear because the methods were not clearly described. Therefore the possibility of a high risk of bias remains in many of these studies.

As none of the participants in the intervention versus control trials could be blinded to whether or not they were receiving an active treatment, it is possible that some of the apparent effect of these interventions may have been because participants knew they were receiving a treatment.

While not rated as a potential risk of bias there also seemed to be inconsistent reporting of PTSD total scores and sub-scores. Some studies also used measures which seemed limited in scale, and therefore to have a higher potential for skewed data, and may have been less sensitive to symptom change.

\section{Agreements and disagreements with other studies or reviews}

The finding of this review that psychological therapies are effective in the treatment of PTSD is in line with the findings of the narrative review by Taylor 2004 that psychological therapies are effective in the treatment of traumatic stress in children and adolescents. Although the psychological therapy for which there was the best evidence of effectiveness was CBT, there is little basis on which to conclude at this stage that one psychological therapy is more effective than the other in the treatment of PTSD in children and adolescents. This apparent lack of a clear difference between psychological therapies is similar to the results of meta-analyses of treatments for other psychological conditions (Churchill 2001; Dennis 2007; Gava 2007).

The finding that CBT appears to be effective in the treatment of PTSD is in line with the recommendation of the UK National Institute for Clinical Excellence (NICE) guidelines that children and young people with PTSD should be offered a course of trauma-focused CBT adapted appropriately to suit their age, circumstances and level of development (NICE 2005). In addi- 
tion, two Cochrane reviews have reported evidence for the effectiveness of CBT in the treatment of PTSD (Bisson 2007) and acute traumatic stress symptoms (Roberts 2010) in adults. Bisson 2007 concluded that there was evidence that individual traumafocused CBT and eye movement desensitisation and reprocessing (EMDR) was more effective in reducing PTSD symptoms than other non-trauma focused psychological therapies, while Roberts 2010 concluded that trauma-focused CBT was more effective for individuals with acute traumatic stress symptoms compared to waiting list and supportive counselling interventions.

\section{A U THORS' CONCLUSIONS}

\section{Implications for practice}

There is fair evidence for the effectiveness of psychological therapies, particularly CBT, for the treatment of PTSD in children and adolescents. At this stage, there is no clear evidence for the effectiveness of one psychological therapy compared to others. There is also not enough evidence to conclude that children and ado- lescents with particular types of trauma are more or less likely to respond to psychological therapies than others.

\section{Implications for research}

To identify whether specific psychological therapies are more effective for the treatment of PTSD in children and adolescents, more trials comparing the various psychological therapies are required. In addition, trials which compare psychological therapies to pharmacological and other treatments are also needed. More details are required in future trials in regards to the types of trauma that preceded the diagnosis of PTSD and whether the traumas are single event or ongoing. More effort also needs to be given to increasing longer-term follow-up. Future studies should also aim to identify the most valid and reliable measures of PTSD symptoms and ensure that all scores, total and sub-scores are consistently reported.

\section{ACKNOWLEDGEMENTS}

Pam Withey (Rogers) and Charles Meekings, co-authors of the protocol for this review (Gillies 2007).

\section{R E F E R E N C E S}

\section{References to studies included in this review}

Ahmad 2007 \{published data only\}

* Ahmad A, Larsson B, Sundelin-Wahlsten V. EMDR treatment for children with PTSD: results of a randomized controlled trial. Nordic Journal of Psychiatry 2007;61(5): $349-54$.

Ahmad A, Sundelin-Wahlsten V. Applying EMDR on children with PTSD. European Child \& Adolescent Psychiatry 2008;17(3):127-32.

Ahrens 2002 \{published data only\}

* Ahrens J, Rexford L. Cognitive processing therapy for incarcerated adolescents with PTSD. Journal of Aggression, Maltreatment and Trauma 2002;6(1):201-16.

Catani 2009 \{published data only\}

* Catani C, Kohiladevy M, Ruf M, Schauer E, Elbert T, Neuner F. Treating children traumatized by war and tsunami: a comparison between exposure therapy and meditation-relaxation in North-East Sri Lanka. BMC Psychiatry 2009;9:22. [DOI: 10.1186/1471-244X-9-22]

Chemtob 2002a \{published data only\}

* Chemtob CM, Nakashima J, Carlson JG. Brief treatment for elementary school children with disaster-related posttraumatic stress disorder: a field study. Journal of Clinical Psychology 2002;58(1):99-112.
Cohen 2004 \{published data only\}

Cohen J A, Deblinger E, Mannarino AP, Steer RA. A multisite, randomized controlled trial for children with sexual abuse-related PTSD symptoms. Journal of the American Academy of Child and Adolescent Psychiatry 2004; 43(4):393-402.

Cohen J, Mannarino A, Deblinger E, Steer R. A multisite treatment study for PTSD in sexually abused children. 19th Annual Meeting, International Society for Traumatic Stress Studies, October 29 - November 1, Chicago, IL. 2003. * Deblinger E, Mannarino AP, Cohen JA, Steer RA. A follow-up study of a multisite, randomized, controlled trial for children with sexual abuse-related PTSD symptoms. Journal of the American Academy of Child and Adolescent Psychiatry 2006;45(12):1474-84.

Cohen 2011 \{published data only\}

Cohen JA, Mannarino AP, Iyengar S. Community treatment of posttraumatic stress disorder for children exposed to intimate partner violence: a randomized controlled trial. Archives of Pediatrics and Adolescent Medicine 2011;165(1): 16-21.

Ertl 2011 \{published data only\}

Ertl V, Pfeiffer A, Schauer E, Elbert T, Neuner F. Community-implemented trauma therapy for former child soldiers in Northern Uganda: a randomized controlled trial. JAMA 2011;306(5):503-12. 
Gilboa-Schechtman 2010 \{published data only\} Gilboa-Schechtman E, Foa EB, Shafran N, Aderka IM, Powers MB, Rachamim 1, et al. Prolonged exposure versus dynamic therapy for adolescent PTSD: a pilot randomized controlled trial. Journal of the American Academy of Child and Adolescent Psychiatry 2010;49(10):1034-42.

Wittmann L, Halpern J. Prolonged exposure and psychodynamic treatment for posttraumatic stress disorder [comment]. Journal of the American Academy of Child \& Adolescent Psychiatry 2011;50(5):521-2 [author reply 522-1, 2011 May]

\section{Gordon 2008 \{published data only\}}

Gordon JS. Treatment of posttraumatic stress disorder in Kosovar high school students using mind-body skills groups: a randomized controlled trial [NCT00136357]. ClinicalTrials.gov [www.clinicaltrials.gov] 2006.

* Gordon JS, Staples JK, Blyta A, Bytyqi M, Wilson AT. Treatment of posttraumatic stress disorder in postwar Kosovar adolescents using mind-body skills groups: a randomized controlled trial. Journal of Clinical Psychiatry 2008;69(9):1469-76.

King 2000 \{published data only\}

* King NJ, Tonge BJ, Mullen P, Myerson N, Heyne D, Rollings $S$, et al. Treating sexually abused children with posttraumatic stress symptoms: a randomized clinical trial. Journal of the American Academy of Child \& Adolescent Psychiatry 2000;39(11):1347-55.

Najavits 2006 \{published data only\}

* Najavits LM Gallop RJ, Weiss RD. Seeking Safety therapy for adolescent girls with PTSD and substance use disorder: a randomized controlled trial. Journal of Behavioral Health Services and Research 2006;33(4):453-63.

Ruf 2010 \{published data only\}

Ruf M, Schauer M, Neuner F, Catani C, Elbert T. Traumatized refugee children in Germany - prevalence and treatment. World Psychiatric Association, International Congress; 2006 July 12 - 16; Istanbul, Turkey. 2006:146. * Ruf M, Schauer M, Neuner F, Catani C, Schauer E, Elbert T. Narrative exposure therapy for 7- to 16-year-olds: a randomized controlled trial with traumatized refugee children. Journal of Traumatic Stress 2010;23(4):437-45.

\section{Schauer 2008 \{unpublished data only\}}

* Schauer E. Trauma treatment for children in war: build-up of an evidence-based large-scale mental health intervention in north-eastern Sri Lanka. PhD thesis submitted to Konstanz University 2008.

Smith 2007 \{published data only\}

Smith P, Yule W, Perrin S, Tranah T, Dalgleish T, Clark DM. A randomised controlled trial of cognitive behaviour therapy for childhood posttraumatic stress disorder. 32nd Congress of the British Association for Behavioural and Cognitive Psychotherapies (jointly with the European Association of Behavioural and Cognitive Therapies); 2004 September 7 - 11; Manchester. 2004:111.

* Smith P, Yule W, Perrin S, Tranah T, Dalgleish T, Clark DM. Cognitive-behavioral therapy for PTSD in children and adolescents: a preliminary randomized controlled trial. Journal of the American Academy of Child and Adolescent Psychiatry 2007;46(8):1051-61.

\section{References to studies excluded from this review}

Berger 2007 \{published data only\}

* Berger R, Pat-Horenczyk R, Gelkopf M. School-based intervention for prevention and treatment of elementarystudents' terror-related distress in Israel: a quasi-randomized controlled trial. Journal of Traumatic Stress 2007;20(4): 541-51.

Berger 2009 \{published data only\}

Berger R, Gelkopf M. School-based intervention for the treatment of tsunami-related distress in children: a quasi-randomized controlled trial. Psychotherapy and Psychosomatics 2009;78(6):364-71.

Berkowitz 2011 \{published data only\}

Berkowitz Steven J, Stover Carla Smith, Marans Steven R. The Child and Family Traumatic Stress Intervention: secondary prevention for youth at risk of developing PTSD. Journal of Child Psychology and Psychiatry 2011;52(6): 676-85.

Berliner 1996 \{published data only\}

* Berliner L, Saunders BE. Treating fear and anxiety in sexually abused children: results of a controlled 2-year follow-up study. Child Maltreatment 1996;1(4):294-309.

Bolton 2007 \{published data only\}

Betancourt T, Bolton P, Bass J, Murray L, Verdeli H, Clougherty K, et al. Phase III: A randomized controlled trial of mental health interventions for Acholi war-affected youth in Gulu, Northern Uganda. 2006:114.

* Bolton P, Bass J, Betancourt T, Speelman L, Onyango G, Clougherty KF, et al. Interventions for depression symptoms among adolescent survivors of war and displacement in northern Uganda: a randomized controlled trial. JAMA 2007;298(5):519-27.

Brown 2003 \{published data only\}

Brown EJ, Goodman RF, Cohen J, Mannarino A. A randomized controlled trial for children's traumatic grief. National Child Traumatic Stress Network Annual Meeting, December 11 - 13, San Diego, CA. 2003.

Celano 1996 \{published data only\} * Celano M, Hazzard A, Webb C, McCall C. Treatment of traumagenic beliefs among sexually abused girls and their mothers: an evaluation study. Journal of Abnormal Child Psychology 1996;24(1):1-17.

Chapman 2001 \{published data only\}

* Chapman L, Morabito D, Ladakakos C, Schreier $\mathrm{H}$, Knudson MM. The effectiveness of art therapy interventions in reducing post traumatic stress disorder (PTSD) symptoms in pediatric trauma patients. Art Therapy 2001;18(2):100-4.

Chemtob 2002 \{published data only\} * Chemtob CM, Nakashima JP, Hamada RS. Psychosocial intervention for post disaster trauma symptoms in 
elementary school children: a controlled community field study. Archives of Pediatrics \& Adolescent Medicine 2002;156 (3):211-6.

Cohen 1997 \{published data only\}

* Cohen J A, Mannarino A P. A treatment study for sexually abused preschool children: outcome during a one-year follow-up. Journal of the American Academy of Child \& Adolescent Psychiatry 1997;36(9):1228-35.

Cohen J A, Mannarino A P. Factors that mediate treatment outcome of sexually abused preschool children. Journal of the American Academy of Child \& Adolescent Psychiatry 1996; 35(10):1402-10.

Cohen J A, Mannarino A P. Factors that mediate treatment outcome of sexually abused preschool children: six- and 12month follow-up. Journal of the American Academy of Child \& Adolescent Psychiatry 1998;37(1):44-51.

Cohen JA, Mannarino AP. A treatment outcome study for sexually abused preschool children: initial findings [erratum appears in J Am Acad Child Adolesc Psychiatry 1996 Jun; 35(6):835]. Journal of the American Academy of Child \& Adolescent Psychiatry 1996;35(1):42-50.

Cohen 1998 \{published data only\}

* Cohen JA, Mannarino AP. Interventions for sexually abused children: initial treatment outcome findings. Child Maltreatment 1998;3(1):17-26.

Cohen 2005 \{published data only\}

Cohen J A, Mannarino A P, Knudsen K. Treatment outcome for sexually abused children at one-year follow-up. 156th Annual Meeting of the American Psychiatric Association, May 17-22, San Francisco CA. 2003, issue 107.

* Cohen JA, Mannarino AP, Knudsen K. Treating sexually abused children: 1 year follow-up of a randomized controlled trial. Child Abuse and Neglect 2005;29(2): $135-45$.

Cohen 2007 \{published data only\}

* Cohen JA, Mannarino AP, Perel JM, Staron V. A pilot randomized controlled trial of combined trauma-focused CBT and sertraline for childhood PTSD symptoms. Journal of the American Academy of Child and Adolescent Psychiatry 2007;46(7):811-9.

Cooley-Strickland 2011 \{published data only\} Cooley-Strickland MR, Griffin RS, Darney D, Otte K, Ko J. Urban African American youth exposed to community violence: a school-based anxiety preventive intervention efficacy study. Journal of Prevention and Intervention in the Community 2011;39(2):149-66.

\section{Cox 2010 \{published data only\}}

Cox CM, Kenardy JA, Hendrikz JK. A randomized controlled trial of a web-based early intervention for children and their parents following unintentional injury. Journal of Pediatric Psychology 2010;35(6):581-92.

Deblinger 1996 \{published data only\}

* Deblinger E, Lippmann J, Steer R. Sexually abused children suffering posttraumatic stress symptoms: initial treatment outcome findings. Child Maltreatment 1996;1

(4):310-21.

* Deblinger E, Steer RA, Lippmann J. Two-year follow-up study of cognitive behavioral therapy for sexually abused children suffering post-traumatic stress symptoms. Child Abuse and Neglect 1999;23(12):1371-8.

Deblinger 2001 \{published data only\}

Deblinger E, Stauffer LB, Steer RA. Comparative efficacies of supportive and cognitive behavioral group therapies for young children who have been sexually abused and their nonoffending mothers. Child Maltreatment 2001;6(4): $332-43$.

Deblinger 2011 \{published data only\} Deblinger E, Mannarino AP, Cohen JA, Runyon MK, Steer RA. Trauma-focused cognitive behavioral therapy for children: impact of the trauma narrative and treatment length. Depression and Anxiety 2011;28(1):67-75.

Dominguez 2001 \{published data only\}

* Dominguez RZ. Evaluation of cognitive-behavioral and supportive treatments for sexually abused children: Analyzing the process of change using individual growth curve analyses. Dissertation Abstracts International. University of Houston, 2001:5370.

Ehntholt 2005 \{published data only\} Ehntholt K A, Smith P, Yule W. School-based CBT group intervention for refugee children who have experienced war-related trauma. 31st Annual Conference of the British Association for Behavioural and Cognitive Psychotherapies; 2003 July 16 - 19, York. 2003, issue 83.

* Ehntholt KA, Smith PA, Yule W. School-based cognitivebehavioural therapy group intervention for refugee children who have experienced war-related trauma. Clinical Child Psychology and Psychiatry 2005;10(2):235-50.

Ensink 2004 \{published data only\}

* Ensink K, Normandin L, Kernberg PF. Efficacy of a Reflective Functioning Treatment (RFT) for young sexually abused children. Society for Psychotherapy Research 35th Annual General Meeting Book of Abstracts. Rome, Italy, June 16 to $19,2004$.

Farkas 2010 \{published data only\}

Farkas L. The effects of Motivation-Adaptive Skills-Trauma Resolution (MASTR) - Eye Movement Desensitization and Reprocessing (EMDR) on traumatized adolescents with conduct problems. Dissertation Abstracts International: Section B: The Sciences and Engineering 2010; Vol. 71, issue 1-B:655.

\section{Gelkopf 2009 \{published data only\}}

Gelkopf M, Berger R. A school-based, teacher-mediated prevention program (ERASE-Stress) for reducing terrorrelated traumatic reactions in Israeli youth: a quasirandomized controlled trial. Journal of Child Psychology and Psychiatry and Allied Disciplines 2009;50(8):962-71.

Goenjian 1997 \{published data only\}

* Goenjian AK, Karayan I, Pynoos RS, Minassian

D, Najarian LM, Steinberg AM, et al. Outcome of 
psychotherapy among early adolescents after trauma. American Journal of Psychiatry 1997;154(4):536-42.

Jaberghaderi 2004 \{published data only\} Jaberghaderi N, Greenwald R, Rubin A, Dalatabadi S, Zand SO. A comparison of CBT and EMDR for sexually-abused Iranian girls. Baltimore, MD, 2002.

* Jaberghaderi N, Greenwald R, Rubin A, Zand Shahin O, Dolatabadi S. A comparison of CBT and EMDR for sexually-abused Iranian girls. Clinical Psychology and Psychotherapy 2004;11(5):358-68.

Jeffres 2004 \{published data only\}

* Jeffres MJ. The efficacy of EMDR with traumatized children. Dissertation Abstracts International 2004:4042.

Jordans 2010 \{published data only\} Jordans MJ, Komproe IH, Tol WA, Kohrt BA, Luitel NP, Macy RD, et al. Evaluation of a classroom-based psychosocial intervention in conflict-affected Nepal: a cluster randomized controlled trial [ISRCTN48004304]. Journal of Child Psychology and Psychiatry, and Allied Disciplines 2010;51(7):818-26.

Kassam-Adams 2011 \{published data only\} Kassam-Adams N, Garcia-Espana JF, Marsac ML, Kohser KL, Baxt C, Nance M, et al. A pilot randomized controlled trial assessing secondary prevention of traumatic stress integrated into pediatric trauma care. Journal of Traumatic Stress 2011;24(3):252-9.

Kataoka 2003 \{published data only\}

* Kataoka SH, Stein BD, Jaycox LH, Wong M, Escudero P, Tu W, et al. A school-based mental health program for traumatized Latino immigrant children. Journal of the American Academy of Child and Adolescent Psychiatry 2003; 42(3):311-8.

Kazak 2004 \{published data only\}

Kazak A, Alderfer M, Streisand R, Simms S, Rourke M, Barakat L, et al. Family treatment of posttraumatic stress in childhood cancer survival. 19th Annual Meeting, International Society for Traumatic Stress Studies, October 29 - November 1, Chicago, IL. 2003.

* Kazak AE, Alderfer MA, Streisand R, Simms S, Rourke MT, Barakat LP, et al. Treatment of posttraumatic stress symptoms in adolescent survivors of childhood cancer and their families: a randomized clinical trial. Journal of Family Psychology 2004;18(3):493-504.

Kemp 2010 \{published data only\}

Kemp M, Drummond P, McDermott B. A wait-list controlled pilot study of eye movement desensitization and reprocessing (EMDR) for children with post-traumatic stress disorder (PTSD) symptoms from motor vehicle accidents. Clinical Child Psychology and Psychiatry 2010;15 (1):5-25.

Layne 2008 \{published data only\}

Layne CM, Saltzman WR, Poppleton L, Burlingame GM, Pasalic A, Durakovic E, et al. Effectiveness of a school-based group psychotherapy program for war-exposed adolescents: a randomized controlled trial [NCT00480480]. Journal of the American Academy of Child and Adolescent Psychiatry

2008;47(9):1048-62.

Lesmana 2009 \{published data only\}

Lesmana CBJ, Suryani LK, Jensen GD, Tiliopoulos N. A spiritual-hypnosis assisted treatment of children with PTSD after the 2002 Bali terrorist attack. American Journal of Clinical Hypnosis 2009;52(1):23-34.

Lieberman 2005 \{published data only\}

* Lieberman AF, Van Horn P, Ippen CG. Toward evidencebased treatment: child-parent psychotherapy with preschoolers exposed to marital violence. Journal of the American Academy of Child and Adolescent Psychiatry 2005; 44(12):1241-8.

\section{Lyshak-Stelzer 2007 \{published data only\}}

Lyshak-Stelzer F, Singer P, St John P, Chemtob C M. Art therapy for adolescents with posttraumatic stress disorder symptoms: a pilot study. Art Therapy 2007;24(4):163-9.

March 1998 \{published data only\}

* March JS, Amaya-Jackson L, Murray MC, Schulte A. Cognitive-behavioral psychotherapy for children and adolescents with posttraumatic stress disorder after a singleincident stressor. Journal of the American Academy of Child \& Adolescent Psychiatry 1998;37(6):585-93.

\section{McWhirter 2011 \{published data only\}} McWhirter PT. Differential therapeutic outcomes of community-based group interventions for women and children exposed to intimate partner violence. Journal of Interpersonal Violence 2011;26(12):2457-82.

Pfeffer 2002 \{published data only\}

* Pfeffer CR, Jiang H, Kakuma T, Hwang J, Metsch M. Group intervention for children bereaved by the suicide of a relative. Journal of the American Academy of Child and Adolescent Psychiatry 2002;41(5):505-13.

Raider 2008 \{published data only\} Raider MC, Steele W, Delillo-Storey M, Jacobs J, Kuban C. Structured sensory therapy (SITCAP-ART) for traumatized adjudicated adolescents in residential treatment. Residential Treatment for Children and Youth 2008;25(2):167-85.

Salloum 2008 \{published data only\} Salloum A. Group therapy for children after homicide and violence: a pilot study. Research on Social Work Practice 2008;18(3):198-211.

Salloum A, Overstreet S. Evaluation of individual and group grief and trauma interventions for children post disaster. Journal of Clinical Child and Adolescent Psychology 2008;37 (3):495-507.

\section{Schaal 2010 \{published data only\}}

* Schaal S, Elbert T, Neuner F. Narrative exposure therapy versus interpersonal psychotherapy: a pilot randomized controlled trial with Rwandan genocide orphans. Psychotherapy and Psychosomatics 2009;78(5):298-306.

\section{Scheeringa 2011 \{published data only\}} Scheeringa MS, Weems CF, Cohen JA, Amaya-Jackson L, Guthrie D. Trauma-focused cognitive-behavioral therapy for posttraumatic stress disorder in three-through six year- 
old children: a randomized clinical trial. Journal of Child Psychology and Psychiatry and Allied Disciplines 2011;52(8): 853-60.

Shechtman 2010 \{published data only\}

Shechtman Z, Mor M. Groups for children and adolescents with trauma-related symptoms: outcomes and processes. International Journal of Group Psychotherapy 2010;60(2): $221-44$.

Shelby 1995 \{published data only\}

* Shelby JS. Crisis intervention with children following Hurricane Andrew: a comparison of two treatment approaches. Dissertation Abstracts International 1995: 1121.

Shooshtary 2008 \{published data only\}

Shooshtary MH, Panaghi L, Moghadam JA. Outcome of cognitive behavioral therapy in adolescents after natural disaster. Journal of Adolescent Health 2008;42(5):466-72.

Stallard 2006 \{published data only\}

Stallard P. A randomised controlled trial to determine whether mental health problems and significant psychological distress in children involved in everyday road traffic accidents can be prevented. National Research Register 2003.

* Stallard P, Velleman R, Salter E, Howse I, Yule W, Taylor G. A randomised controlled trial to determine the effectiveness of an early psychological intervention with children involved in road traffic accidents. Journal of Child Psychology and Psychiatry and Allied Disciplines 2006;47(2): 127-34.

Stallard P, Velleman R, Salter E, Howse I, Yule W, Taylor $\mathrm{G}$, et al. A randomised controlled trial to determine the effectiveness of an early intervention with child trauma victims. 31st Annual Conference of the British Association for Behavioural and Cognitive Psychotherapies; 2003 July 16 - 19, York. 2003:83.

Stallard P, Velleman R, Salter W, Howse I, Yule W, Taylor G, et al. Does early intervention prevent psychological distress in children involved in road traffic accidents? The results of a randomised controlled trial. 32nd Congress of the British Association for Behavioural and Cognitive Psychotherapies (jointly with the European Association of Behavioural and Cognitive Therapies); 2004 September 7 - 11; Manchester. 2004:111.

Stein 2003 \{published data only\}

* Stein BD, Jaycox LH, Kataoka SH, Wong M, Tu W, Elliott $\mathrm{MN}$, et al. A mental health intervention for schoolchildren exposed to violence: a randomized controlled trial. JAMA 2003;290(5):603-11.

Taussig 2010 \{published data only\}

Taussig HN, Culhane SE. Impact of a mentoring and skills group program on mental health outcomes for maltreated children in foster care [NCT00809315]. Archives of Pediatrics and Adolescent Medicine 2010;164(8):739-46.

Thabet 2005 \{published data only\}

* Thabet AA, Vostanis P, Karim K. Group crisis intervention for children during ongoing war conflict. European Child and Adolescent Psychiatry 2005;14(5):262-9.
Tol 2010 \{published data only\}

Tol W A, Komproe I H, Susanty D, Jordans M J, Macy R D, De Jong J T. School-based mental health intervention for children affected by political violence in Indonesia: a cluster randomized trial. JAMA 2008;300(6):655-62. Tol WA, Komproe IH, Jordans MJ, Gross AL, Susanty $\mathrm{D}$, Macy RD, et al. Mediators and moderators of a psychosocial intervention for children affected by political violence. Journal of Consulting and Clinical Psychology 2010; 78(6):818-28.

Trowell 2002 \{published data only\}

McCrone P, Weeramanthri T, Knapp M, Rushton A, Trowell J, Miles G, et al. Cost- effectiveness of individual versus group psychotherapy for sexually abused girls. Child and Adolescent Mental Health 2005;10(1):26-31.

Trowell J, Kolvin I. Lessons from a psychotherapy outcome study with sexually abused girls. Clinical Child Psychology and Psychiatry 1999;4(1):79-89.

* Trowell J, Kolvin I, Weeramanthri T, Sadowski H, Berelowitz M, Glasser D, et al. Psychotherapy for sexually abused girls: psychopathological outcome findings and patterns of change. British Journal of Psychiatry 2002;180: 234-47.

Trowell JA, Berelowitz M, Kolvin I. In: Aveline M, Shapiro DA editor(s). Design and Methodological Issues In Setting Up A Psychotherapy Outcome Study With Girls Who Have Been Sexually Abused. Chichester: John Wiley, 1995.

Wang 2011 \{published data only\}

Wang Z-Y, Yang F, Wang Y-Y, Gao J, Qian M-Y. Effects of group intervention on depression and post-traumatic stress symptoms among junior middle school students in earthquake area. Chinese Mental Health Journal 2011;25(4): 284-8.

Wolmer 2011a \{published data only\}

Wolmer L, Hamiel D, Laor N. Preventing children's posttraumatic stress after disaster with teacher-based intervention: a controlled study. Journal of the American Academy of Child and Adolescent Psychiatry 2011;50(4): 340-8.

\section{Wolmer 2011b \{published data only\}}

Wolmer L, Hamiel D, Barchas JD, Slone M, Laor N. Teacher-delivered resilience-focused intervention in schools with traumatized children following the second Lebanon War. Journal of Traumatic Stress 2011;24(3):309-16.

Zehnder 2010 \{published data only\}

Zehnder D, Meuli M, Landolt M A. Effectiveness of a single-session early psychological intervention for children after road traffic accidents: a randomised controlled trial [NCT00296842]. Child and Adolescent Psychiatry and Mental Health 2010;4:7.

\section{References to ongoing studies}

\section{Bryant 2011 \{unpublished data only\}}

Bryant R. Randomised controlled trial of cognitive behavior therapy and supportive counselling for reduction in posttraumatic stress disorder (PTSD) symptoms in 
Acehnese children [ACTRN12611000080921]. Australian New Zealand Clinical Trials Registry (www.anzctr.org.au) 2011.

\section{Chemtob 2008 \{unpublished data only\}}

Chemtob CM, Luthra R. Creating a collaborative field research organization [NCT00614068]. ClinicalTrials.gov (www.clinicaltrials.gov) 2008.

Foa 2009 \{unpublished data only\}

Foa EB. Treating adolescents with CSA related PTSD [NCT00417300]. ClinicalTrials.gov (www.clinicaltrials.gov) 2009.

Goldbeck 2011 \{unpublished data only\} Goldbeck L. Effectiveness of trauma-focused cognitivebehavioral therapy (TF-CBT) for children with post-traumatic stress disorder [NCT01516827]. ClinicalTrials.gov (www.clinicaltrials.gov) 2012.

Kenardy 2010 \{published and unpublished data\} Kenardy J. Comparison of cognitive-behavioural treatments for children with post-traumatic stress disorder (PTSD) following an accidental injury: a multicentre randomised controlled trial [ISRCTN79049138]. ControlledTrials.com (www.controlled-trials.com/isrctn) 2012.

* Kenardy J, Cobham V, Nixon RD, McDermott B, March, S. Protocol for a randomised controlled trial of risk screening and early intervention comparing child- and family-focused cognitive-behavioural therapy for PTSD in children following accidental injury (corrected). $B M C$ Psychiatry 2011;11:15.

Kenardy J, Cobham V, Nixon RDV, McDermott B, March S. Protocol for a randomised controlled trial of risk screening and early intervention comparing child- and family-focused cognitive-behavioural therapy for PTSD in children following accidental injury (original). $B M C$ Psychiatry 2010;10:92.

\section{Additional references}

\section{AACAP 1998}

American Academy of Child, Adolescent Psychiatry. Practice parameters for the assessment and treatment of children and adolescents with posttraumatic stress disorder. Journal of the American Academy of Child and Adolescent Psychiatry 1998;37 Suppl 10:4-26.

\section{AACAP 2010}

Cohen JA, Bukstein O, Walter H, Benson RS, Chrisman A, Farchione TR, et al. Practice parameter for the assessment and treatment of children and adolescent with posttraumatic stress disorder. Journal of the American Academy of Child and Adolescent Psychiatry 2010;49(4):414-30.

Achenbach 1983

Achenbach TM, Edelbrock CS. Manual for the Child Behavior Checklist. Burlington, VT: University of Vermont, Department of Psychiatry, 1983.

Altman 1996

Altman DG, Bland JM. Detecting skewness from summary information. BMJ 1996;313:1200.

\section{Altman 2000}

Altman DG. Statistics in medical journals: some recent trends. Statistics in Medicine 2000;19(23):3275-89.

\section{Amaya-Jackson 2007}

Amaya-Jackson L, Derosa RR. Treatment considerations for clinicians in applying evidence-based practice to complex presentations in child trauma. Journal of Traumatic Stress 2007;20(4):379-90.

\section{APA 2000}

American Psychiatric Association. Diagnostic and Statistical Manual of Mental Disorders (DSM-IV-TR). 4th Edition. Washington, DC: American Psychiatric Association, 2000: 463-468.

Bisson 2007

Bisson J, Andrew M. Psychological treatment of posttraumatic stress disorder (PTSD). Cochrane Database of Systematic Reviews 2007, Issue 3. [DOI: 10.1002/ 14651858.CD003388.pub3]

BluePages 2012

BluePages. http://bluepages.anu.edu.au/treatments/ what ' works/psychological treatments/ (accessed 20 August 2012).

Bryant 2001

Bryant RA, Friedman M. Medication and non-medication treatments of post-traumatic stress disorder. Current Opinion in Psychiatry 2001;14(2):119-23.

Carr 2004

Carr A. Interventions for post-traumatic stress disorder in children and adolescents. Pediatric Rehabilitation 2004;7 (4):231-44.

\section{Churchill 2001}

Churchill R, Hunot V, Corney R, Knapp M, McGuire H, Tylee A, et al. A systematic review of controlled trials of the effectiveness and cost-effectiveness of brief psychological treatments for depression. Health Technology Assessment 2001;5(35):1-173.

Dennis 2007

Dennis CL, Hodnett ED. Psychosocial and psychological interventions for treating postpartum depression. Cochrane Database of Systematic Reviews 2007, Issue 4. [DOI: 10.1002/14651858.CD006116.pub2]

Donnelly 2002

Donnelly CL, Amaya-Jackson L. Post-traumatic stress disorder in children and adolescents: epidemiology, diagnosis and treatment options. Paediatric Drugs 2002;4 (3):159-70

\section{Egger 1997}

Egger M, Smith GD, Schneider M, Minder C. Bias in meta-analysis detected by a simple, graphical test. $B M J$ 1997;315:629-34.

\section{Fewtrell 2008}

Fewtrell MS, Kennedy K, Singhal A, Martin RM, Ness A, Hadders-Algra M, et al. How much loss to follow-up is acceptable in long-term randomised trials and prospective 
studies?. Archives of Disease in Childhood 2008;93(6): 458-61.

Fletcher 2003

Fletcher KE. Childhood posttraumatic stress disorder. In: Mash EJ, Barkley RA editor(s). Child Psychopathology. 2nd Edition. New York, NY: The Guildford Press, 2003: 330-71.

Foa 1997

Foa EB, Meadows EA. Psychosocial treatments for posttraumatic stress disorder: a critical review. Annual Review of Psychology 1997;48:449-80.

Ford 2009

Ford JD, Connor DF, Hawke J. Complex trauma among psychiatrically impaired children: a cross-sectional, chartreview study. Journal of Clinical Psychiatry 2009;70(8): 1155-63.

Foy 1996

Foy DW, Madvig BT, Pynoos RS, Camilleri AJ. Etiologic factors in the development of posttraumatic stress disorder in children and adolescents. Journal of School Psychology 1996;34(2):133-45.

Gava 2007

Gava I, Barbui C, Aguglia E, Carlino D, Churchill R, De Vanna M, et al. Psychological treatments versus treatment as usual for obsessive compulsive disorder (OCD). Cochrane Database of Systematic Reviews 2007, Issue 2. [DOI: 10.1002/14651858.CD005333.pub2]

Higgins 2008

Higgins JPT, Green S (editors). Cochrane Handbook for Systematic Reviews of Interventions Version 5.1.0 [updated March 2011]. The Cochrane Collaboration, 2011. Available from www.cochrane-handbook.org.

\section{Kovacs 1992}

Kovacs M. Children's Depression Inventory. https:/ /www.mhs.com/ecom/(3jkh5055rnqsekfhnxgzn145)/ TechBrochures/CDI.pdf 1992 (accessed 18 May 2007).

\section{McNally 1996}

McNally RJ. Assessment of posttraumatic stress disorder in children and adolescents. Journal of School Psychology 1996; 3(2):147-61.

\section{Moher 1998}

Moher D, Pham B, Jones A, Cook DJ, Jadad AR, Moher $\mathrm{M}$, et al. Does quality of reports of randomised trials affect estimates of intervention efficacy reported in meta-analyses? . Lancet 1998;352(9128):609-13.

Neuner 2004

Neuner F, Schauer M, Klaschik C, Karunakara U, Elbert T. A comparison of narrative exposure therapy, supportive counseling, and psychoeducation for treating posttraumatic stress disorder in an African refugee settlement. Journal of Consulting and Clinical Psychology 2004;72(4):579-87.

\section{NICE 2005}

National Institute for Clinical Excellence. Post-traumatic stress disorder: the management of PTSD in adults and children in primary and secondary care. National
Clinical Practice Guideline Number 26 2005:http:// www.nice.org.uk/nicemedia/live/10966/29769/29769.pdf.

Parry-Jones 1995

Parry-Jones W, Barton J. Post-traumatic stress disorder in children and adolescents. Current Opinion in Psychiatry 1995;8(4):227-30.

\section{Perrin 2000}

Perrin S, Smith P, Yule W. Practitioner review: the assessment and treatment of post-traumatic stress disorder in children and adolescents. Journal of Child Psychology and Psychiatry and Allied Disciplines 2000;41(3):277-89.

\section{Roberts 2010}

Roberts NP, Kitchiner NJ, Kenardy J, Bisson JI. Early psychological interventions to treat acute traumatic stress symptoms. Cochrane Database of Systematic Reviews 2010, Issue 3. [DOI: 10.1002/14651858.CD007944.pub2]

\section{Robertson 2004}

Robertson M, Humphreys L, Ray R. Psychological treatments for posttraumatic stress disorder: recommendations for the clinician based on a review of the literature. Journal of Psychiatric Practice 2004;10(2):106-18.

\section{Saigh 1996}

Saigh PA, Green BL, Korol M. The history and prevalence of posttraumatic stress disorder with special reference to children and adolescents. Journal of School Psychology 1996; 34(2):107-31.

\section{Saigh 2000}

Saigh PA, Yasik AE, Oberfield RA, Green BL, Halamandaris PV, Rubenstein $\mathrm{H}$, et al. The Children's PTSD Inventory: development and reliability. Journal of Traumatic Stress 2000;13(3):369-80.

\section{Scheeringa 1995}

Scheeringa MS, Zeanah CH, Drell MJ, Carrieu JA. Two approaches to the diagnosis of post-traumatic stress disorder in infancy and early childhood. Journal of the American Academy of Child and Adolescent Psychiatry 1995;34: 191-200.

\section{Schwarz 1994}

Schwarz ED, Perry BD. The post-traumatic response in children and adolescents. Psychiatric Clinics of North America 1994;17(2):311-26.

Sones 2011

Sones HM, Thorp SR, Raskind M. Prevention of posttraumatic stress disorder. Psychiatric Clinics of North America 2011:34(1):79-94.

Spielberger 1973 Spielberger CD. Manual for the State-Trait Anxiety Inventory for Children. Palo Alto, CA: Consulting Psychologists Press, 1973.

\section{Spinazzola 2005}

Spinazzola J, Ford JD, Zucker M, van der Kolk BA, Silva S, Smith SF, et al. Survey evaluates complex trauma exposure, outcome, and intervention among children and adolescents. Psychiatric Annals 2005;35(5):433-9. 
Taylor 2004

Taylor TL, Chemtob CM. Efficacy of treatment for child and adolescent traumatic stress. Archives of Pediatrics and Adolescent Medicine 2004;158(8):786-91.

Terr 1991

Terr LC. Childhood traumas: an outline and overview. American Journal of Psychiatry 1991;148(1):10-20.

van der Kolk 2005

van der Kolk BA, Roth S, Pelcovitz D, Sunday S, Spinazzola J. Disorders of extreme stress: the empirical foundation of a complex adaptation to trauma. Journal of Traumatic Stress 2005;18(5):389-99.

\section{Varni 2001}

Varni JW, Seid M, Kurtin PS. PedsQL ${ }^{\text {TM }}$ 4.0: reliability and validity of the Pediatric Quality of Life Inventory ${ }^{\mathrm{TM}}$ Version 4.0 Generic Core Scales in Healthy and Patient Populations. Medical Care 2001;39(8):800-12.

\section{Vickers 2005}

Vickers B. Cognitive model of the maintenance and treatment of post-traumatic stress disorder applied to children and adolescents. Clinical Child Psychology and Psychiatry 2005;10(2):217-34.

\section{WHO 1990}

World Health Organization. Chapter V: Mental and Behavioural Disorders (F40-F48). International Classification of Diseases 10. Geneva: World Health Organization, 1990.

Yule 1994

Yule W, Canterbury R. The treatment of post traumatic stress disorder in children and adolescents. International Review of Psychiatry 1994;6(2-3):141-51.

Yule 2001

Yule W. Post-traumatic stress disorder in children and adolescents. International Review of Psychiatry 2001;13(3): 194-200.

\section{References to other published versions of this review}

Gillies 2007

Gillies D, O’Brien L, Rogers P, Meekings C. Psychological therapies for the prevention and treatment of post-traumatic stress disorder in children and adolescents. Cochrane Database of Systematic Reviews 2007, Issue 3. [DOI: 10.1002/14651858.CD006726]

* Indicates the major publication for the study 


\section{CHARACTERISTICS OF STUDIES}

\section{Characteristics of included studies [ordered by study ID]}

\section{Ahmad 2007}

Methods

Randomised trial of eye movement and desensitising and reprocessing (EMDR) versus waiting list control

Participants

Included $(n=33)$

Children aged 6 to 16 attending a child psychiatric outpatient clinic who met criteria for PTSD (DSM-IV diagnosis); at least 1 traumatic experience and grown up in at least one "socially exposed" condition, i.e. family member with criminality, substance abuse, chronic illness, handicap, mentally or physically unavailable caregiver

Mean age: 10 years

Female: 20

Swedish ethnicity: 19

Baseline symptom score: EMDR 35.5, waiting list 35.5

DSM-IV co-morbidity: depression 15, ADHD 10, oppositional defiant disorder 7, separation anxiety 6 , conduct disorder 4 , autism spectrum

Most terrifying trauma: maltreatment 12 , sexual abuse 7 , motor vehicle accident 5 , witnessing unnatural death 4 , other 2

Time since event: < 1 year: 6,1 to 2 years: $16,>3$ years: 11

Excluded

Need for other types of treatment (e.g. CBT, play therapy, medication) or receiving social welfare service

Setting

Child psychiatric outpatient clinic, Sweden

\section{$\operatorname{EMDR}(n=17)$}

A manualised adult version adjusted for children. The child was asked to attend 8 weekly outpatient sessions of up to 45 minutes without the caregiver unless they requested them to be there. Eye movements were replaced by tapping when needed. The child was randomised to 1 of 2 therapists. The mean number of sessions attended was 5.9

Waiting list control $(n=16)$

Had to wait 2 months for treatment

\section{Risk of bias}


Ahmad 2007 (Continued)

\begin{tabular}{|c|c|c|}
\hline $\begin{array}{l}\text { Random sequence generation (selection } \\
\text { bias) }\end{array}$ & Unclear risk & Not stated \\
\hline Allocation concealment (selection bias) & Unclear risk & $\begin{array}{l}\text { Therapists 'administered' randomisation, } \\
\text { no further details provided }\end{array}$ \\
\hline $\begin{array}{l}\text { Blinding (performance bias and detection } \\
\text { bias) } \\
\text { All outcomes }\end{array}$ & Low risk & $\begin{array}{l}\text { Evaluators were blind to treatment alloca- } \\
\text { tion }\end{array}$ \\
\hline $\begin{array}{l}\text { Incomplete outcome data (attrition bias) } \\
\text { All outcomes }\end{array}$ & Low risk & $\begin{array}{l}\text { Regression analysis was used to estimate } \\
\text { data for the } 1 \text { participant lost to follow-up }\end{array}$ \\
\hline Selective reporting (reporting bias) & Low risk & All outcomes appear to have been reported \\
\hline Other bias & Unclear risk & $\begin{array}{l}\text { Higher proportion of children of Swedish } \\
\text { ethnicity in EMDR group }\end{array}$ \\
\hline
\end{tabular}

\section{Ahrens 2002}

\begin{tabular}{|c|c|}
\hline Methods & Randomised trial of cognitive processing therapy versus waiting list control \\
\hline Participants & $\begin{array}{l}\text { Included }(n=38) \\
\text { Incarcerated adolescent males aged } 15 \text { to } 18 \text { years who met DSM-IV criteria for PTSD } \\
\text { Mean age: } 16.4 \text { years } \\
\text { Ethnicity: African American 10, Caucasian 23, Hispanic 2, Native American 2, other } 1 \\
\text { Baseline symptom score: cognitive processing } 16.89 \text {, waiting list } 19.36 \\
\text { Excluded } \\
\text { Not stated } \\
\text { Setting } \\
\text { Youth correctional facility in the US }\end{array}$ \\
\hline Interventions & $\begin{array}{l}\text { Cognitive processing therapy }(n=19) \\
8 \text { weekly sessions of } 60 \text { minutes in exposure and cognitive restructuring. Sessions con- } \\
\text { sisted of } 2 \text { educational sessions: PTSD symptoms, exercise distinguishing thoughts and } \\
\text { feelings, examining thoughts associated with trauma, and antecedents, beliefs and con- } \\
\text { sequences, } 2 \text { exposure sessions: participants shared narratives of the trauma and their } \\
\text { thoughts and feelings, } 2 \text { sessions of challenging beliefs: taught to identify and challenge } \\
\text { maladaptive beliefs and examined beliefs in safety, trust, power, esteem and intimacy } \\
\text { Waiting list control ( } n=19) \\
\text { Therapists and supervision } \\
\text { Therapy was manualised and conducted by a psychologist and doctoral student }\end{array}$ \\
\hline Outcomes & $\begin{array}{l}\text { PTSD symptoms } \\
\text { Scale: Impact of Events Scale (15 items) } \\
\text { Scores: sub-scores for intrusion and avoidance } \\
\text { Rater: self report } \\
\text { Scale: Child PTSD Symptoms Scale ( } 17 \text { items) }\end{array}$ \\
\hline
\end{tabular}

Psychological therapies for the treatment of post-traumatic stress disorder in children and adolescents (Review)

Copyright $\odot 2012$ The Cochrane Collaboration. Published by John Wiley \& Sons, Ltd. 
Ahrens 2002 (Continued)

Scores: 3 sub-scales were 'combined'

Rater: self report

Depression

Scale: Beck Depression Inventory (21 items)

Rater: self report

When

4 weeks

Notes

Impact of Events data used for PTSD symptoms because the PTSD Symptom Scale data were skewed

Loss to follow-up: not clear

\section{Risk of bias}

\begin{tabular}{l|ll}
\hline Bias & Authors' judgement & Support for judgement \\
\hline $\begin{array}{l}\text { Random sequence generation (selection } \\
\text { bias) }\end{array}$ & Unclear risk & Not reported \\
\hline $\begin{array}{l}\text { Allocation concealment (selection bias) } \\
\text { Blinding (performance bias and detection } \\
\text { bias) } \\
\text { All outcomes }\end{array}$ & Unclear risk & Not reported \\
\hline $\begin{array}{l}\text { Incomplete outcome data (attrition bias) } \\
\text { All outcomes }\end{array}$ & Unclear risk & Not reported \\
\hline $\begin{array}{l}\text { Selective reporting (reporting bias) } \\
\text { Other bias }\end{array}$ & High risk & Loss to follow-up not clear \\
\hline
\end{tabular}

\section{Catani 2009}

Methods

Narrative exposure therapy (KIDNET) versus meditation/relaxation

Participants

Included $(n=31)$

Children aged 8 to 14 years living in an area in northern-eastern Sri Lanka severely affected by the 2004 tsunami and civil war diagnosed with DSM-IV PTSD

Mean age: 12 years

Female: 14

Baseline symptom score: KIDNET 37.94, meditation/relaxation 36.58

Excluded

None of the children met the exclusion criteria of mental retardation, neurological disorder or psychosis

Setting

A refugee camp in northern-eastern Sri Lanka within the first months after the tsunami 
Catani 2009 (Continued)

Interventions
The counsellor assists the child to construct a detailed chronological account of his or
her own biography. During the confrontation with aversive life events therapists ask
for current and past emotional, physiological and cognitive and behavioural reactions.
Particular attention was given to trauma experiences. Exposure to traumatic experiences
was not terminated until there was a significant reduction in the fear reaction. In the last
session the participant received a written report of his/her biography
Meditation-relaxation $(n=15)$
The first session was psycho education followed by a thorough assessment of the child's
problem and ending with a breathing exercise. Subsequent sessions focus on relaxation
techniques including breathing, meditation and mantras
Both
Both treatments consisted of 6 x 60 to 90 -minute sessions over 2 weeks
Therapists and supervision
Therapist and interviewers were recruited from a group of 6 female school teachers trained
as counsellors to assist children with war-related trauma. Therapists were supervised by
local trainers and therapy assessed for treatment adherence and quality

Outcomes

Improvement

Scale: UCLA PTSD Index for DSM-IV diagnosis

Rater: clinician interview

PTSD symptoms

Scale: UCLA PTSD Index

When

Post-treatment and 6-month follow-up

Notes

PTSD domain scores were reported graphically

KIDNET post-treatment PTSD total scores were skewed

Loss to follow-up: $1 / 31$

\section{Risk of bias}

\begin{tabular}{|c|c|c|}
\hline Bias & Authors' judgement & Support for judgement \\
\hline $\begin{array}{l}\text { Random sequence generation (selection } \\
\text { bias) }\end{array}$ & Low risk & Random allocation by coin toss \\
\hline Allocation concealment (selection bias) & Unclear risk & Not reported \\
\hline $\begin{array}{l}\text { Blinding (performance bias and detection } \\
\text { bias) } \\
\text { All outcomes }\end{array}$ & Low risk & Outcome measurement was blinded \\
\hline $\begin{array}{l}\text { Incomplete outcome data (attrition bias) } \\
\text { All outcomes }\end{array}$ & Low risk & $\begin{array}{l}\text { ITT analysis was used with the last obser- } \\
\text { vation carried forward. However, as there } \\
\text { was no difference in results the completer } \\
\text { analysis was used for the 6-month follow- } \\
\text { up data }\end{array}$ \\
\hline
\end{tabular}

Psychological therapies for the treatment of post-traumatic stress disorder in children and adolescents (Review) 
Catani 2009 (Continued)

\begin{tabular}{l|ll}
\hline Selective reporting (reporting bias) & Low risk & All outcomes appear to have been reported \\
\hline Other bias & Low risk & No other apparent bias \\
\hline
\end{tabular}

Chemtob 2002a

Methods

Randomised trial of eye movement desensitisation and reprocessing (EMDR) versus waiting list control

Participants

Included $(n=32)$

Children aged 6 to 12 who had undergone trauma from hurricane exposure 3.5 years previously, met DSM-IV criteria for disaster-related PTSD and had not responded to brief psychosocial counselling

Mean age: 8.4 years

Female: 22

Ethnicity: Hawaiian or part-Hawaiian 31.3\%, Caucasian 18.8\%, Japanese 12.5\%, mixed $9.4 \%$

Baseline symptom score: EMDR 36.54, waiting list 39.60

Excluded

Not stated

Setting

Hawaiian study

Interventions

EMDR (17 completers)

Consisted of 1 diagnostic and 3 weekly sessions. Treatment encompassed worst memory, current reminders and future events. During sessions, participants were asked to visually track movement of the therapist's hand while concentrating on trauma related memories, thoughts and sensations

Waiting list control (15 completers)

Therapists and supervision

Therapists were 4 doctoral level clinicians, with over 10 years experience with children, and had received 16 hours of EMDR training. Therapy was manualised and therapists received a minimum of 4 supervision sessions. Therapists also met weekly to review treatment fidelity and adherence

Outcomes

PTSD symptoms

Scale: UCLA PTSD Reaction Index

Rater: clinician-rated

Depression

Scale: Children's Depression Inventory (27 items)

Rater: self report

Anxiety

Scale: Revised Children's Manifest Anxiety Scale (37 items)

Rater: self report

When

Post-treatment and 6-month follow-up 


\section{Risk of bias}

\begin{tabular}{|c|c|c|}
\hline Bias & Authors' judgement & Support for judgement \\
\hline $\begin{array}{l}\text { Random sequence generation (selection } \\
\text { bias) }\end{array}$ & Unclear risk & Not reported \\
\hline Allocation concealment (selection bias) & Unclear risk & Not reported \\
\hline $\begin{array}{l}\text { Blinding (performance bias and detection } \\
\text { bias) } \\
\text { All outcomes }\end{array}$ & Low risk & Outcome measurement was blinded \\
\hline $\begin{array}{l}\text { Incomplete outcome data (attrition bias) } \\
\text { All outcomes }\end{array}$ & Unclear risk & $\begin{array}{l}\text { Completer analysis was reported but loss to } \\
\text { follow-up was low }\end{array}$ \\
\hline Selective reporting (reporting bias) & Low risk & All outcomes appear to have been reported \\
\hline Other bias & Low risk & No other apparent bias \\
\hline
\end{tabular}

Cohen 2004

Methods

Randomised trial of trauma-focused CBT (TF-CBT) versus child-centred therapy (CCT)

Participants

Included $(n=203)$

Children aged 8 to 14 years who met at least 5 criteria for sexual abuse related DSM-IV PTSD; including at least 1 symptom in each of the PTSD clusters. 180 (89\%) met the diagnostic criteria for PTSD. More than $90 \%$ had been exposed to multiple traumas Mean age: 10.8 years

Female: $79 \%$

Ethnicity: white 60\%, African American 28\%, Hispanic 4\%, biracial 7\%, other 1\% Excluded

Children, or children with parents, who had an active psychotic disorder or substance use disorder which would significantly impair adaptive functioning. Children who were not fluent in English or had a documented developmental disorder were also excluded Setting

2 academically affiliated outpatient clinical treatment programmes for abused/traumatised children in the US

Interventions

$T F-C B T(n=114)$

The TF-CBT model included skills in expressing feelings, training in coping skills, recognising the relationships between thoughts, feelings and behaviours, gradual exposure, cognitive processing of the abuse experience, psycho education about child sexual abuse and body safety, and parent management skills. In 3 sessions, 30 minutes was used for a joint caretaker-child session

$\operatorname{CCT}(n=115)$

CCT is a child/parent-centred treatment model focused on establishing a trusting ther- 
Cohen 2004 (Continued)

apeutic relationship that is self affirming, empowering and validating for the parent and child. CCT aims to reverse the difficulties related to the violation of trust and disempowerment by establishing an empowering trusting relationship and by encouraging children and parents to direct the content and structure of their own treatment, thereby allowing them to choose when, how and whether to address aspects of the child's sexual abuse. Therapists provided active listening, reflection, accurate empathy, encouragement to talk about feelings and belief in the child's and parent's ability to develop positive coping strategies for abuse-related difficulties. Written psycho educational information about child sexual abuse was also provided

Both

Both interventions consisted of 12 weekly 45-minute sessions each for the caretaker and the child

Therapists and supervision

Therapists were psychologists and social workers. All therapists were trained over 3 days in both treatments and delivered both. Both treatments were manualised. Therapists received weekly supervision and fidelity was monitored

Scale: PTSD section of the Schedule for Affective Disorders and Schizophrenia for School age Children - Present and Lifetime version (K-SADS-PL)

Rater: semi-structured interviews with parent and child

PTSD symptoms

Scale: K-SADS-PL

Scores: avoidance, hyperarousal and re-experiencing sub-scores

Depression

Scale: CDI

Rater: self report

Anxiety

Scale: State-trait Anxiety Inventory for Children

Scores: state and trait scores

Rater: self report

Behaviour

Scale: Child Behaviour Checklist

Rater: parent report

When

Post-treatment, 6 and 12-month follow-up

Risk of bias

\begin{tabular}{lll}
\hline Bias & Authors' judgement & Support for judgement \\
\hline $\begin{array}{l}\text { Random sequence generation (selection } \\
\text { bias) }\end{array}$ & Unclear risk & Not reported \\
\hline Allocation concealment (selection bias) & Unclear risk & Not reported
\end{tabular}


Cohen 2004 (Continued)

\begin{tabular}{l|l|l}
\hline $\begin{array}{l}\text { Blinding (performance bias and detection } \\
\text { bias) } \\
\text { All outcomes }\end{array}$ & Unclear risk & Not reported \\
\hline $\begin{array}{l}\text { Incomplete outcome data (attrition bias) } \\
\text { All outcomes }\end{array}$ & High risk & $\begin{array}{l}\text { ITT analysis was used to test for group dif- } \\
\text { ferences but follow-up means and SDs were } \\
\text { reported }\end{array}$ \\
\hline Selective reporting (reporting bias) & Low risk & All outcomes appear to have been reported \\
\hline Other bias & Low risk & No other apparent bias \\
\hline
\end{tabular}

Cohen 2011

Methods

Randomised trial of trauma-focused cognitive behaviour therapy (TF-CBT) versus child centred therapy (CCT)

Participants

Included $(n=50)$

Children of mothers attending a community women's health service in the US, aged 7 to

14 years with at least 5 interpersonal violence (IPV) related PTSD symptoms, including at least 1 symptom from each of the 3 clusters, who were fluent in English and had an English speaking mother who was a direct victim of IPV

Mean age: 9.64 years

Female: 63

Ethnicity: White 69, Black 41, Biracial 14

Only $14.5 \%$ no longer had contact with the perpetrator

Excluded

Significant development disorder; IQ $<80$; serious psychotic symptoms in parent or child; living in a IPV shelter

Setting

A community women's centre for victims of interpersonal violence, US

Interventions

$T F-C B T(n=32)$

Develops a narrative of the child's experiences, correcting maladaptive cognitions, and mastery of trauma reminders. It included psycho education about trauma, developing individualised relaxation skills, expressing and modulating upsetting feelings, and cognitive coping skills. Some of the session time was given to joint child-parent sessions where the child was encouraged to discuss their IPV experience and safety plans $\operatorname{CCT}(n=18)$

Is aimed at establishing an empowering and trusting relationship between the therapist and client by encouraging the child and parent to direct the content of their own treatment. The therapist provides active listening, reflection, accurate empathy, encouragement to talk about feelings and belief in the client's ability to develop positive coping strategies

Both

The child and parent each attended $8 \times 45$-minute individual therapy sessions. The same therapist saw the child and parent

Therapists and supervision 
Cohen 2011 (Continued)

Three Masters-level trained social workers providing child therapy at the Women's Center and Shelter were trained in the TF-CBT model and distinctions between the TF-CBT and CCT models. They were supervised and adherence to therapy was checked with blinded rating of $25 \%$ of randomly selected sessions. A manual which differentiated CCT from TF-CBT was also available

\begin{tabular}{|c|c|c|}
\hline Outcomes & \multicolumn{2}{|c|}{$\begin{array}{l}\text { Improvement } \\
\text { Scale: Schedule for Affective Disorders and Schizophrenia for School age Children - } \\
\text { Present and Lifetime version (K-SADS-PL) } \\
\text { Rater: child and parent interview } \\
\text { When } \\
\text { Post-treatment }\end{array}$} \\
\hline Notes & \multicolumn{2}{|c|}{$\begin{array}{l}\text { Most of the data in this study included participants who were not diagnosed with PTSD. } \\
\text { These data will be included in the accompanying prevention review } \\
\text { Loss to follow-up of those diagnosed with PTSD was not clear } \\
\text { The K-SADS-PL data were used for PTSD symptoms }\end{array}$} \\
\hline \multicolumn{3}{|l|}{ Risk of bias } \\
\hline Bias & Authors' judgement & Support for judgement \\
\hline $\begin{array}{l}\text { Random sequence generation (selection } \\
\text { bias) }\end{array}$ & Low risk & $\begin{array}{l}\text { Random assignment to treatment using } \\
\text { computer-generated random number se- } \\
\text { ries. However, } 24 \text { received the same treat- } \\
\text { ment as the randomised sibling }\end{array}$ \\
\hline Allocation concealment (selection bias) & Low risk & $\begin{array}{l}\text { Randomisation lists were locked in the } \\
\text { therapists' offices }\end{array}$ \\
\hline $\begin{array}{l}\text { Blinding (performance bias and detection } \\
\text { bias) } \\
\text { All outcomes }\end{array}$ & Low risk & $\begin{array}{l}2 \text { project co-ordinators blinded to treat- } \\
\text { ment assignment were trained in the ad- } \\
\text { ministration of the K-SADS-PL }\end{array}$ \\
\hline $\begin{array}{l}\text { Incomplete outcome data (attrition bias) } \\
\text { All outcomes }\end{array}$ & Unclear risk & $\begin{array}{l}\text { Loss to follow-up of those diagnosed with } \\
\text { PTSD was not clear }\end{array}$ \\
\hline Selective reporting (reporting bias) & Low risk & All outcomes appear to have been reported \\
\hline Other bias & Unclear risk & $\begin{array}{l}\text { Data came from a subset of children diag- } \\
\text { nosed with PTSD }\end{array}$ \\
\hline
\end{tabular}



substance abuse and suicidal ideation were included

Mean age: 18 years

Females: 47

Baseline symptom score: narrative therapy 67.03, academic catch-up 62.54, waiting list 63.61

Excluded

2 participants with psychotic symptoms

Setting

Participants' homes within internally displaced persons camps, Northern Uganda

A biography of the participant's life history was composed to reconstruct fragmented memories of trauma and achieve habituation

Academic catch-up $(n=28)$

Approximately half the time focused on helping the young person catch up on education they had missed while abducted. The rest of the time was spent discussing coping with symptoms and dealing with current problems

\section{Both therapies}

The first session always included psychoeducation on PTSD, its symptoms and consequences, and treatment rationale. Both interventions consisted of 8 individual sessions of 90 to 120 minutes 3 times per week

$W$ aiting list control $(n=28)$

Participants were not offered any psychosocial or therapeutic intervention unless they exhibited high levels of suicide ideation when a suicide intervention was provided ( $\mathrm{n}$ = 10). Those still meeting criteria for PTSD after 12 months were offered narrative exposure therapy

Therapists and supervision

Both interventions were done by 14 intensively trained local lay counsellors. Treatment was supervised and adherence was monitored

Rater: clinician rating

PTSD symptoms

Scale: CAPS

Depression

Scale: Mini International Neuropsychiatric Interview (MINI) - Module A for major depression

Rater: clinician rating

Adverse events

Suicide

When

3,6 and 12 months 


\section{Ertl 2011 (Continued)}

\begin{tabular}{|c|c|c|}
\hline Notes & \multicolumn{2}{|l|}{ Loss to follow-up: $9 / 85$} \\
\hline \multicolumn{3}{|l|}{ Risk of bias } \\
\hline Bias & Authors' judgement & Support for judgement \\
\hline $\begin{array}{l}\text { Random sequence generation (selection } \\
\text { bias) }\end{array}$ & Unclear risk & Not reported \\
\hline Allocation concealment (selection bias) & Unclear risk & Not reported \\
\hline $\begin{array}{l}\text { Blinding (performance bias and detection } \\
\text { bias) } \\
\text { All outcomes }\end{array}$ & Unclear risk & Not reported \\
\hline $\begin{array}{l}\text { Incomplete outcome data (attrition bias) } \\
\text { All outcomes }\end{array}$ & High risk & ITT analysis was used but was not reported \\
\hline Selective reporting (reporting bias) & Low risk & All outcomes appear to have been reported \\
\hline Other bias & Low risk & No other apparent bias \\
\hline
\end{tabular}

Gilboa-Schechtman 2010

Methods

Participants
Randomised trial of prolonged exposure therapy (PEA-A) or time-limited dynamic psychotherapy (TLDP-A)

\section{Included $(n=38)$}

Participants aged 12 to 18 years with a primary diagnosis of PTSD related to a single traumatic event, and fluent in Hebrew. Participants with a history of substance abuse or conduct disorder, or suicidal ideation were included

Mean age: 14.05 years

Female: 24

Trauma type: MVA 16, sexual assault 8, terrorist attack 5, non-sexual assault 2, other 7 Internalising disorders 19 , externalising 5 , both 6

Stable psychiatric medication 5

Baseline symptom score: 27.11 across all groups

Excluded

Organic brain damage, mental retardation, ongoing trauma threat, suicidal ideation posing imminent danger, current substance dependence, pending legal issues, ongoing psychological treatment, or initiation of psychotropic medication in the previous 6 weeks Setting

Children's medical centre, Israel

Interventions

Prolonged exposure therapy $(n=19)$

Consisted of 3 modules: psychoeducation, exposure and treatment termination and relapse prevention over 12 to 15 weekly sessions of 60 to 90 minutes (mean 16.78 hours) . Therapists received 5 days training 
Time-limited dynamic psychotherapy $(n=19)$

Is a non-directive, non-trauma focused, time-limited psychodynamic psychotherapy which aimed to change entrenched patterns of inter- and intra-personal relatedness. The sessions focused on building a working alliance, defining and working through the central issue over 15 to 18 sessions of 50 minutes (mean 16.90 hours). Therapists received 2 days training

Both

Both treatments included case management

Therapists and supervision

Treatments were manualised and provided by 11 Masters-level clinicians. Clinicians received weekly corrective supervision, and fidelity and adherence were checked

Outcomes

Improvement

Scale: Schedule for Affective Disorders and Schizophrenia for School age Children Present and Lifetime version (K-SADS-PL)

Rater: semi-structured interviews with parent and child

PTSD symptoms

Scale: Child PTSD Symptoms Scale (17 items)

Rater: self report

Scores: total score

Depression

Scale: Beck Depression Inventory (21 items)

Rater: self report

When

Post-treatment

Notes

Loss to follow-up: at end of treatment 8/38, at 6 months $11 / 38$, at 17 months $17 / 38$

Loss to follow-up was more than $50 \%$ in the TDLP group at 17 months

\section{Risk of bias}

\begin{tabular}{|c|c|c|}
\hline Bias & Authors' judgement & Support for judgement \\
\hline $\begin{array}{l}\text { Random sequence generation (selection } \\
\text { bias) }\end{array}$ & Low risk & Block randomisation was used \\
\hline Allocation concealment (selection bias) & Unclear risk & Not reported \\
\hline $\begin{array}{l}\text { Blinding (performance bias and detection } \\
\text { bias) } \\
\text { All outcomes }\end{array}$ & Unclear risk & Not reported \\
\hline $\begin{array}{l}\text { Incomplete outcome data (attrition bias) } \\
\text { All outcomes }\end{array}$ & Unclear risk & $\begin{array}{l}\text { ITT analysis based on the last observation } \\
\text { carried forward was reported but the loss to } \\
\text { follow-up was high }\end{array}$ \\
\hline Selective reporting (reporting bias) & Low risk & All outcomes appear to have been reported \\
\hline
\end{tabular}


Gilboa-Schechtman 2010 (Continued)

\begin{tabular}{l|ll}
\hline Other bias & Low risk & No other apparent bias
\end{tabular}

Gordon 2008

\begin{tabular}{ll} 
Methods & Randomised trial of mind body skills versus waiting list control \\
\hline Participants & Included $(n=82)$ \\
& High School students in Kosovo aged 14 to 18 years who met criteria for PTSD after \\
interview and screening using the Harvard Trauma Questionnaire \\
Mean age: 16.3 years \\
Female: 62 \\
Excluded \\
Not stated \\
Setting \\
High School in Kosovo \\
\hline
\end{tabular}

Interventions

Mind Body Skills programme $(n=41)$

12 twice-weekly sessions of 2 hours over 6 weeks with approximately 10 students per group. Activities included guided imagery, relaxation techniques, active techniques to reduce stress, self expression through words, drawing, and movements and genograms to explore the emotional support in their families

$W$ aiting list control $(n=41)$

Received the intervention after the first group completed the initial programme Therapists and supervision

The Mind Body Skills programme was taught by 4 of the school's teachers who had taken part in a 10-day intensive training course in 1999. Teachers were supervised by faculty psychologists and psychiatrists

Outcomes PTSD symptoms

Scale: Harvard Trauma Questionnaire (16 items)

Scores: average item score and the prevalence of re-experiencing, avoidance and arousal determined by at least 3 of the re-experiencing and avoidance symptoms and 2 of the hyperarousal symptoms

Rater: teacher interview with child

When

Post-treatment (control scores were not available for the 3-month follow-up)

Notes

Loss to follow-up: $4 / 82$

Risk of bias

Bias Authors' judgement

Random sequence generation (selection Low risk bias)

\section{Support for judgement}

Participants were stratified according to gender and assigned using random numbers generated in Microsoft Excel 


\section{Gordon 2008 (Continued)}

\begin{tabular}{|c|c|c|}
\hline Allocation concealment (selection bias) & Low risk & $\begin{array}{l}\text { Participants were randomly assigned by the } \\
\text { research director }\end{array}$ \\
\hline $\begin{array}{l}\text { Blinding (performance bias and detection } \\
\text { bias) } \\
\text { All outcomes }\end{array}$ & Unclear risk & Not reported \\
\hline $\begin{array}{l}\text { Incomplete outcome data (attrition bias) } \\
\text { All outcomes }\end{array}$ & Unclear risk & $\begin{array}{l}\text { Completer analysis reported but loss to fol- } \\
\text { low-up was low }\end{array}$ \\
\hline Selective reporting (reporting bias) & Low risk & All outcomes appear to have been reported \\
\hline Other bias & Unclear risk & $\begin{array}{l}\text { Not clear how the cut-offs for the sub- } \\
\text { scores of re-experiencing, avoidance and } \\
\text { arousal were determined }\end{array}$ \\
\hline
\end{tabular}

King 2000

\begin{tabular}{|c|c|}
\hline Methods & Randomised trial of child only CBT versus family CBT versus waiting list control \\
\hline Participants & $\begin{array}{l}\text { Included }(n=36) \\
\text { Children with validated contact sexual abuse who met diagnostic criteria for PTSD or } \\
\text { severe stress reactions. Children and non-offending parents had to be English-speaking. } \\
25 \text { participants had a primary diagnosis of PTSD and } 11 \text { had several PTSD symptoms } \\
\text { Mean age: } 11.4 \text { years } \\
\text { Female: } 69 \% \\
\text { Baseline symptom score: child CBT } 13.33 \text {, family CBT } 13.58 \text {, waiting list } 12.83 \\
\text { Excluded } \\
\text { Ongoing unsupervised contact with the perpetrator; severe intellectual disability, psy- } \\
\text { chosis or suicidal behaviour; on antidepressant or anti-anxiety medication } \\
\text { Setting: children's support centre, Australia }\end{array}$ \\
\hline Interventions & $\begin{array}{l}\text { Child CBT ( } n=12) \\
\text { Consisted of } 20 \text { weekly sessions of } 50 \text { minutes. These included psychoeducation, coping } \\
\text { skills, relaxation, graded exposure and relapse prevention } \\
\text { Family CBT }(n=12) \\
\text { Mothers also attended } 20 \text { weekly sessions of } 50 \text { minutes in child behaviour management } \\
\text { skills and parent-child communication } \\
W \text { aiting list }(n=12) \\
\text { No contact for the 24-week waiting period } \\
\text { Therapists and supervision } \\
\text { Therapists were registered psychologists who received } 15 \text { to } 20 \text { hours of training in } \\
\text { each therapy. All were rotated across both treatments. Treatments were manualised and } \\
\text { supervised and assessed for adherence }\end{array}$ \\
\hline Outcomes & $\begin{array}{l}\text { Improvement } \\
\text { Scale: child version of the Anxiety Disorders Interview Schedule (ADIS) } \\
\text { Rater: interview with parent and child }\end{array}$ \\
\hline
\end{tabular}


King 2000 (Continued)

\begin{tabular}{|c|c|c|}
\hline & \multicolumn{2}{|c|}{$\begin{array}{l}\text { PTSD symptoms } \\
\text { Scale: ADIS } \\
\text { Scores: total and avoidance, hyperarousal and re-experiencing sub-scores } \\
\text { Anxiety } \\
\text { Scale: Revised Children's Manifest Anxiety Scale ( } 37 \text { items) } \\
\text { Rater: self report } \\
\text { Depression } \\
\text { Scale: Children's Depression Inventory ( } 27 \text { items) } \\
\text { Rater: self report } \\
\text { Behaviour } \\
\text { Scale: Child Behaviour Check List (CBCL) } \\
\text { Rater: mother rated } \\
\text { When } \\
\text { Post-treatment and 12-week follow-up }\end{array}$} \\
\hline Notes & \multicolumn{2}{|c|}{$\begin{array}{l}\text { Loss to follow-up: } 8 / 36 \\
\text { Data were pooled for the } 2 \text { CBT groups }\end{array}$} \\
\hline \multicolumn{3}{|l|}{ Risk of bias } \\
\hline Bias & Authors' judgement & Support for judgement \\
\hline $\begin{array}{l}\text { Random sequence generation (selection } \\
\text { bias) }\end{array}$ & Unclear risk & Not reported \\
\hline Allocation concealment (selection bias) & Unclear risk & Not reported \\
\hline $\begin{array}{l}\text { Blinding (performance bias and detection } \\
\text { bias) } \\
\text { All outcomes }\end{array}$ & Unclear risk & Not reported \\
\hline $\begin{array}{l}\text { Incomplete outcome data (attrition bias) } \\
\text { All outcomes }\end{array}$ & Unclear risk & $\begin{array}{l}\text { Baseline scores were used as follow-up } \\
\text { scores for non completers }\end{array}$ \\
\hline Selective reporting (reporting bias) & Unclear risk & CBCL outcomes were not reported \\
\hline Other bias & Low risk & No other apparent bias \\
\hline
\end{tabular}

Najavits 2006

Methods

Participants
Randomised trial of seeking safety therapy versus treatment as usual

Included $(n=33)$

Adolescent girls who were outpatients with DSM-IV criteria for PTSD, substance use disorder and reported substance use within the previous 60 days. Most (31) had substance dependence.

Mean age: 16.06 years

Ethnicity: Caucasian 26, Asian/pacific islander 4, African American 1, Hispanic 1, mul- 
Najavits 2006 (Continued)

tiethnic 1
Trauma: sexual abuse 29, disaster/accident 27, physical abuse 24, crime 13
Mean age at first trauma: 8.75 years; mean age of PTSD onset 11.91 years
Excluded
Patients with bipolar disorder, psychotic disorder, were mandated to treatment, had char-
acteristics that would interfere with treatment completion (mental retardation, home-
lessness, impending incarceration or life-threatening illness)
Setting
US study

Interventions

Seeking safety therapy $(n=18)$

A manualised psychotherapy for PTSD and substance use disorder consisting of 25 individual format sessions of 50 minutes over 3 months. SS is a coping skills therapy which targets current PTSD and substance used disorder. Therapy was manualised and was based on the principles of safety as priority, integrated treatment, focus on ideals, cognitive, behavioural, interpersonal domains, case management and attention to therapist processes

Treatment as usual ( $n=15)$

All participants in this group could any attend any treatments that were sought naturalistically

Therapists and supervision

Therapists were a psychiatrist or psychologist. Therapy was supervised and assessed for adherence

PTSD symptoms
Scale: Trauma Symptom Checklist for Children (54 items)
Scores: 6 subscales
Rater: self report
Depression
Scale: Adolescent Psychopathology Scale
Rater: self report
When
Post-treatment and 3-month follow-up

Notes

Loss to follow-up: 7/33 at end of treatment, 13/33 at follow-up

\section{Risk of bias}

\section{Bias}

Authors' judgement

Support for judgement

Random sequence generation (selection Unclear risk

Not reported

bias)

\begin{tabular}{l|ll}
\hline Allocation concealment (selection bias) & Unclear risk & Not reported \\
\hline $\begin{array}{l}\text { Blinding (performance bias and detection } \\
\text { bias) }\end{array}$ & Unclear risk & Not reported \\
All outcomes & & \\
\hline
\end{tabular}

Psychological therapies for the treatment of post-traumatic stress disorder in children and adolescents (Review) 


\section{Najavits 2006 (Continued)}

\begin{tabular}{l|l|l}
\hline $\begin{array}{l}\text { Incomplete outcome data (attrition bias) } \\
\text { All outcomes }\end{array}$ & High risk & Completer analysis reported \\
\hline Selective reporting (reporting bias) & High risk & $\begin{array}{l}\text { Other than sexual concerns and sexual dis- } \\
\text { tress, PTSD symptoms or improvement } \\
\text { were not reported }\end{array}$ \\
\hline Other bias & High risk & $\begin{array}{l}\text { Scores for anorexia, loss of control, sexual } \\
\text { concerns and sexual distress were higher in } \\
\text { the in the TAU group }\end{array}$ \\
\hline
\end{tabular}

Ruf 2010

Methods

Participants
Randomised trial of KIDNET versus waiting list control

Included $(n=26)$

Traumatised refugee children and adolescents aged from 7 to 16 years diagnosed with PTSD according to DSM-IV criteria

Mean age: 11 years

Female: 12

21 were living in a refugee centre

Trauma: violent attacks against the parent or other family members at home 19, witnessing attacks outside the home 13, accidents 9, living in a place of war 9, seeing dead bodies 9 , traumatic medical treatments 7 , the death of a beloved person 7 , earthquakes 5 , other natural disasters 3, sexual abuse 2

Baseline symptom score: KIDNET 43.3, waiting list 38.3

Excluded

Acute psychotic symptoms but none of the children met this criterion

Setting

Research outpatient clinic for refugees, Germany, 2003-6

Interventions

$\operatorname{KIDNET}(n=13)$

See Catani 2009 above for description of intervention. 8 sessions were provided on a weekly basis but this was also based on the therapist's impression so that participants attended between 7 and 9 sessions

$W$ aiting list control $(n=13)$

Therapists and supervision

8 clinical psychologists, all with experience treating traumatised survivors of war and violence carried out KIDNET. Interpreters were also used where required

\section{Outcomes}

\section{Improvement}

Scale: UCLA PTSD Index

Rater: interview with trained clinical psychologist

PTSD symptoms

Scale: UCLA PTSD Index

Scores: total, and avoidance, hyperarousal and re-experiencing sub-scores

When

6 months 
Ruf 2010 (Continued)

\begin{tabular}{|c|c|c|}
\hline Notes & \multicolumn{2}{|c|}{$\begin{array}{l}\text { Loss to follow-up: appears to be } 1 / 26 \\
\text { The scale used to measure function was not validated } \\
\text { No control data were available at } 12 \text { months }\end{array}$} \\
\hline \multicolumn{3}{|l|}{ Risk of bias } \\
\hline Bias & Authors' judgement & Support for judgement \\
\hline $\begin{array}{l}\text { Random sequence generation (selection } \\
\text { bias) }\end{array}$ & Low risk & Permuted block randomisation was used \\
\hline Allocation concealment (selection bias) & Unclear risk & Not reported \\
\hline $\begin{array}{l}\text { Blinding (performance bias and detection } \\
\text { bias) } \\
\text { All outcomes }\end{array}$ & Low risk & $\begin{array}{l}\text { "These assessors were left blind about the } \\
\text { group assignment" }\end{array}$ \\
\hline $\begin{array}{l}\text { Incomplete outcome data (attrition bias) } \\
\text { All outcomes }\end{array}$ & High risk & Completer analysis reported \\
\hline Selective reporting (reporting bias) & Low risk & All outcomes appear to have been reported \\
\hline Other bias & Low risk & No other apparent bias \\
\hline
\end{tabular}

Schauer 2008

\begin{tabular}{|c|c|}
\hline Methods & Cluster-randomised trial of KIDNET versus meditation/relaxation \\
\hline Participants & $\begin{array}{l}\text { Included }(n=47) \\
\text { War-affected children who suffered from severe PTSD and met DSM-IV criteria (CAPS- } \\
\text { CA) for PTSD } \\
\text { Mean age: } 13.1 \text { years } \\
\text { Females: } 29 \\
\text { They had experienced a mean of } 6 \text { traumatic events with exposure to war the most } \\
\text { common }(60 \%) \text { and had a mean CAPS trauma score of } 65.5 \\
\text { Baseline symptom score: KIDNET } 63.2 \text {, meditation/relaxation } 71.2 \\
\text { Excluded } \\
\text { Not stated } \\
\text { Setting: } 6 \text { primary schools in North-Eastern Sri Lanka, 2002-5 }\end{array}$ \\
\hline Interventions & $\begin{array}{l}\text { KIDNET }(n=25) \\
\text { See Catani } 2009 \text { for description of intervention. There were } 6 \text { treatment sessions at times } \\
\text { agreed between the counsellor and participant } \\
\text { Meditation/relaxation }(n=22) \\
\text { Was a locally designed protocol comprised of multi-cultural meditation/relaxation exer- } \\
\text { cises } \\
\text { Children with moderate to high suicidality were monitored closely by a consultant } \\
\text { psychiatrist. Some of these children received treatment in an outpatient setting }\end{array}$ \\
\hline
\end{tabular}

Psychological therapies for the treatment of post-traumatic stress disorder in children and adolescents (Review)

Copyright @ 2012 The Cochrane Collaboration. Published by John Wiley \& Sons, Ltd. 
Schauer 2008 (Continued)

\section{Both therapies}

Both therapies were manualised school-based therapies provided over 6 treatment sessions of 60 to 90 minutes over 3 to 4 weeks. The first session consisted of psycho education in both groups

Therapists and supervision

Counsellors were teachers in the schools who had been trained as counsellors. Each counsellor had 2 to 4 children for therapy. Therapies were checked for adherence and counsellors were supervised

\begin{tabular}{|c|c|c|}
\hline Outcomes & \multicolumn{2}{|c|}{$\begin{array}{l}\text { Improvement } \\
\text { Scale: Clinician Administered PTSD Scale for Children and Adolescents (CAPS-CA) } \\
\text { Rater: structured interview } \\
\text { PTSD symptoms } \\
\text { Scale: CAPS-CA } \\
\text { Depression } \\
\text { Scale: Mini International Neuropsychiatric Interview (MINI) - KID module A } \\
\text { When } \\
5 \text { months }\end{array}$} \\
\hline Notes & \multicolumn{2}{|c|}{$\begin{array}{l}\text { Loss to follow-up: } 1 / 47 \\
\text { Depression data were not reported and could not be obtained }\end{array}$} \\
\hline \multicolumn{3}{|l|}{ Risk of bias } \\
\hline Bias & Authors' judgement & Support for judgement \\
\hline $\begin{array}{l}\text { Random sequence generation (selection } \\
\text { bias) }\end{array}$ & Low risk & $\begin{array}{l}\text { Cluster-randomised controlled trial where } \\
\text { the } 6 \text { schools were randomised to groups }\end{array}$ \\
\hline Allocation concealment (selection bias) & Low risk & $\begin{array}{l}\text { Allocation was based on the order of draw- } \\
\text { ing sealed envelopes which contained a } \\
\text { piece of paper with the school name }\end{array}$ \\
\hline $\begin{array}{l}\text { Blinding (performance bias and detection } \\
\text { bias) } \\
\text { All outcomes }\end{array}$ & Unclear risk & Not reported \\
\hline $\begin{array}{l}\text { Incomplete outcome data (attrition bias) } \\
\text { All outcomes }\end{array}$ & Unclear risk & $\begin{array}{l}\text { Follow-up data were reported but only } 1 \\
\text { person was lost to follow-up }\end{array}$ \\
\hline Selective reporting (reporting bias) & Low risk & All outcomes appear to have been reported \\
\hline Other bias & Unclear risk & $\begin{array}{l}\text { Although not statistically significant the } \\
\text { CAPS trauma score was higher in the med- } \\
\text { itation/relaxation group (KIDNET 63.2, } \\
\text { meditation/relaxation 71.2) }\end{array}$ \\
\hline
\end{tabular}


Methods

Participants

Interventions

Loss to follow-up: 0/24

Included $(n=24)$

Mean age: 14 years

Female: 12

Excluded ment

Setting

$\operatorname{TF}-C B T(n=12)$ stimulus discrimination

W aiting list $(n=12)$

Improvement

PTSD symptoms

Rater: self report

Rater: self report

Depression

When
Children and young people aged 8 to 18 years with a major presenting problem of DSM-

IV PTSD relating to a single event trauma and fluent in English

Ethnicity: white 23, black 10, Asian 2, other/not stated 3

Trauma: motor vehicle accident 21 , interpersonal violence 12 , witnessing violence 4

Time since trauma: 2.3 to 71 months

Baseline symptom score (CAPS-CA): TF-CBT 60.9, waiting list 54.7; baseline Child

PTSD Symptoms Scale: TF-CBT 28.1, waiting list 28.3

Presence of organic brain damage, unconscious for more than 15 minutes during the trauma, significant learning difficulty, ongoing trauma-related threat, psychotropic medication begun within previous 3 months, currently receiving another psychological treat-

Specialist NHS trauma clinic for young people, UK

This therapy was an adaption of the model of Ehlers and Clark (2000) for young people. It consisted of 10 weekly sessions with the child and joint parent-child sessions as necessary. Treatment components included psychoeducation, activity rescheduling/ reclaiming life, imaginal reliving, cognitive restructuring, revisiting the trauma site and

Participants were given an appointment 10 weeks after randomisation

Therapists and supervision

CBT was manualised and delivered by psychologists with at least 10 years experience of working with traumatised children Therapists received monthly supervision

Scale: Clinician Administered PTSD Scale for Children and Adolescents (CAPS-CA)

Rater: interview with doctoral level clinical psychologists

Scale: Child PTSD Symptoms Scale

Scale: Children's Revised Impact of Event Scale (CRIES)

Scale: Depression Self Rating Scale

Post-treatment (no control data available at 6 months follow-up)

\section{Risk of bias}


Smith 2007 (Continued)

\begin{tabular}{|c|c|c|}
\hline Bias & Authors' judgement & Support for judgement \\
\hline $\begin{array}{l}\text { Random sequence generation (selection } \\
\text { bias) }\end{array}$ & Low risk & $\begin{array}{l}\text { Using a computer program randomisation } \\
\text { was stratified by age, gender and symptom } \\
\text { severity }\end{array}$ \\
\hline Allocation concealment (selection bias) & Unclear risk & Not reported \\
\hline $\begin{array}{l}\text { Blinding (performance bias and detection } \\
\text { bias) } \\
\text { All outcomes }\end{array}$ & Low risk & $\begin{array}{l}\text { Participants were reassessed by "assessors } \\
\text { who were blind to condition" }\end{array}$ \\
\hline $\begin{array}{l}\text { Incomplete outcome data (attrition bias) } \\
\text { All outcomes }\end{array}$ & Low risk & $100 \%$ follow-up \\
\hline Selective reporting (reporting bias) & Low risk & All outcomes appear to have been reported \\
\hline Other bias & Low risk & No other apparent bias \\
\hline
\end{tabular}

ADHD: attention deficit hyperactivity disorder

ADIS: Anxiety Disorders Interview Schedule

CAPS: Clinician Administered PTSD Scale

CAPS-CA: CAPS for children and adolescents

CBCL: Child Behaviour Check List

CBT: cognitive behavioural therapy

CCT: child-centred therapy

DSM-IV: Statistical Manual of Mental Disorders IV

EMDR: eye movement desensitisation and reprocessing

IPV: interpersonal violence

ITT: intention-to-treat

KIDNET: narrative exposure therapy

K-SADS-PL: Schedule for Affective Disorders and Schizophrenia for School age Children - Present and Lifetime version

MVA: motor vehicle accident

PTSD: post-traumatic stress disorder

SS: seeking safety (therapy)

TAU: treatment as usual

TDLP: time-limited dynamic psychotherapy

TF-CBT: trauma-focused CBT

UCLA: University of California at Los Angeles 


\begin{tabular}{l|l}
\hline Study & Reason for exclusion \\
\hline Berger 2007 & $\begin{array}{l}\text { Reviewed in Cochrane review 'Psychological therapies for the prevention of post-traumatic stress disorder } \\
\text { in children and adolescents' }\end{array}$ \\
\hline Berger 2009 & $\begin{array}{l}\text { Reviewed in Cochrane review 'Psychological therapies for the prevention of post-traumatic stress disorder } \\
\text { in children and adolescents' }\end{array}$ \\
\hline Berkowitz 2011 & $\begin{array}{l}\text { Reviewed in Cochrane review 'Psychological therapies for the prevention of post-traumatic stress disorder } \\
\text { in children and adolescents' }\end{array}$ \\
\hline Berliner 1996 & $\begin{array}{l}\text { Reviewed in Cochrane review 'Psychological therapies for the prevention of post-traumatic stress disorder } \\
\text { in children and adolescents' }\end{array}$ \\
\hline Bolton 2007 & $\begin{array}{l}\text { Reviewed in Cochrane review 'Psychological therapies for the prevention of post-traumatic stress disorder } \\
\text { in children and adolescents' }\end{array}$ \\
\hline
\end{tabular}

Brown 2003 Reviewed in Cochrane review 'Psychological therapies for the prevention of post-traumatic stress disorder in children and adolescents'

Celano 1996 Reviewed in Cochrane review 'Psychological therapies for the prevention of post-traumatic stress disorder in children and adolescents'

Chapman $2001 \quad$ Reviewed in Cochrane review 'Psychological therapies for the prevention of post-traumatic stress disorder in children and adolescents'

Chemtob 2002 Reviewed in Cochrane review 'Psychological therapies for the prevention of post-traumatic stress disorder in children and adolescents'

Cohen 1997 Reviewed in Cochrane review 'Psychological therapies for the prevention of post-traumatic stress disorder in children and adolescents'

Cohen 1998 Reviewed in Cochrane review 'Psychological therapies for the prevention of post-traumatic stress disorder in children and adolescents'

Cohen 2005

Reviewed in Cochrane review 'Psychological therapies for the prevention of post-traumatic stress disorder in children and adolescents'

Cohen 2007

Reviewed in Cochrane review 'Psychological therapies for the prevention of post-traumatic stress disorder in children and adolescents'

Cooley-Strickland 2011 Reviewed in Cochrane review 'Psychological therapies for the prevention of post-traumatic stress disorder in children and adolescents'

Cox 2010

Reviewed in Cochrane review 'Psychological therapies for the prevention of post-traumatic stress disorder in children and adolescents'

Deblinger 1996

Reviewed in Cochrane review 'Psychological therapies for the prevention of post-traumatic stress disorder in children and adolescents' 
(Continued)

Deblinger $2001 \quad$ Reviewed in Cochrane review 'Psychological therapies for the prevention of post-traumatic stress disorder in children and adolescents'

Deblinger $2011 \quad$ Reviewed in Cochrane review 'Psychological therapies for the prevention of post-traumatic stress disorder in children and adolescents'

Dominguez $2001 \quad$ Reviewed in Cochrane review 'Psychological therapies for the prevention of post-traumatic stress disorder in children and adolescents'

Ehntholt $2005 \quad$ Reviewed in Cochrane review 'Psychological therapies for the prevention of post-traumatic stress disorder in children and adolescents'

Ensink $2004 \quad$ Reviewed in Cochrane review 'Psychological therapies for the prevention of post-traumatic stress disorder in children and adolescents'

Farkas 2010

Reviewed in Cochrane review 'Psychological therapies for the prevention of post-traumatic stress disorder in children and adolescents'

Gelkopf 2009 Reviewed in Cochrane review 'Psychological therapies for the prevention of post-traumatic stress disorder in children and adolescents'

Goenjian 1997 Reviewed in Cochrane review 'Psychological therapies for the prevention of post-traumatic stress disorder in children and adolescents'

Jaberghaderi 2004 Reviewed in Cochrane review 'Psychological therapies for the prevention of post-traumatic stress disorder in children and adolescents'

Jeffres 2004

Reviewed in Cochrane review 'Psychological therapies for the prevention of post-traumatic stress disorder in children and adolescents'

Jordans 2010

Reviewed in Cochrane review 'Psychological therapies for the prevention of post-traumatic stress disorder in children and adolescents'

Kassam-Adams 2011 Reviewed in Cochrane review 'Psychological therapies for the prevention of post-traumatic stress disorder in children and adolescents'

Kataoka 2003

Reviewed in Cochrane review 'Psychological therapies for the prevention of post-traumatic stress disorder in children and adolescents'

Kazak 2004

Reviewed in Cochrane review 'Psychological therapies for the prevention of post-traumatic stress disorder in children and adolescents'

Kemp 2010

Reviewed in Cochrane review 'Psychological therapies for the prevention of post-traumatic stress disorder in children and adolescents'

Layne 2008

Reviewed in Cochrane review 'Psychological therapies for the prevention of post-traumatic stress disorder in children and adolescents'

Lesmana 2009

Not randomised, children were allowed to select groups "while not knowing which of the two groups they were choosing" 
(Continued)

Lieberman $2005 \quad$ Reviewed in Cochrane review 'Psychological therapies for the prevention of post-traumatic stress disorder in children and adolescents'

Lyshak-Stelzer 2007 Reviewed in Cochrane review 'Psychological therapies for the prevention of post-traumatic stress disorder in children and adolescents'

\begin{tabular}{l|l} 
March 1998 & Not randomised \\
\hline McWhirter 2011 & $\begin{array}{l}\text { Reviewed in Cochrane review 'Psychological therapies for the prevention of post-traumatic stress disorder } \\
\text { in children and adolescents' }\end{array}$ \\
\hline
\end{tabular}

Pfeffer $2002 \quad$ Reviewed in Cochrane review 'Psychological therapies for the prevention of post-traumatic stress disorder in children and adolescents'

Raider 2008 Reviewed in Cochrane review 'Psychological therapies for the prevention of post-traumatic stress disorder in children and adolescents'

Salloum 2008 Reviewed in Cochrane review 'Psychological therapies for the prevention of post-traumatic stress disorder in children and adolescents'

Schaal $2010 \quad$ Average age of participants was 19 years

Scheeringa 2011 Reviewed in Cochrane review 'Psychological therapies for the prevention of post-traumatic stress disorder in children and adolescents'

Shechtman $2010 \quad$ Reviewed in Cochrane review 'Psychological therapies for the prevention of post-traumatic stress disorder in children and adolescents'

Shelby 1995 Reviewed in Cochrane review 'Psychological therapies for the prevention of post-traumatic stress disorder in children and adolescents'

Shooshtary $2008 \quad$ Reviewed in Cochrane review 'Psychological therapies for the prevention of post-traumatic stress disorder in children and adolescents'

Stallard 2006

Reviewed in Cochrane review 'Psychological therapies for the prevention of post-traumatic stress disorder in children and adolescents'

Stein 2003

Reviewed in Cochrane review 'Psychological therapies for the prevention of post-traumatic stress disorder in children and adolescents'

Taussig 2010

Reviewed in Cochrane review 'Psychological therapies for the prevention of post-traumatic stress disorder in children and adolescents'

Thabet 2005

Reviewed in Cochrane review 'Psychological therapies for the prevention of post-traumatic stress disorder in children and adolescents'

Tol 2010

Reviewed in Cochrane review 'Psychological therapies for the prevention of post-traumatic stress disorder in children and adolescents' 
(Continued)

Trowell $2002 \quad$ Reviewed in Cochrane review 'Psychological therapies for the prevention of post-traumatic stress disorder in children and adolescents'

Wang $2011 \quad$ Reviewed in Cochrane review 'Psychological therapies for the prevention of post-traumatic stress disorder in children and adolescents'

Wolmer 2011a

Reviewed in Cochrane review 'Psychological therapies for the prevention of post-traumatic stress disorder in children and adolescents'

Wolmer 2011b

Reviewed in Cochrane review 'Psychological therapies for the prevention of post-traumatic stress disorder in children and adolescents'

Zehnder 2010

Reviewed in Cochrane review 'Psychological therapies for the prevention of post-traumatic stress disorder in children and adolescents'

Characteristics of ongoing studies [ordered by study ID]

\section{Bryant 2011}

\begin{tabular}{|c|c|}
\hline Trial name or title & $\begin{array}{l}\text { Randomised controlled trial of cognitive behavior therapy and supportive counselling for reduction in post- } \\
\text { traumatic stress disorder (PTSD) symptoms in Acehnese children }\end{array}$ \\
\hline Methods & $\begin{array}{l}\text { This study will randomly allocate children with PTSD to either cognitive behaviour therapy or supportive } \\
\text { counselling }\end{array}$ \\
\hline Participants & $\begin{array}{l}\text { Children aged } 8 \text { to } 12 \text { years who have undergone exposure to trauma in Aceh and meet criteria for PTSD } \\
\text { Excluded: suicidal intent, psychotic, substance-dependent }\end{array}$ \\
\hline Interventions & Cognitive behavioural therapy or supportive counselling \\
\hline \multicolumn{2}{|l|}{ Outcomes } \\
\hline Starting date & March 2011 \\
\hline Contact information & $\begin{array}{l}\text { Name: Professor Richard Bryant } \\
\text { Address: School of Psychology, University of New South Wales, Anzac Parade, Kensington, Sydney, NSW, } \\
2052 \\
\text { Country: Australia } \\
\text { Tel: 61-2-93853640 } \\
\text { Email: r.bryant@unsw.edu.au }\end{array}$ \\
\hline Notes & $\begin{array}{l}\text { Registered as not yet recruiting } \\
\text { Email sent requesting any information } 17 \text { May } 2012\end{array}$ \\
\hline
\end{tabular}


Chemtob 2008

Trial name or title Effectiveness of trauma-focused cognitive behavioral therapy in treating children with post-traumatic stress disorder

Methods $\quad$ RCT of the effectiveness of trauma-focused cognitive behavioural (TF-CBT) versus treatment as usual (TAU) in treating children with PTSD in community clinics

Participants Children aged 8 years to 18 years in community clinics who meet DSM-IV criteria for PTSD, are stable on medication for 1 month before study entry and English-speaking

Exclusion criteria: active suicidality or peri-traumatic life circumstances (e.g. active current abuse), uncon-

trolled psychosis, severe mental retardation or severe brain damage, severe language comprehension barriers

\begin{tabular}{ll}
\hline Interventions & TF-CBT versus TAU \\
\hline Outcomes & PTSD symptoms \\
\hline Starting date & January 2007 \\
\hline
\end{tabular}

Contact information Claude Chemtob, Mount Sinai School of Medicine

Email: claude.chemtob@mssm.edu

Notes Currently registered as active

Email sent requesting any information 17 May 2012

Foa 2009

\begin{tabular}{l|l}
\hline Trial name or title & Treating adolescents with CSA related PTSD \\
\hline Methods & $\begin{array}{l}\text { This RCT will evaluate the comparative effectiveness of prolonged exposure therapy and supportive coun- } \\
\text { selling in treating adolescents with PTSD that is related to childhood sexual abuse or assault }\end{array}$ \\
\hline Participants & Adolescents with PTSD related to childhood sexual abuse or assault \\
\hline Interventions & Prolonged exposure therapy for adolescents (PE-A) or client centered therapy (CCT) \\
\hline Outcomes & PTSD symptoms, attitudes, attributions and perceptions, depression, behaviour, mood \\
\hline Starting date & January 2007 \\
\hline Contact information & $\begin{array}{l}\text { Sandy Capaldi, MA, MS 215-746-3327 sandraca@mail.med.upenn.edu } \\
\text { Alissa B. Worly, BA 215-746-3334 aworly@mail.med.upenn.edu }\end{array}$ \\
\hline Notes & $\begin{array}{l}\text { Status not known } \\
\text { Email sent requesting any information 17 May 2012 }\end{array}$ \\
\hline
\end{tabular}

Psychological therapies for the treatment of post-traumatic stress disorder in children and adolescents (Review) 
Goldbeck 2011

\begin{tabular}{ll} 
Trial name or title & Effectiveness of trauma-focused cognitive-behavioral therapy for children with post-traumatic stress disorder \\
\hline Methods & $\begin{array}{l}\text { Multi-site randomised controlled trial compares the effectiveness of trauma-focused cognitive-behavioural } \\
\text { therapy (TF-CBT) in children with PTSD }\end{array}$ \\
\hline Participants & $\begin{array}{l}\text { Children aged } 7 \text { to } 14 \text { years who were exposed to traumatic events beyond the age of 3 years, at least 3 before } \\
\text { assessment, a major mental health diagnosis of PTSD (score of at least 35 on the CAPS-CA) } \\
\text { Excluded: psychosis, suicidality, major brain injury }\end{array}$ \\
\hline Interventions & TF-CBT versus waiting list \\
\hline Outcomes & PTSD symptoms, psychopathology, anxiety, depression, impairment, cognitions \\
\hline Starting date & February 2012 \\
\hline Contact information & $\begin{array}{l}\text { Lutz Goldbeck, Section for Psychotherapy Research and Behavioural Medicine, University of Ulm } \\
\text { E-mail: lutz.goldbeck@uniklinik-ulm.de }\end{array}$ \\
\hline Notes & $\begin{array}{l}\text { Registered as not yet open } \\
\text { Email sent requesting any information 17 May 2012 }\end{array}$ \\
\hline
\end{tabular}

\section{Kenardy 2010}

\begin{tabular}{ll}
\hline Trial name or title & $\begin{array}{l}\text { Protocol for a randomised controlled trial of risk screening and early intervention comparing child- and } \\
\text { family-focused cognitive-behavioural therapy for PTSD in children following accidental injury }\end{array}$ \\
\hline Methods & A RCT comparing the effectiveness of child-focused CBT, family-focused CBTand a waiting list control \\
\hline Participants & Children experiencing PTSD following accidental injury \\
\hline Interventions & Child-focused CBT and family-focused CBTas early interventions, and a waiting list control \\
\hline Outcomes & PTSD diagnosis and symptoms, anxiety, depression, quality of life, behaviour \\
\hline Starting date & February 2010 \\
\hline Contact information & $\begin{array}{l}\text { Justin Kenardy } \\
\text { Centre of National Research on Disability and Rehabilitation Medicine } \\
\text { University of Queensland } \\
\text { Herston QLD } 4029 \\
\text { Australia } \\
\text { j.kenardy@uq.edu.au }\end{array}$ \\
\hline Notes & $\begin{array}{l}\text { Study is expected to be completed at the end of } 2012 \\
\text { Email sent requesting any information } 17 \text { May } 2012\end{array}$ \\
\hline
\end{tabular}

CAPS-CA: Clinician Administered PTSD Scale for children and adolescents 
CBT: cognitive behavioural therapy

CSA: childhood sexual abuse

DSM-IV: Statistical Manual of Mental Disorders IV

PTSD: post-traumatic stress disorder

RCT: randomised controlled trial

TAU: treatment as usual

TF-CBT: trauma-focused CBT 
DATA ANDANALYSES

Comparison 1. All psychological therapies versus control

\begin{tabular}{|c|c|c|c|c|}
\hline Outcome or subgroup title & $\begin{array}{l}\text { No. of } \\
\text { studies }\end{array}$ & $\begin{array}{c}\text { No. of } \\
\text { participants }\end{array}$ & Statistical method & Effect size \\
\hline 1 Improvement & 4 & & Odds Ratio (M-H, Random, 95\% CI) & Subtotals only \\
\hline 1.1 Short-term & 2 & 49 & Odds Ratio (M-H, Random, 95\% CI) & $8.64[2.01,37.14]$ \\
\hline 1.2 Medium-term & 2 & 50 & Odds Ratio (M-H, Random, 95\% CI) & $9.46[2.46,36.32]$ \\
\hline 1.3 Long-term & 1 & 53 & Odds Ratio (M-H, Random, 95\% CI) & $1.84[0.60,5.65]$ \\
\hline 2 PTSD total & 8 & & Std. Mean Difference (IV, Random, 95\% CI) & Subtotals only \\
\hline 2.1 Short-term & 6 & 241 & Std. Mean Difference (IV, Random, 95\% CI) & $-1.05[-1.52,-0.58]$ \\
\hline 2.2 Medium-term & 3 & 115 & Std. Mean Difference (IV, Random, 95\% CI) & $-0.58[-0.97,-0.18]$ \\
\hline 2.3 Long-term & 1 & 53 & Std. Mean Difference (IV, Random, 95\% CI) & $-0.44[-0.98,0.11]$ \\
\hline 3 Anxiety & 3 & & Std. Mean Difference (IV, Random, 95\% CI) & Subtotals only \\
\hline 3.1 Short-term & 3 & 91 & Std. Mean Difference (IV, Random, 95\% CI) & $-0.57[1.00,-0.13]$ \\
\hline 3.2 Medium-term & 1 & 36 & Std. Mean Difference (IV, Random, 95\% CI) & $-0.63[-1.34,0.08]$ \\
\hline 4 Depression & 6 & & Std. Mean Difference (IV, Random, 95\% CI) & Subtotals only \\
\hline 4.1 Short-term & 5 & 156 & Std. Mean Difference (IV, Random, 95\% CI) & $-0.74[-1.11,-0.36]$ \\
\hline 4.2 Medium-term & 3 & 110 & Std. Mean Difference (IV, Random, 95\% CI) & $0.02[-0.36,0.40]$ \\
\hline 4.3 Long-term & 1 & 53 & Std. Mean Difference (IV, Random, 95\% CI) & $0.02[-0.52,0.56]$ \\
\hline 5 Loss to follow-up & 7 & & Odds Ratio (M-H, Random, 95\% CI) & Subtotals only \\
\hline 5.1 Short-term & 5 & 208 & Odds Ratio (M-H, Random, 95\% CI) & $1.59[0.56,4.49]$ \\
\hline 5.2 Medium-term & 3 & 116 & Odds Ratio (M-H, Random, 95\% CI) & $1.54[0.47,5.04]$ \\
\hline 5.3 Long-term & 1 & 57 & Odds Ratio (M-H, Random, 95\% CI) & $10.06[0.52,196.10]$ \\
\hline
\end{tabular}

\section{Comparison 2. CBT versus control}

\begin{tabular}{|c|c|c|c|c|}
\hline Outcome or subgroup title & $\begin{array}{l}\text { No. of } \\
\text { studies }\end{array}$ & $\begin{array}{c}\text { No. of } \\
\text { participants }\end{array}$ & Statistical method & Effect size \\
\hline 1 Improvement & 2 & & Odds Ratio (M-H, Random, 95\% CI) & Subtotals only \\
\hline 1.1 Short-term & 2 & 49 & Odds Ratio (M-H, Random, 95\% CI) & $8.64[2.01,37.14]$ \\
\hline 1.2 Medium-term & 1 & 25 & Odds Ratio (M-H, Random, 95\% CI) & $8.00[1.21,52.69]$ \\
\hline 2 PTSD total & 3 & & Std. Mean Difference (IV, Random, 95\% CI) & Subtotals only \\
\hline 2.1 Short-term & 3 & 98 & Std. Mean Difference (IV, Random, 95\% CI) & $-1.34[-1.79,-0.89]$ \\
\hline 2.2 Medium-term & 1 & 36 & Std. Mean Difference (IV, Random, 95\% CI) & $-0.73[-1.44,-0.01]$ \\
\hline 3 PTSD avoidance & 1 & & Std. Mean Difference (IV, Random, 95\% CI) & Totals not selected \\
\hline 3.1 Short-term & 1 & & Std. Mean Difference (IV, Random, 95\% CI) & $0.0[0.0,0.0]$ \\
\hline 3.2 Medium-term & 1 & & Std. Mean Difference (IV, Random, 95\% CI) & $0.0[0.0,0.0]$ \\
\hline 4 PTSD hyperarousal & 1 & & Std. Mean Difference (IV, Random, 95\% CI) & Totals not selected \\
\hline 4.1 Short-term & 1 & & Std. Mean Difference (IV, Random, 95\% CI) & $0.0[0.0,0.0]$ \\
\hline 4.2 Medium-term & 1 & & Std. Mean Difference (IV, Random, 95\% CI) & $0.0[0.0,0.0]$ \\
\hline 5 PTSD re-experiencing & 1 & & Std. Mean Difference (IV, Random, 95\% CI) & Totals not selected \\
\hline 5.1 Short-term & 1 & & Std. Mean Difference (IV, Random, 95\% CI) & $0.0[0.0,0.0]$ \\
\hline 5.2 Medium-term & 1 & & Std. Mean Difference (IV, Random, 95\% CI) & $0.0[0.0,0.0]$ \\
\hline 6 Anxiety & 2 & & Std. Mean Difference (IV, Random, 95\% CI) & Subtotals only \\
\hline
\end{tabular}




\begin{tabular}{clllll} 
6.1 Short-term & 2 & 59 & & Std. Mean Difference (IV, Random, 95\% CI) & $-0.66[-1.33,0.01]$ \\
6.2 Medium-term & 1 & 36 & Std. Mean Difference (IV, Random, 95\% CI) & $-0.63[-1.34,0.08]$ \\
7 Depression & 3 & & & Std. Mean Difference (IV, Random, 95\% CI) & Subtotals only \\
7.1 Short-term & 3 & 98 & Std. Mean Difference (IV, Random, 95\% CI) & $-0.80[-1.47,-0.13]$ \\
7.2 Medium-term & 1 & 36 & Std. Mean Difference (IV, Random, 95\% CI) & $-0.19[-0.88,0.51]$ \\
8 L Loss to follow-up & 2 & & Odds Ratio (M-H, Random, 95\% CI) & Totals not selected \\
8.1 Short-term & 2 & & Odds Ratio (M-H, Random, 95\% CI) & $0.0[0.0,0.0]$ \\
\hline
\end{tabular}

Comparison 3. Narrative versus control

\begin{tabular}{|c|c|c|c|c|}
\hline Outcome or subgroup title & $\begin{array}{l}\text { No. of } \\
\text { studies }\end{array}$ & $\begin{array}{c}\text { No. of } \\
\text { participants }\end{array}$ & Statistical method & Effect size \\
\hline 1 Improvement & 2 & & Odds Ratio (M-H, Random, 95\% CI) & Totals not selected \\
\hline 1.1 Medium-term & 1 & & Odds Ratio (M-H, Random, 95\% CI) & $0.0[0.0,0.0]$ \\
\hline 1.2 Long-term & 1 & & Odds Ratio (M-H, Random, 95\% CI) & $0.0[0.0,0.0]$ \\
\hline 2 PTSD total & 2 & & Std. Mean Difference (IV, Random, 95\% CI) & Subtotals only \\
\hline 2.1 Medium-term & 2 & 79 & Std. Mean Difference (IV, Random, 95\% CI) & $-0.57[-1.23,0.09]$ \\
\hline 2.2 Long-term & 1 & 53 & Std. Mean Difference (IV, Random, 95\% CI) & $-0.44[-0.98,0.11]$ \\
\hline 3 PTSD avoidance & 1 & & Std. Mean Difference (IV, Random, 95\% CI) & Totals not selected \\
\hline 3.1 Medium-term & 1 & & Std. Mean Difference (IV, Random, 95\% CI) & $0.0[0.0,0.0]$ \\
\hline 4 PTSD hyperarousal & 1 & & Std. Mean Difference (IV, Random, 95\% CI) & Totals not selected \\
\hline 4.1 Medium-term & 1 & & Std. Mean Difference (IV, Random, 95\% CI) & $0.0[0.0,0.0]$ \\
\hline 5 PTSD re-experiencing & 1 & & Std. Mean Difference (IV, Random, 95\% CI) & Totals not selected \\
\hline 5.1 Medium-term & 1 & & Std. Mean Difference (IV, Random, 95\% CI) & $0.0[0.0,0.0]$ \\
\hline 6 Depression & 1 & & Std. Mean Difference (IV, Random, 95\% CI) & Totals not selected \\
\hline 6.1 Medium-term & 1 & & Std. Mean Difference (IV, Random, 95\% CI) & $0.0[0.0,0.0]$ \\
\hline 6.2 Long-term & 1 & & Std. Mean Difference (IV, Random, 95\% CI) & $0.0[0.0,0.0]$ \\
\hline 7 Loss to follow-up & 2 & & Odds Ratio (M-H, Random, 95\% CI) & Subtotals only \\
\hline 7.1 Medium-term & 2 & 83 & Odds Ratio (M-H, Random, 95\% CI) & $5.13[0.56,47.28]$ \\
\hline 7.2 Long-term & 1 & 57 & Odds Ratio (M-H, Random, 95\% CI) & $10.06[0.52,196.10]$ \\
\hline
\end{tabular}

\section{Comparison 4. EMDR versus control}

\begin{tabular}{|c|c|c|c|c|}
\hline Outcome or subgroup title & $\begin{array}{l}\text { No. of } \\
\text { studies }\end{array}$ & $\begin{array}{c}\text { No. of } \\
\text { participants }\end{array}$ & Statistical method & Effect size \\
\hline 1 PTSD & 2 & & Std. Mean Difference (IV, Random, 95\% CI) & Subtotals only \\
\hline 1.1 Short-term & 2 & 65 & Std. Mean Difference (IV, Random, 95\% CI) & $-0.61[-1.96,0.74]$ \\
\hline 2 PTSD avoidance & 1 & & Std. Mean Difference (IV, Random, 95\% CI) & Totals not selected \\
\hline 2.1 Short-term & 1 & & Std. Mean Difference (IV, Random, 95\% CI) & $0.0[0.0,0.0]$ \\
\hline 3 PTSD hyperarousal & 1 & & Std. Mean Difference (IV, Random, 95\% CI) & Totals not selected \\
\hline 3.1 Short-term & 1 & & Std. Mean Difference (IV, Random, 95\% CI) & $0.0[0.0,0.0]$ \\
\hline 4 PTSD re-experiencing & 1 & & Std. Mean Difference (IV, Random, 95\% CI) & Totals not selected \\
\hline 4.1 Short-term & 1 & & Std. Mean Difference (IV, Random, 95\% CI) & $0.0[0.0,0.0]$ \\
\hline 5 Anxiety & 1 & & Std. Mean Difference (IV, Random, 95\% CI) & Totals not selected \\
\hline 5.1 Short-term & 1 & & Std. Mean Difference (IV, Random, 95\% CI) & $0.0[0.0,0.0]$ \\
\hline
\end{tabular}

Psychological therapies for the treatment of post-traumatic stress disorder in children and adolescents (Review)

Copyright @ 2012 The Cochrane Collaboration. Published by John Wiley \& Sons, Ltd. 
6 Depression

6.1 Short-term

7 Loss to follow-up

7.1 Short-term
Std. Mean Difference (IV, Random, 95\% CI)

Std. Mean Difference (IV, Random, 95\% CI)

Odds Ratio (M-H, Random, 95\% CI)

Odds Ratio (M-H, Random, 95\% CI)
Totals not selected $0.0[0.0,0.0]$

Totals not selected $0.0[0.0,0.0]$

Comparison 5. Other psychological therapies versus control

\begin{tabular}{|c|c|c|c|c|}
\hline Outcome or subgroup title & $\begin{array}{l}\text { No. of } \\
\text { studies }\end{array}$ & $\begin{array}{c}\text { No. of } \\
\text { participants }\end{array}$ & Statistical method & Effect size \\
\hline 1 PTSD total & 1 & & Std. Mean Difference (IV, Random, 95\% CI) & Totals not selected \\
\hline 1.1 Short-term & 1 & & Std. Mean Difference (IV, Random, 95\% CI) & $0.0[0.0,0.0]$ \\
\hline 2 PTSD avoidance & 1 & & Odds Ratio (M-H, Random, 95\% CI) & Totals not selected \\
\hline 2.1 Medium-term & 1 & & Odds Ratio (M-H, Random, 95\% CI) & $0.0[0.0,0.0]$ \\
\hline 3 PTSD hyperarousal & 1 & & Odds Ratio (M-H, Random, 95\% CI) & Totals not selected \\
\hline 3.1 Medium-term & 1 & & Odds Ratio (M-H, Random, 95\% CI) & $0.0[0.0,0.0]$ \\
\hline 4 PTSD re-experiencing & 1 & & Odds Ratio (M-H, Random, 95\% CI) & Totals not selected \\
\hline 4.1 Medium-term & 1 & & Odds Ratio (M-H, Random, 95\% CI) & $0.0[0.0,0.0]$ \\
\hline 5 Depression & 1 & & Std. Mean Difference (IV, Random, 95\% CI) & Totals not selected \\
\hline 5.1 Short-term & 1 & & Std. Mean Difference (IV, Random, 95\% CI) & $0.0[0.0,0.0]$ \\
\hline 5.2 Medium-term & 1 & & Std. Mean Difference (IV, Random, 95\% CI) & $0.0[0.0,0.0]$ \\
\hline 6 Loss to follow-up & 2 & & Odds Ratio (M-H, Random, 95\% CI) & Subtotals only \\
\hline 6.1 Short-term & 2 & 115 & Odds Ratio (M-H, Random, 95\% CI) & $1.38[0.35,5.52]$ \\
\hline 6.2 Medium-term & 1 & 33 & Odds Ratio (M-H, Random, 95\% CI) & $0.95[0.23,3.88]$ \\
\hline
\end{tabular}

Comparison 6. CBT versus supportive counselling

\begin{tabular}{|c|c|c|c|c|}
\hline Outcome or subgroup title & $\begin{array}{l}\text { No. of } \\
\text { studies }\end{array}$ & $\begin{array}{c}\text { No. of } \\
\text { participants }\end{array}$ & Statistical method & Effect size \\
\hline 1 Improvement & 2 & & Odds Ratio (M-H, Random, 95\% CI) & Subtotals only \\
\hline 1.1 Short-term & 2 & 208 & Odds Ratio (M-H, Random, 95\% CI) & $3.18[1.76,5.74]$ \\
\hline 2 PTSD avoidance & 1 & & Std. Mean Difference (IV, Random, 95\% CI) & Totals not selected \\
\hline 2.1 Short-term & 1 & & Std. Mean Difference (IV, Random, 95\% CI) & $0.0[0.0,0.0]$ \\
\hline 2.2 Medium-term & 1 & & Std. Mean Difference (IV, Random, 95\% CI) & $0.0[0.0,0.0]$ \\
\hline 2.3 Long-term & 1 & & Std. Mean Difference (IV, Random, 95\% CI) & $0.0[0.0,0.0]$ \\
\hline 3 PTSD hyperarousal & 1 & & Std. Mean Difference (IV, Random, 95\% CI) & Totals not selected \\
\hline 3.1 Short-term & 1 & & Std. Mean Difference (IV, Random, 95\% CI) & $0.0[0.0,0.0]$ \\
\hline 3.2 Medium-term & 1 & & Std. Mean Difference (IV, Random, 95\% CI) & $0.0[0.0,0.0]$ \\
\hline 3.3 Long-term & 1 & & Std. Mean Difference (IV, Random, 95\% CI) & $0.0[0.0,0.0]$ \\
\hline 4 PTSD re-experiencing & 1 & & Std. Mean Difference (IV, Random, 95\% CI) & Totals not selected \\
\hline 4.1 Short-term & 1 & & Std. Mean Difference (IV, Random, 95\% CI) & $0.0[0.0,0.0]$ \\
\hline 4.2 Medium-term & 1 & & Std. Mean Difference (IV, Random, 95\% CI) & $0.0[0.0,0.0]$ \\
\hline 5 Anxiety state & 1 & & Std. Mean Difference (IV, Random, 95\% CI) & Totals not selected \\
\hline 5.1 Short-term & 1 & & Std. Mean Difference (IV, Random, 95\% CI) & $0.0[0.0,0.0]$ \\
\hline 5.2 Medium-term & 1 & & Std. Mean Difference (IV, Random, 95\% CI) & $0.0[0.0,0.0]$ \\
\hline 5.3 Long-term & 1 & & Std. Mean Difference (IV, Random, 95\% CI) & $0.0[0.0,0.0]$ \\
\hline
\end{tabular}

Psychological therapies for the treatment of post-traumatic stress disorder in children and adolescents (Review)

Copyright @ 2012 The Cochrane Collaboration. Published by John Wiley \& Sons, Ltd. 
6 Anxiety trait

6.1 Short-term

6.2 Medium-term

6.3 Long-term

7 Depression

7.1 Short-term

8 Behaviour

8.1 Short-term

8.2 Medium-term

8.3 Long-term

9 Loss to follow-up

9.1 Short-term

9.2 Medium-term

9.3 Long-term
Std. Mean Difference (IV, Random, 95\% CI)

Std. Mean Difference (IV, Random, 95\% CI)

Std. Mean Difference (IV, Random, 95\% CI)

Std. Mean Difference (IV, Random, 95\% CI)

Std. Mean Difference (IV, Random, 95\% CI)

Std. Mean Difference (IV, Random, 95\% CI)

Std. Mean Difference (IV, Random, 95\% CI)

Std. Mean Difference (IV, Random, 95\% CI)

Std. Mean Difference (IV, Random, 95\% CI)

Std. Mean Difference (IV, Random, 95\% CI)

Odds Ratio (M-H, Random, 95\% CI)

Odds Ratio (M-H, Random, 95\% CI)

Odds Ratio (M-H, Random, 95\% CI)

Odds Ratio (M-H, Random, 95\% CI)
Totals not selected

$0.0[0.0,0.0]$

$0.0[0.0,0.0]$

$0.0[0.0,0.0]$

Totals not selected $0.0[0.0,0.0]$

Totals not selected $0.0[0.0,0.0]$

$0.0[0.0,0.0]$

$0.0[0.0,0.0]$

Totals not selected

$0.0[0.0,0.0]$

$0.0[0.0,0.0]$ $0.0[0.0,0.0]$

Comparison 7. Narrative versus supportive counselling

\begin{tabular}{|c|c|c|c|c|}
\hline Outcome or subgroup title & $\begin{array}{l}\text { No. of } \\
\text { studies }\end{array}$ & $\begin{array}{c}\text { No. of } \\
\text { participants }\end{array}$ & Statistical method & Effect size \\
\hline 1 Improvement & 1 & & Odds Ratio (M-H, Random, 95\% CI) & Totals not selected \\
\hline 1.1 Long-term & 1 & & Odds Ratio (M-H, Random, 95\% CI) & $0.0[0.0,0.0]$ \\
\hline 2 PTSD total & 1 & & Std. Mean Difference (IV, Random, 95\% CI) & Totals not selected \\
\hline 2.1 Medium-term & 1 & & Std. Mean Difference (IV, Random, 95\% CI) & $0.0[0.0,0.0]$ \\
\hline 2.2 Long-term & 1 & & Std. Mean Difference (IV, Random, 95\% CI) & $0.0[0.0,0.0]$ \\
\hline 3 Depression & 1 & & Std. Mean Difference (IV, Random, 95\% CI) & Totals not selected \\
\hline 3.1 Medium-term & 1 & & Std. Mean Difference (IV, Random, 95\% CI) & $0.0[0.0,0.0]$ \\
\hline 3.2 Long-term & 1 & & Std. Mean Difference (IV, Random, 95\% CI) & $0.0[0.0,0.0]$ \\
\hline 4 Loss to follow-up & 1 & & Odds Ratio (M-H, Random, 95\% CI) & Totals not selected \\
\hline 4.1 Medium-term & 1 & & Odds Ratio (M-H, Random, 95\% CI) & $0.0[0.0,0.0]$ \\
\hline 4.2 Long-term & 1 & & Odds Ratio (M-H, Random, 95\% CI) & $0.0[0.0,0.0]$ \\
\hline
\end{tabular}

Comparison 8. Narrative versus meditation/relaxation

\begin{tabular}{|c|c|c|c|c|}
\hline Outcome or subgroup title & $\begin{array}{l}\text { No. of } \\
\text { studies }\end{array}$ & $\begin{array}{c}\text { No. of } \\
\text { participants }\end{array}$ & Statistical method & Effect size \\
\hline 1 Improvement & 2 & & Odds Ratio (M-H, Random, 95\% CI) & Subtotals only \\
\hline 1.1 Short-term & 1 & 31 & Odds Ratio (M-H, Random, 95\% CI) & $1.5[0.32,7.14]$ \\
\hline 1.2 Medium-term & 2 & 76 & Odds Ratio (M-H, Random, 95\% CI) & $1.09[0.41,2.88]$ \\
\hline 2 PTSD total & 2 & & Std. Mean Difference (IV, Random, 95\% CI) & Subtotals only \\
\hline 2.1 Short-term & 1 & 30 & Std. Mean Difference (IV, Random, 95\% CI) & $-0.01[-0.73,0.70]$ \\
\hline 2.2 Medium-term & 2 & 76 & Std. Mean Difference (IV, Random, 95\% CI) & $0.06[-0.39,0.51]$ \\
\hline 3 Loss to follow-up & 2 & & Odds Ratio (M-H, Random, 95\% CI) & Subtotals only \\
\hline 3.1 Short-term & 1 & 31 & Odds Ratio (M-H, Random, 95\% CI) & $0.0[0.0,0.0]$ \\
\hline 3.2 Medium-term & 2 & 78 & Odds Ratio (M-H, Random, 95\% CI) & $0.29[0.03,2.89]$ \\
\hline
\end{tabular}




\begin{tabular}{|c|c|c|c|c|}
\hline Outcome or subgroup title & $\begin{array}{l}\text { No. of } \\
\text { studies }\end{array}$ & $\begin{array}{c}\text { No. of } \\
\text { participants }\end{array}$ & Statistical method & Effect size \\
\hline 1 Improvement & 1 & & Odds Ratio (M-H, Random, 95\% CI) & Totals not selected \\
\hline 1.1 Short-term & 1 & & Odds Ratio (M-H, Random, 95\% CI) & $0.0[0.0,0.0]$ \\
\hline 1.2 Medium-term & 1 & & Odds Ratio (M-H, Random, 95\% CI) & $0.0[0.0,0.0]$ \\
\hline 2 PTSD total & 1 & & Std. Mean Difference (IV, Random, 95\% CI) & Totals not selected \\
\hline 2.1 Short-term & 1 & & Std. Mean Difference (IV, Random, 95\% CI) & $0.0[0.0,0.0]$ \\
\hline 2.2 Medium-term & 1 & & Std. Mean Difference (IV, Random, 95\% CI) & $0.0[0.0,0.0]$ \\
\hline 2.3 Long-term & 1 & & Std. Mean Difference (IV, Random, 95\% CI) & $0.0[0.0,0.0]$ \\
\hline 3 Depression & 1 & & Std. Mean Difference (IV, Random, 95\% CI) & Totals not selected \\
\hline 3.1 Short-term & 1 & & Std. Mean Difference (IV, Random, 95\% CI) & $0.0[0.0,0.0]$ \\
\hline 3.2 Medium-term & 1 & & Std. Mean Difference (IV, Random, 95\% CI) & $0.0[0.0,0.0]$ \\
\hline 3.3 Long-term & 1 & & Std. Mean Difference (IV, Random, 95\% CI) & $0.0[0.0,0.0]$ \\
\hline 4 Loss to follow-up & 1 & & Odds Ratio (M-H, Random, 95\% CI) & Totals not selected \\
\hline 4.1 Short-term & 1 & & Odds Ratio (M-H, Random, 95\% CI) & $0.0[0.0,0.0]$ \\
\hline 4.2 Medium-term & 1 & & Odds Ratio (M-H, Random, 95\% CI) & $0.0[0.0,0.0]$ \\
\hline 4.3 Long-term & 1 & & Odds Ratio (M-H, Random, 95\% CI) & $0.0[0.0,0.0]$ \\
\hline
\end{tabular}

Comparison 10. Sensitivity analysis: types of therapy

\begin{tabular}{|c|c|c|c|c|}
\hline Outcome or subgroup title & $\begin{array}{l}\text { No. of } \\
\text { studies }\end{array}$ & $\begin{array}{c}\text { No. of } \\
\text { participants }\end{array}$ & Statistical method & Effect size \\
\hline 1 Improvement & 4 & & Odds Ratio (M-H, Random, 95\% CI) & Subtotals only \\
\hline $1.1 \mathrm{CBT}$ & 2 & 49 & Odds Ratio (M-H, Random, 95\% CI) & $8.64[2.01,37.14]$ \\
\hline 1.2 Narrative & 2 & 78 & Odds Ratio (M-H, Random, 95\% CI) & $3.82[0.67,21.80]$ \\
\hline 2 PTSD total & 8 & & Std. Mean Difference (IV, Random, 95\% CI) & Subtotals only \\
\hline 2.1 CBT & 3 & 98 & Std. Mean Difference (IV, Random, 95\% CI) & $-1.34[-1.79,-0.89]$ \\
\hline 2.2 Narrative & 2 & 79 & Std. Mean Difference (IV, Random, 95\% CI) & $-0.57[-1.23,0.09]$ \\
\hline 2.3 EMDR & 2 & 65 & Std. Mean Difference (IV, Random, 95\% CI) & $-0.61[-1.96,0.74]$ \\
\hline $\begin{array}{l}2.4 \text { Other psychological } \\
\text { therapies }\end{array}$ & 1 & 78 & Std. Mean Difference (IV, Random, 95\% CI) & $-1.12[-1.60,-0.64]$ \\
\hline
\end{tabular}

Comparison 11. Sensitivity analysis: types of trauma

\begin{tabular}{lccll} 
Outcome or subgroup title & $\begin{array}{c}\text { No. of } \\
\text { studies }\end{array}$ & $\begin{array}{c}\text { No. of } \\
\text { participants }\end{array}$ & \multicolumn{1}{c}{ Statistical method } & Effect size \\
\hline 1 Improvement & 4 & & Odds Ratio (M-H, Random, 95\% CI) & Subtotals only \\
1.1 Sexual abuse & 1 & 25 & Odds Ratio (M-H, Random, 95\% CI) & $6.0[0.93,38.63]$ \\
$\begin{array}{l}1.2 \text { Civil/social violence } \\
1.3 \text { Physical trauma }\end{array}$ & 2 & 78 & Odds Ratio (M-H, Random, 95\% CI) & $3.82[0.67,21.80]$ \\
2 PTSD total & 7 & 24 & Odds Ratio (M-H, Random, 95\% CI) & $15.40[1.47,160.97]$ \\
\hline
\end{tabular}

Psychological therapies for the treatment of post-traumatic stress disorder in children and adolescents (Review) 
2.1 Sexual abuse

2.2 Civil/social violence

2.3 Physical trauma

2.4 Natural disaster
36

157

62

32
Std. Mean Difference (IV, Random, 95\% CI)

Std. Mean Difference (IV, Random, 95\% CI)

Std. Mean Difference (IV, Random, 95\% CI)

Std. Mean Difference (IV, Random, 95\% CI)
$-1.05[-1.79,-0.31]$

$-0.79[-1.35,-0.24]$

$-1.51[-2.08,-0.94]$

$-1.31[-2.08,-0.54]$

Comparison 12. Sensitivity analysis: allocation concealment

\begin{tabular}{lcccc} 
Outcome or subgroup title & $\begin{array}{c}\text { No. of } \\
\text { studies }\end{array}$ & $\begin{array}{c}\text { No. of } \\
\text { participants }\end{array}$ & Statistical method & Effect size \\
\hline 1 PTSD total & 8 & & Std. Mean Difference (IV, Random, 95\% CI) & Subtotals only \\
1.1 Low risk & 1 & 78 & Std. Mean Difference (IV, Random, 95\% CI) & $-1.12[-1.60,-0.64]$ \\
1.2 Unclear risk & 7 & 242 & Std. Mean Difference (IV, Random, 95\% CI) & $-0.90[-1.38,-0.43]$ \\
\hline
\end{tabular}

Comparison 13. Sensitivity analysis: blinding

\begin{tabular}{lccll} 
Outcome or subgroup title & $\begin{array}{c}\text { No. of } \\
\text { studies }\end{array}$ & $\begin{array}{c}\text { No. of } \\
\text { participants }\end{array}$ & \multicolumn{1}{c}{ Statistical method } & Effect size \\
\hline 1 Improvement & 4 & & Odds Ratio (M-H, Random, 95\% CI) & Subtotals only \\
$\quad 1.1$ Low risk & 2 & 49 & Odds Ratio (M-H, Random, 95\% CI) & $12.76[2.89,56.44]$ \\
1.2 Unclear risk & 1 & 53 & Odds Ratio (M-H, Random, 95\% CI) & $1.84[0.60,5.65]$ \\
1.3 High risk & 1 & 25 & Odds Ratio (M-H, Random, 95\% CI) & $6.0[0.93,38.63]$ \\
2 PTSD total & 4 & & Std. Mean Difference (IV, Random, 95\% CI) & Subtotals only \\
2.1 Low risk & 4 & 114 & Std. Mean Difference (IV, Random, 95\% CI) & $-0.91[-1.65,-0.16]$ \\
2.2 Unclear risk & 4 & 206 & Std. Mean Difference (IV, Random, 95\% CI) & $-0.96[-1.47,-0.46]$ \\
\hline
\end{tabular}

Comparison 14. Sensitivity analysis: skewed and non-skewed data

\begin{tabular}{lccll} 
Outcome or subgroup title & $\begin{array}{c}\text { No. of } \\
\text { studies }\end{array}$ & $\begin{array}{c}\text { No. of } \\
\text { participants }\end{array}$ & Statistical method & Effect size \\
\hline 1 PTSD total & 7 & & Std. Mean Difference (IV, Random, 95\% CI) & Subtotals only \\
1.1 Non-skewed & 4 & 206 & Std. Mean Difference (IV, Random, 95\% CI) & $-0.96[-1.47,-0.46]$ \\
1.2 Skewed & 3 & 90 & Std. Mean Difference (IV, Random, 95\% CI) & $-0.73[-1.59,0.14]$ \\
\hline
\end{tabular}




\begin{tabular}{lcccc} 
Outcome or subgroup title & $\begin{array}{c}\text { No. of } \\
\text { studies }\end{array}$ & $\begin{array}{c}\text { No. of } \\
\text { participants }\end{array}$ & Statistical method & Effect size \\
\hline 1 Improvement & 3 & & Odds Ratio (M-H, Random, 95\% CI) & Subtotals only \\
1.1 Best-case & 3 & 116 & Odds Ratio (M-H, Random, 95\% CI) & $5.79[1.66,20.12]$ \\
1.2 Worst-case & 3 & 116 & Odds Ratio (M-H, Random, 95\% CI) & $2.02[0.74,5.50]$ \\
\hline
\end{tabular}

\section{Analysis I.I. Comparison I All psychological therapies versus control, Outcome I Improvement.}

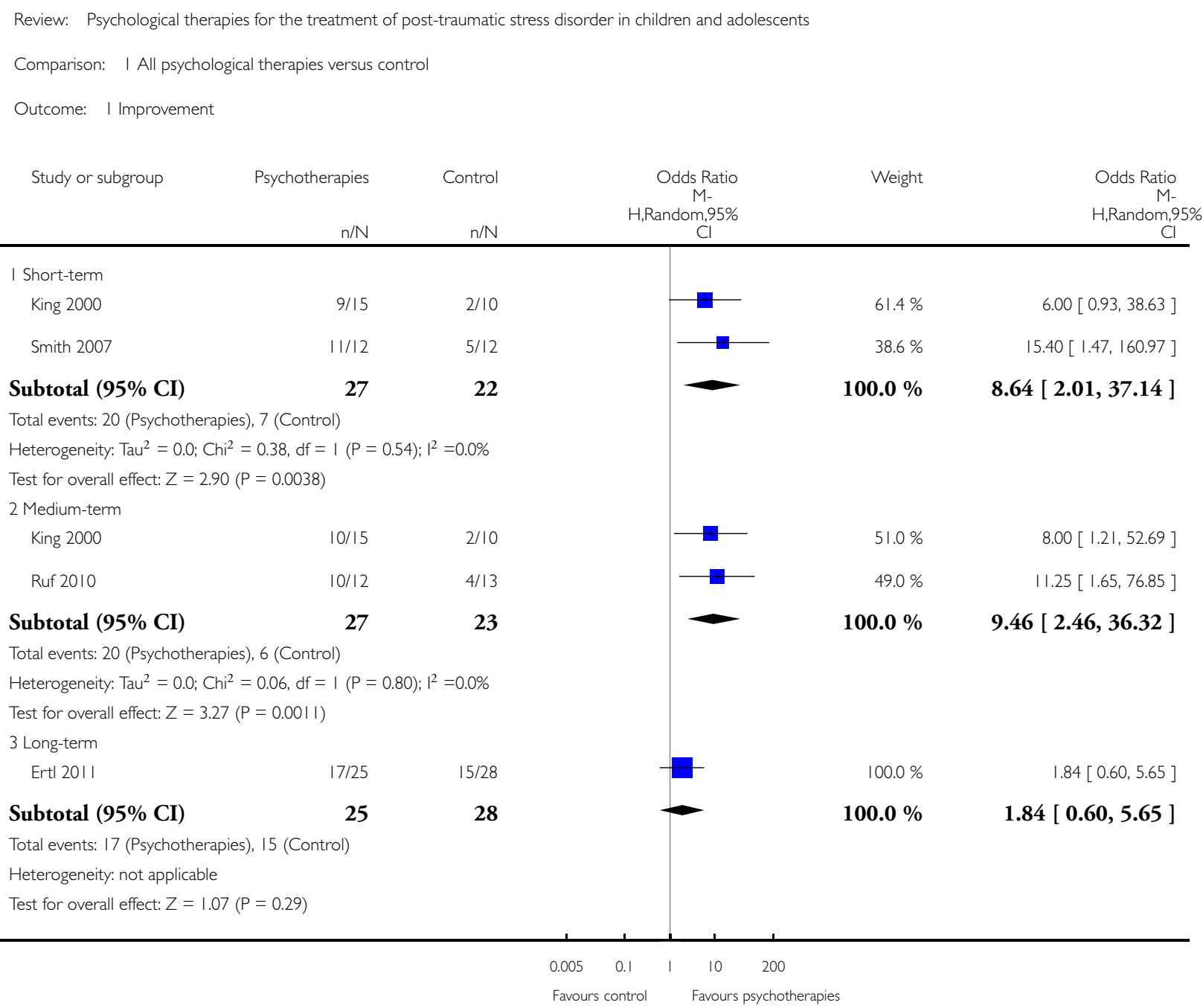




\section{Analysis I.2. Comparison I All psychological therapies versus control, Outcome 2 PTSD total.}

Review: Psychological therapies for the treatment of post-traumatic stress disorder in children and adolescents

Comparison: I All psychological therapies versus control

Outcome: 2 PTSD total

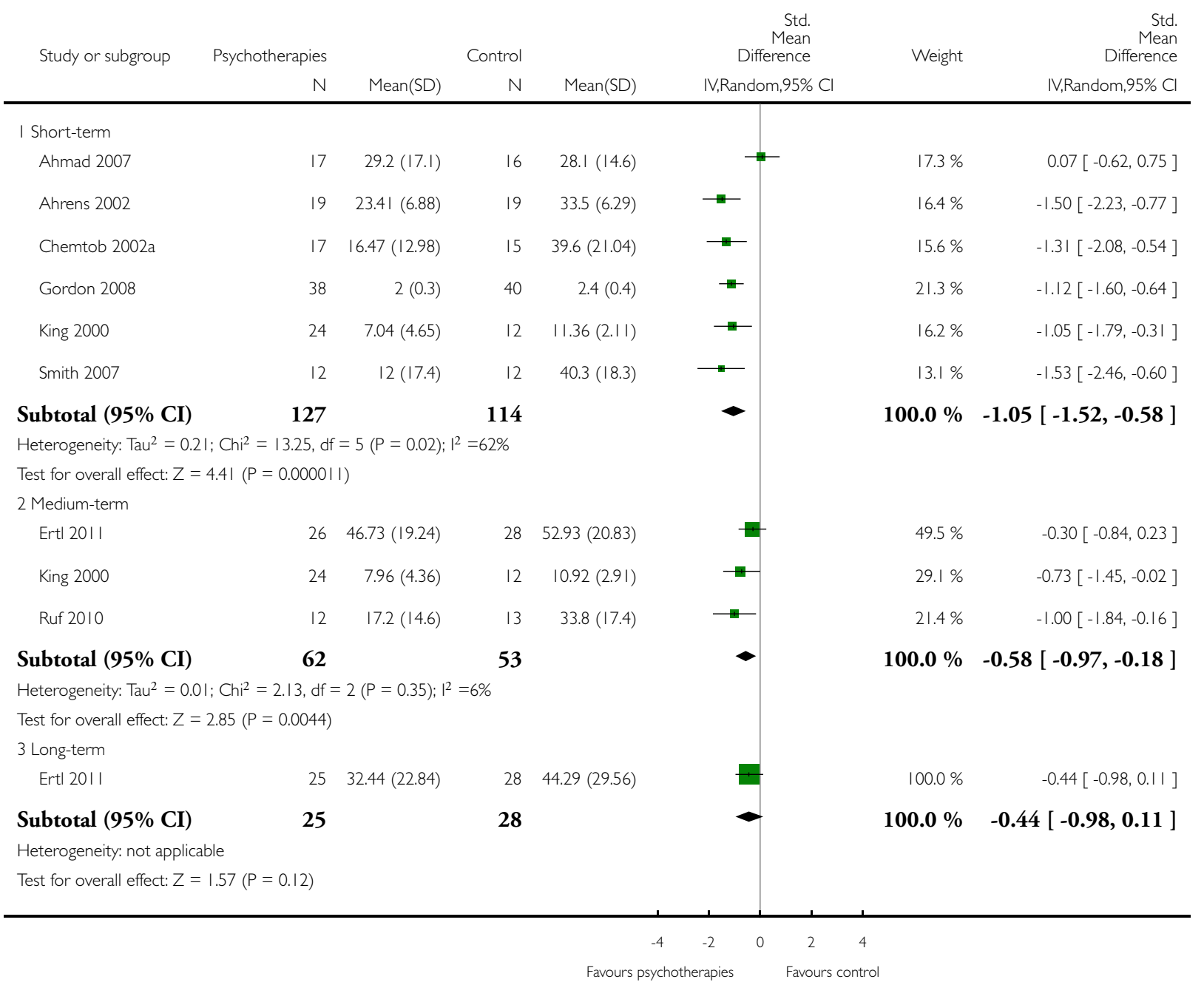




\section{Analysis I.3. Comparison I All psychological therapies versus control, Outcome 3 Anxiety.}

Review: Psychological therapies for the treatment of post-traumatic stress disorder in children and adolescents

Comparison: I All psychological therapies versus control

Outcome: 3 Anxiety

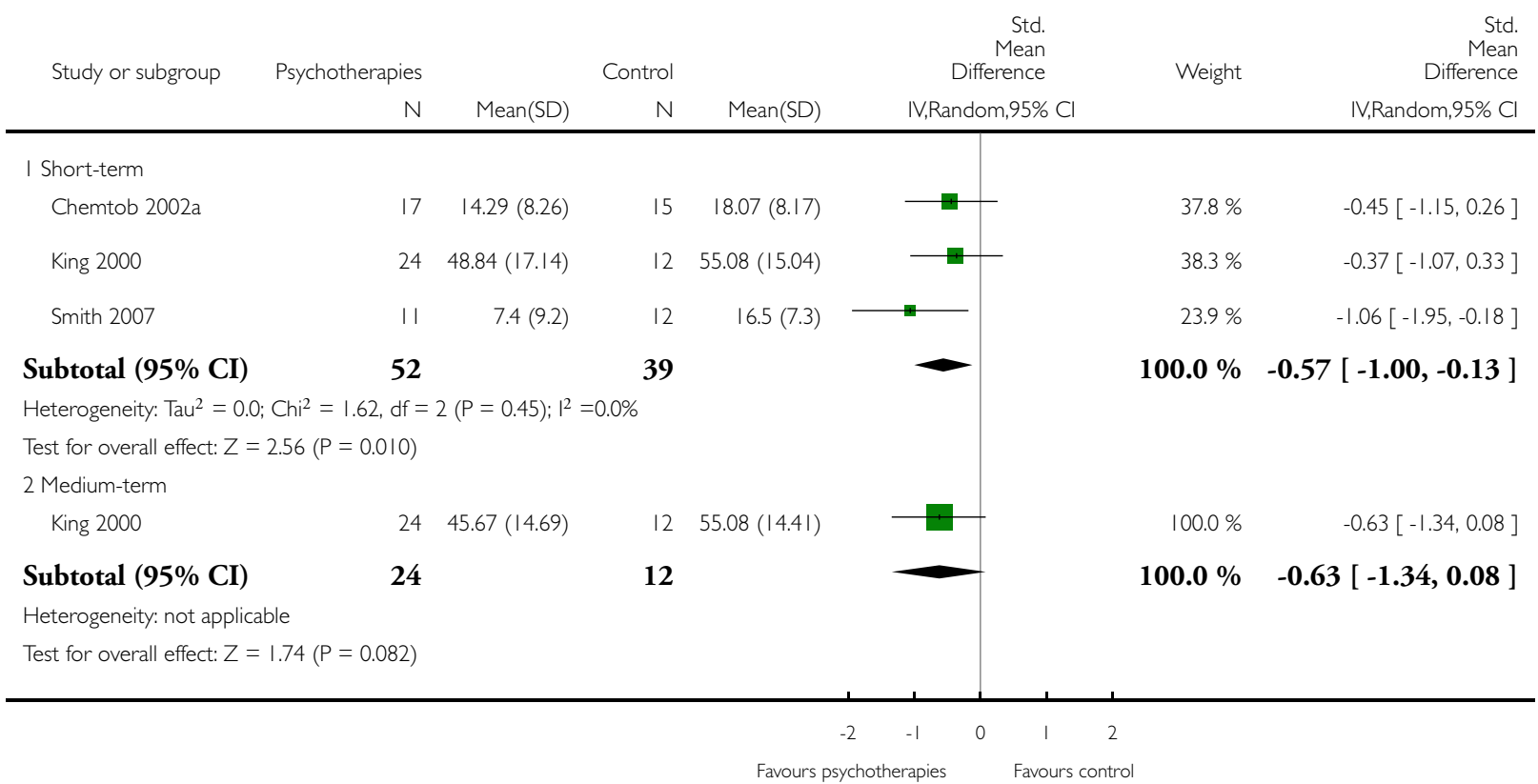




\section{Analysis I.4. Comparison I All psychological therapies versus control, Outcome 4 Depression.}

Review: Psychological therapies for the treatment of post-traumatic stress disorder in children and adolescents

Comparison: I All psychological therapies versus control

Outcome: 4 Depression

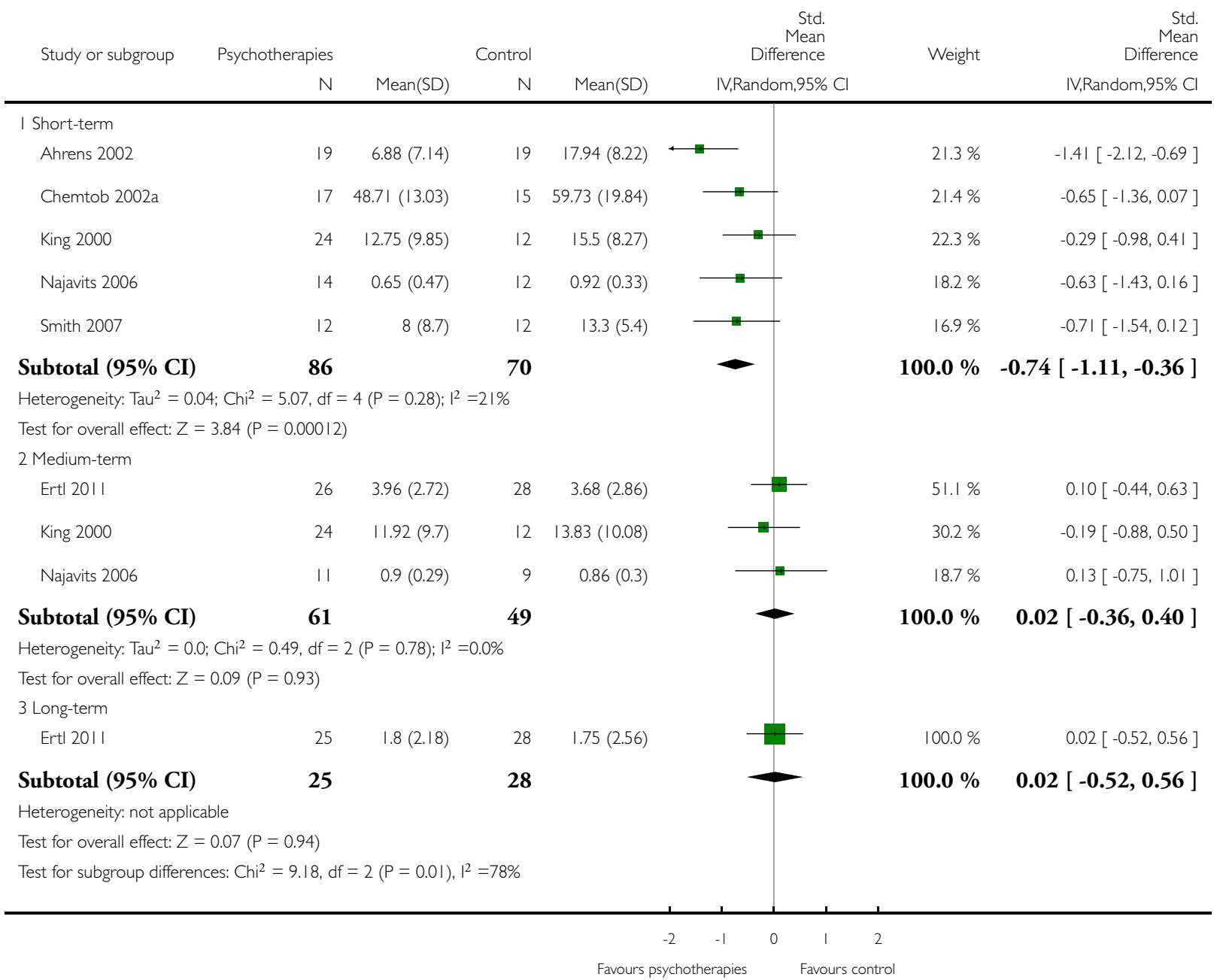




\section{Analysis I.5. Comparison I All psychological therapies versus control, Outcome 5 Loss to follow-up.}

Review: Psychological therapies for the treatment of post-traumatic stress disorder in children and adolescents

Comparison: I All psychological therapies versus control

Outcome: 5 Loss to follow-up

$\begin{array}{lcc} & \mathrm{n} / \mathrm{N} & \mathrm{n} / \mathrm{N} \\ \begin{array}{l}\text { I Short-term } \\ \text { Ahmad 2007 }\end{array} & 1 / 17 & 0 / 16 \\ \text { Gordon 2008 } & 2 / 41 & 1 / 41 \\ \text { King 2000 } & 6 / 24 & 2 / 12 \\ \text { Najavits 2006 } & 4 / 18 & 3 / 15 \\ \text { Smith 2007 } & 0 / 12 & 0 / 12 \\ \text { Subtotal (95\% CI) } & \mathbf{1 1 2} & \mathbf{9 6}\end{array}$

Subtotal (95\% CI)

112

96

Odds Ratio

H.Random,95\%

Weight

Odds Ratio

$\mathrm{H}, \mathrm{Random}, 95 \%$

$/ \mathrm{N}$

Cl

$\mathrm{Cl}$

Total events: 13 (Psychotherapies), 6 (Control)

Heterogeneity: $\mathrm{Tau}^{2}=0.0 ; \mathrm{Chi}^{2}=0.34, \mathrm{df}=3(\mathrm{P}=0.95) ; \mathrm{I}^{2}=0.0 \%$

Test for overall effect: $Z=0.88(P=0.38)$

2 Medium-term

$\begin{array}{lcc}\text { Ertl 2011 } & 3 / 29 & 0 / 28 \\ \text { Najavits 2006 } & 7 / 18 & 6 / 15 \\ \text { Ruf 2010 } & 1 / 13 & 0 / 13\end{array}$

Subtotal (95\% CI)

60

56

Total events: II (Psychotherapies), 6 (Control)

Heterogeneity: $\mathrm{Tau}^{2}=0.0 ; \mathrm{Chi}^{2}=1.76, \mathrm{df}=2(\mathrm{P}=0.4 \mathrm{I}) ; \mathrm{I}^{2}=0.0 \%$

Test for overall effect: $Z=0.7 \mid(P=0.47)$

3 Long-term

Ertl 201।

$4 / 29 \quad 0 / 28$

Subtotal (95\% CI)

29

$0 / 28$

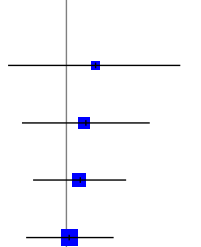

$10.0 \%$

$3.00[0.11,79.13]$

\section{1}

12

15

12

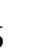

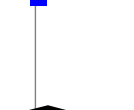

Total events: 4 (Psychotherapies), 0 (Control)

Heterogeneity: not applicable

Test for overall effect: $Z=1.52(P=0.13)$

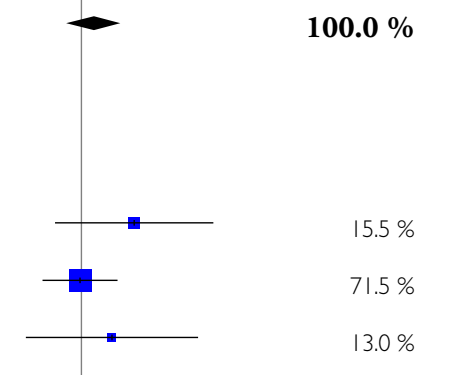

$7.53[0.37,152.73]$

$0.95[0.23,3.88]$

$3.24[0.12,87.13]$

$100.0 \%$

$1.54[0.47,5.04]$

$100.0 \%$

$10.06[0.52,196.10]$

$100.0 \%$

10.06 [ 0.52, 196.10 ] 


\section{Analysis 2.I. Comparison 2 CBT versus control, Outcome I Improvement.}

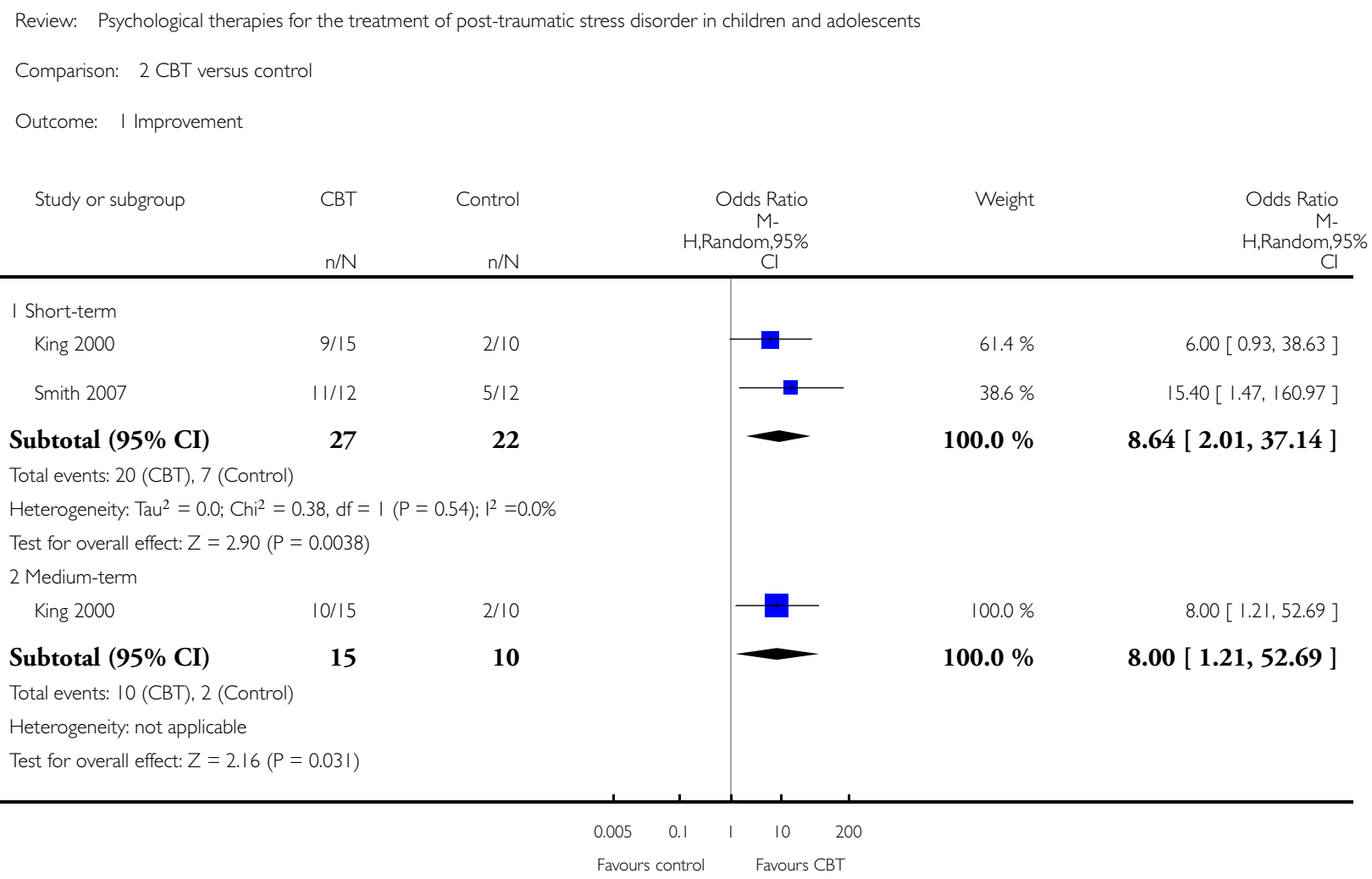




\section{Analysis 2.2. Comparison 2 CBT versus control, Outcome 2 PTSD total.}

Review: Psychological therapies for the treatment of post-traumatic stress disorder in children and adolescents

Comparison: 2 CBT versus control

Outcome: 2 PTSD total

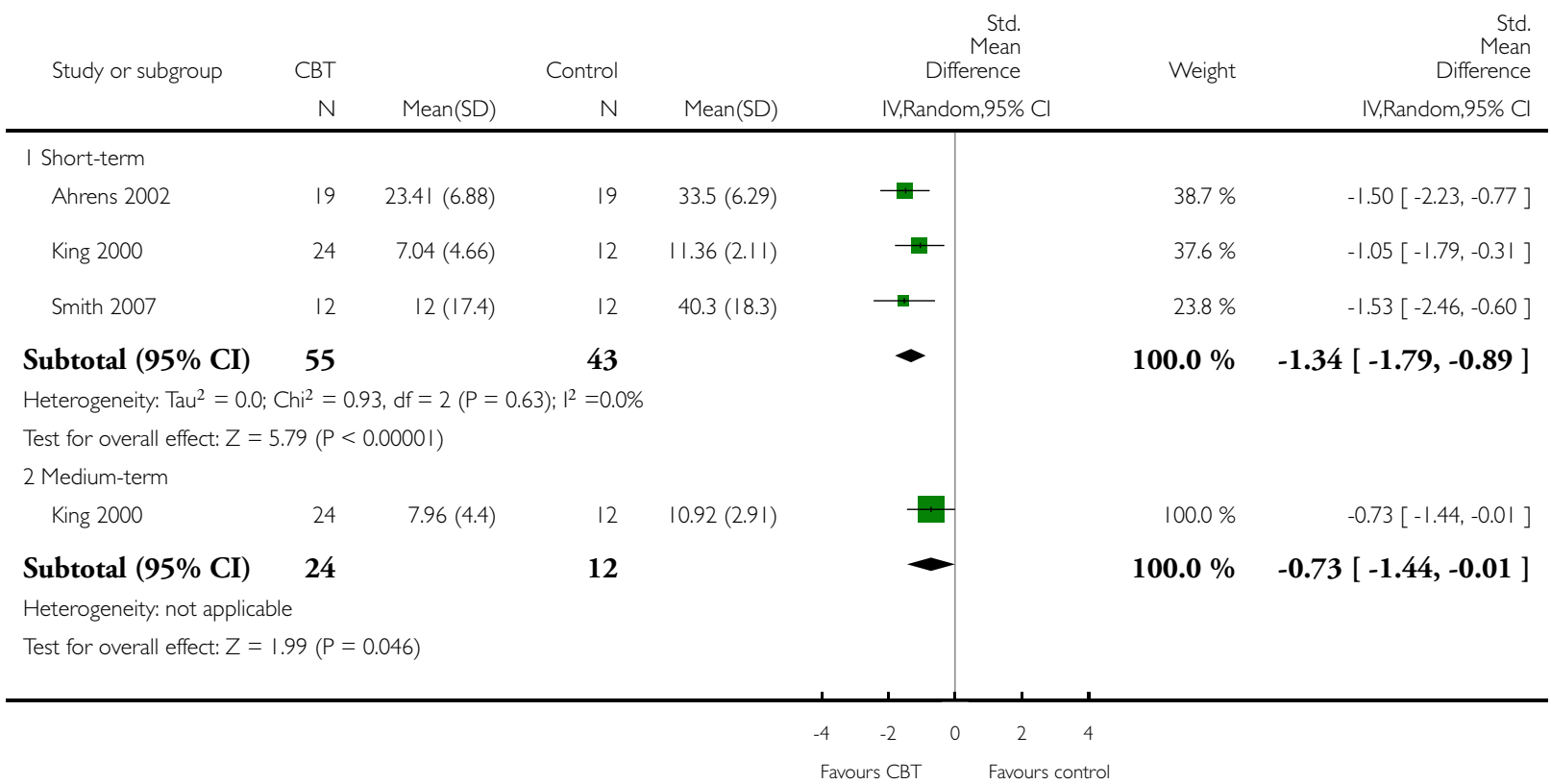




\section{Analysis 2.3. Comparison 2 CBT versus control, Outcome 3 PTSD avoidance.}

Review: Psychological therapies for the treatment of post-traumatic stress disorder in children and adolescents

Comparison: 2 CBT versus control

Outcome: 3 PTSD avoidance

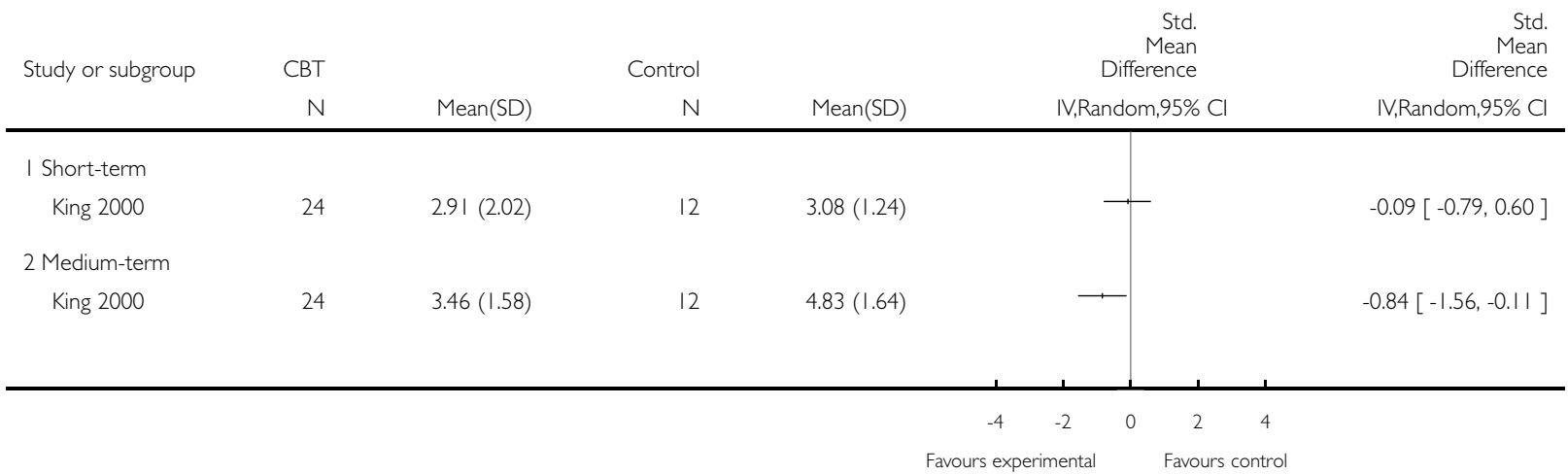

Analysis 2.4. Comparison 2 CBT versus control, Outcome 4 PTSD hyperarousal.

Review: Psychological therapies for the treatment of post-traumatic stress disorder in children and adolescents

Comparison: 2 CBT versus control

Outcome: 4 PTSD hyperarousal

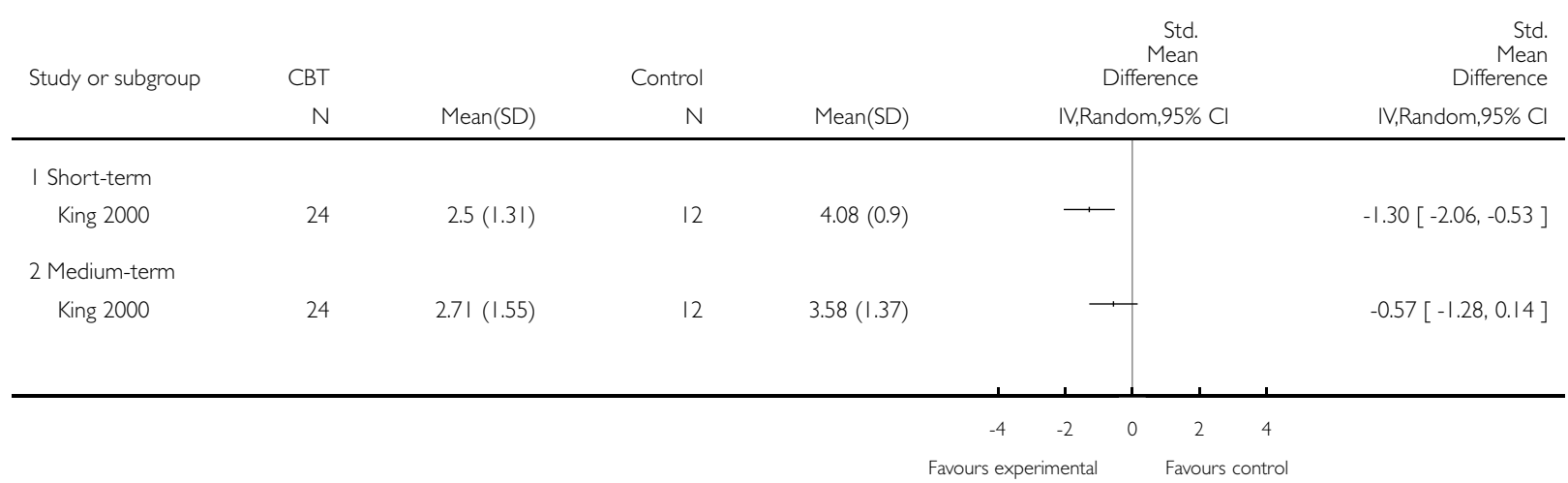

Psychological therapies for the treatment of post-traumatic stress disorder in children and adolescents (Review) 


\section{Analysis 2.5. Comparison 2 CBT versus control, Outcome 5 PTSD re-experiencing.}

Review: Psychological therapies for the treatment of post-traumatic stress disorder in children and adolescents

Comparison: 2 CBT versus control

Outcome: 5 PTSD re-experiencing

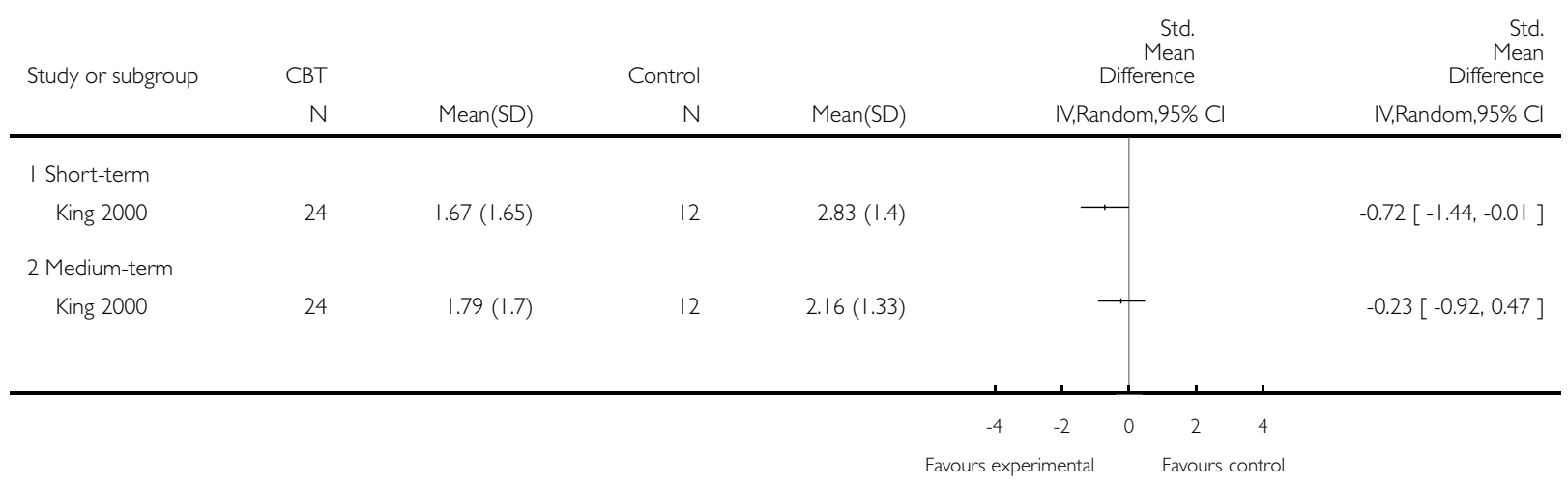

Psychological therapies for the treatment of post-traumatic stress disorder in children and adolescents (Review)

Copyright (๑) 2012 The Cochrane Collaboration. Published by John Wiley \& Sons, Ltd. 


\section{Analysis 2.6. Comparison 2 CBT versus control, Outcome 6 Anxiety.}

Review: Psychological therapies for the treatment of post-traumatic stress disorder in children and adolescents

Comparison: 2 CBT versus control

Outcome: 6 Anxiety

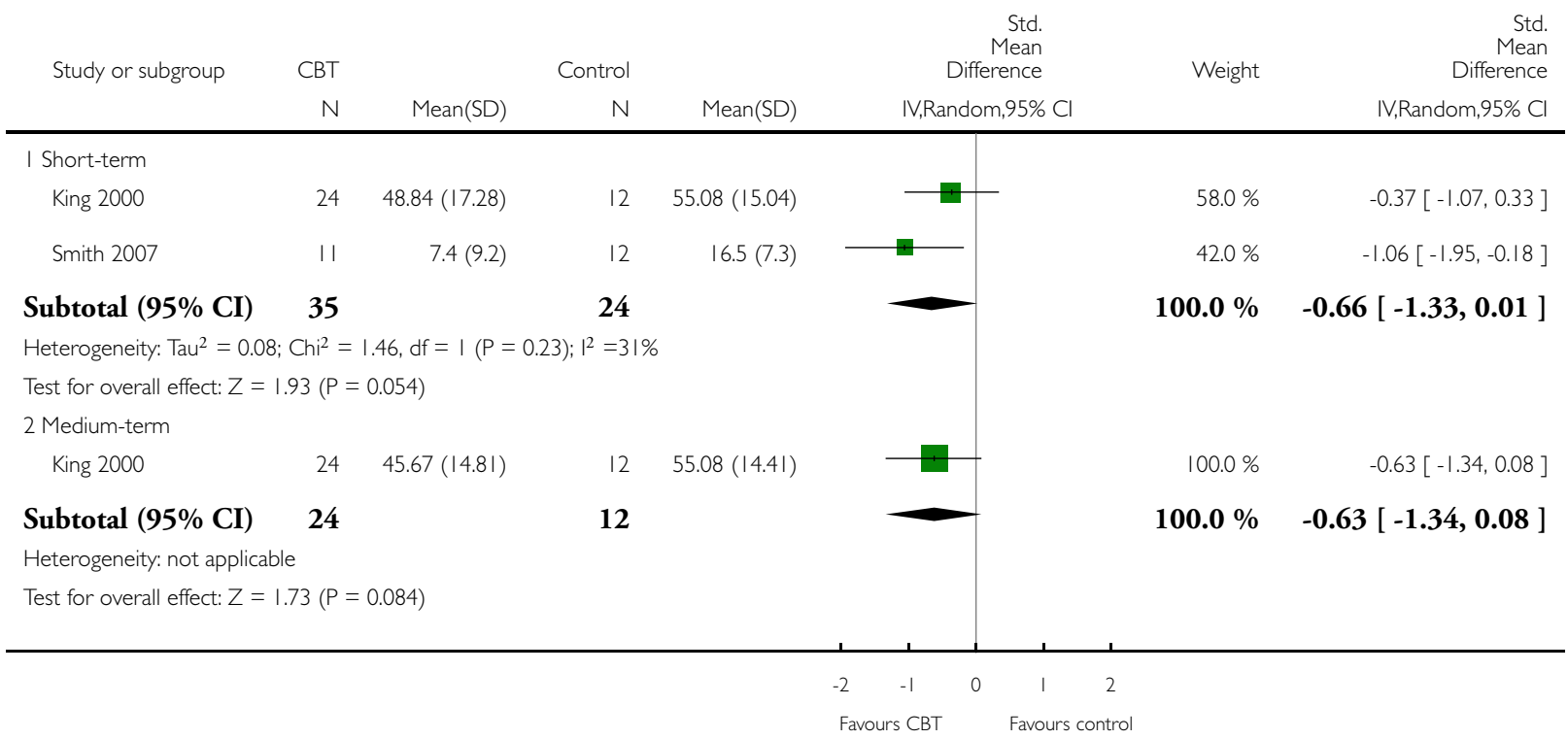




\section{Analysis 2.7. Comparison 2 CBT versus control, Outcome 7 Depression.}

Review: Psychological therapies for the treatment of post-traumatic stress disorder in children and adolescents

Comparison: 2 CBT versus control

Outcome: 7 Depression

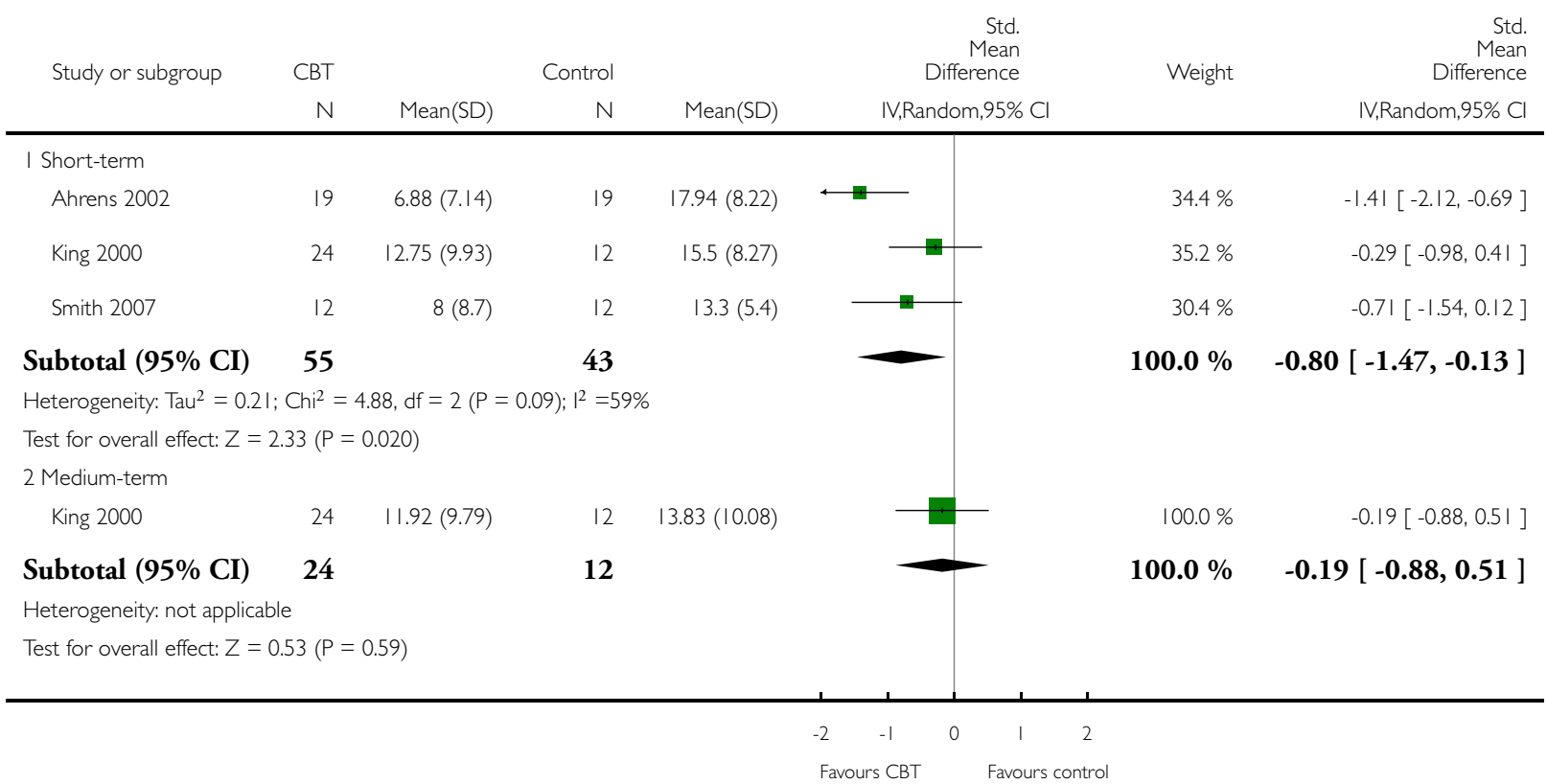




\section{Analysis 2.8. Comparison 2 CBT versus control, Outcome 8 Loss to follow-up.}

Review: Psychological therapies for the treatment of post-traumatic stress disorder in children and adolescents

Comparison: 2 CBT versus control

Outcome: 8 Loss to follow-up

Study or subgroup

Favours CBT

Control

Odds Ratio

H,Random, $95 \%$

Odds Ratio

H,Random, $95 \%$

$n / N \quad n / N$

H,Random, Cl

H,Random,

| Short-term

King 2000

$6 / 24$

$2 / 12$

\begin{tabular}{l|l} 
& \\
\hline &
\end{tabular}

$1.67[0.28,9.86]$

Smith 2007

$0 / 12$

$0 / 12$

Not estimable

\section{Analysis 3.I. Comparison 3 Narrative versus control, Outcome I Improvement.}

Review: Psychological therapies for the treatment of post-traumatic stress disorder in children and adolescents

Comparison: 3 Narrative versus control

Outcome: I Improvement

Study or subgroup

Narrative

Control

Odds Ratio

$\mathrm{M-}$

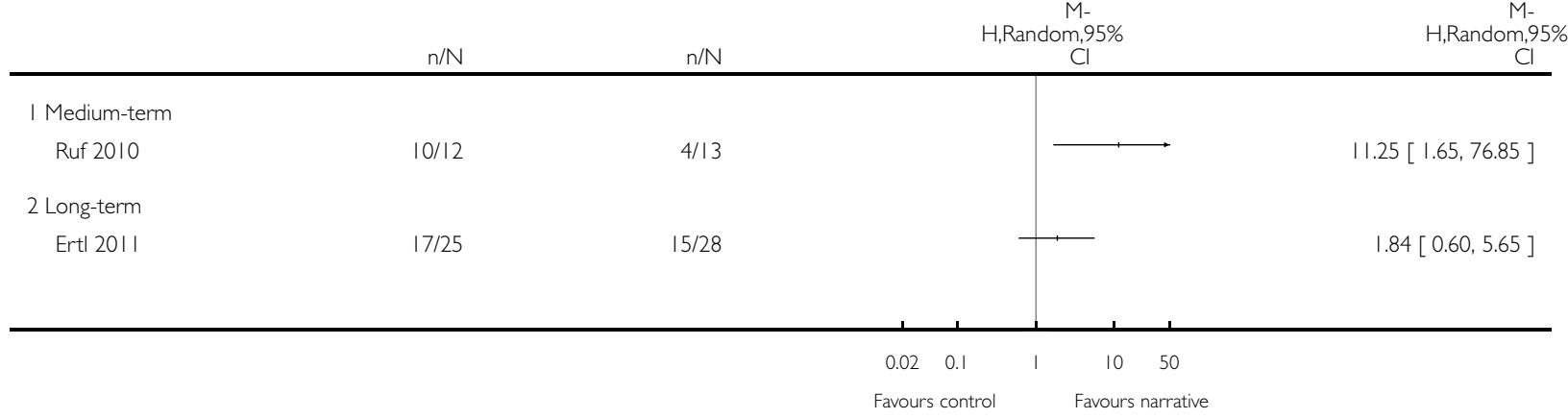

Psychological therapies for the treatment of post-traumatic stress disorder in children and adolescents (Review)

Copyright @ 2012 The Cochrane Collaboration. Published by John Wiley \& Sons, Ltd. 


\section{Analysis 3.2. Comparison 3 Narrative versus control, Outcome 2 PTSD total.}

Review: Psychological therapies for the treatment of post-traumatic stress disorder in children and adolescents

Comparison: 3 Narrative versus control

Outcome: 2 PTSD total

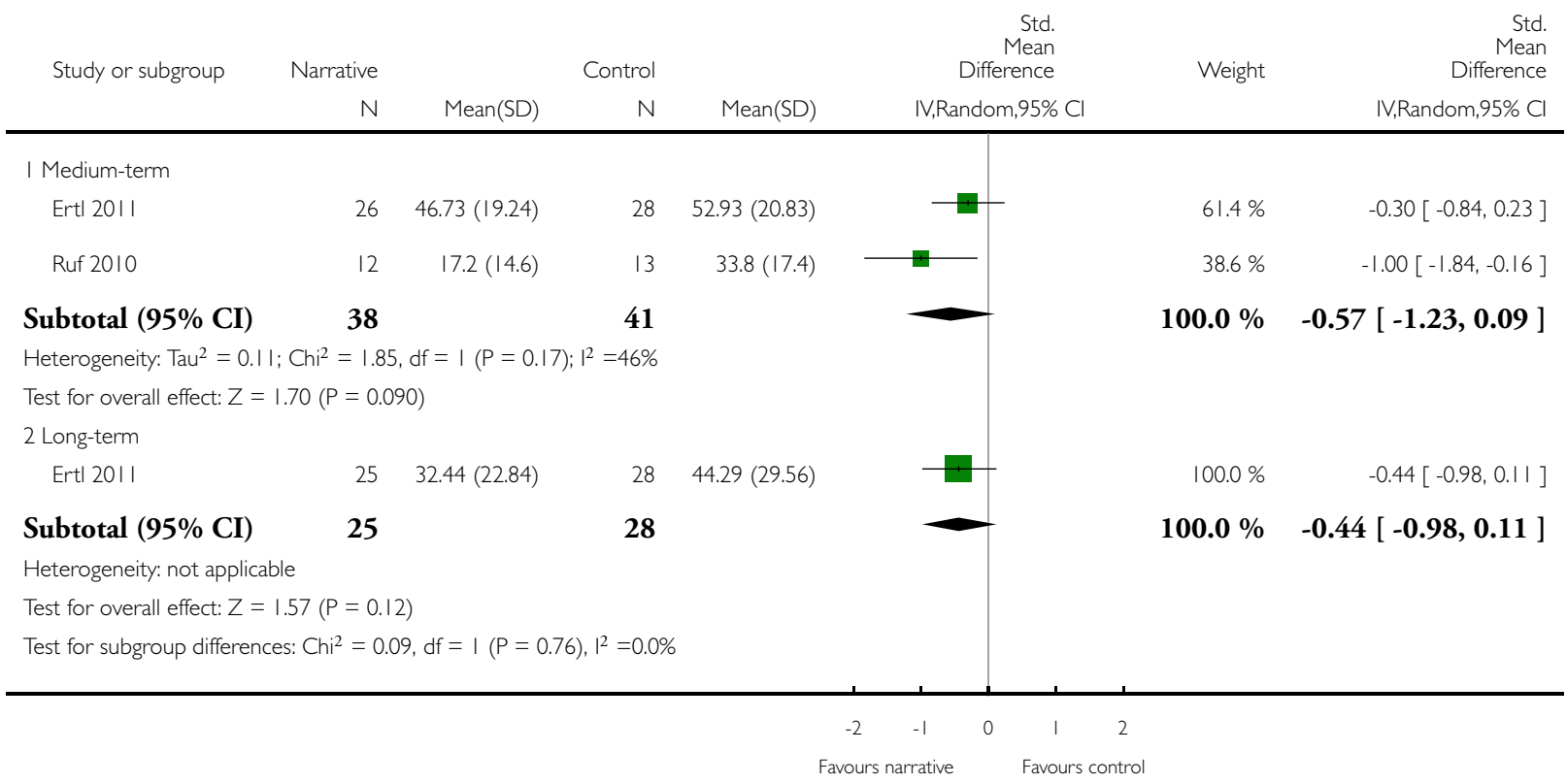




\section{Analysis 3.3. Comparison 3 Narrative versus control, Outcome 3 PTSD avoidance.}

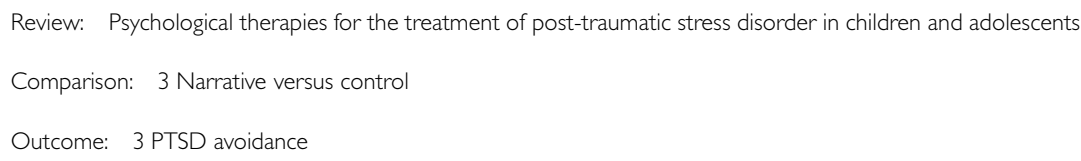

\begin{tabular}{|c|c|c|c|c|c|c|}
\hline \multirow[t]{2}{*}{ Study or subgroup } & \multirow{2}{*}{$\begin{array}{r}\text { Narrative } \\
N\end{array}$} & \multicolumn{3}{|c|}{ Control } & \multirow{2}{*}{$\begin{array}{r}\text { Std. } \\
\text { Mean } \\
\text { Difference } \\
\text { IV,Random,95\% Cl }\end{array}$} & \multirow{2}{*}{$\begin{array}{r}\text { Std. } \\
\text { Mean } \\
\text { Difference } \\
\text { IV,Random, } 95 \% \mathrm{Cl}\end{array}$} \\
\hline & & Mean(SD) & $\mathrm{N}$ & Mean(SD) & & \\
\hline \multicolumn{7}{|l|}{ I Medium-term } \\
\hline Ruf 2010 & 12 & $4.3(4.3)$ & 13 & $12.5(8.8)$ & + & $-1.13[-1.99,-0.27]$ \\
\hline
\end{tabular}

Analysis 3.4. Comparison 3 Narrative versus control, Outcome 4 PTSD hyperarousal.

Review: Psychological therapies for the treatment of post-traumatic stress disorder in children and adolescents

Comparison: 3 Narrative versus control

Outcome: 4 PTSD hyperarousal

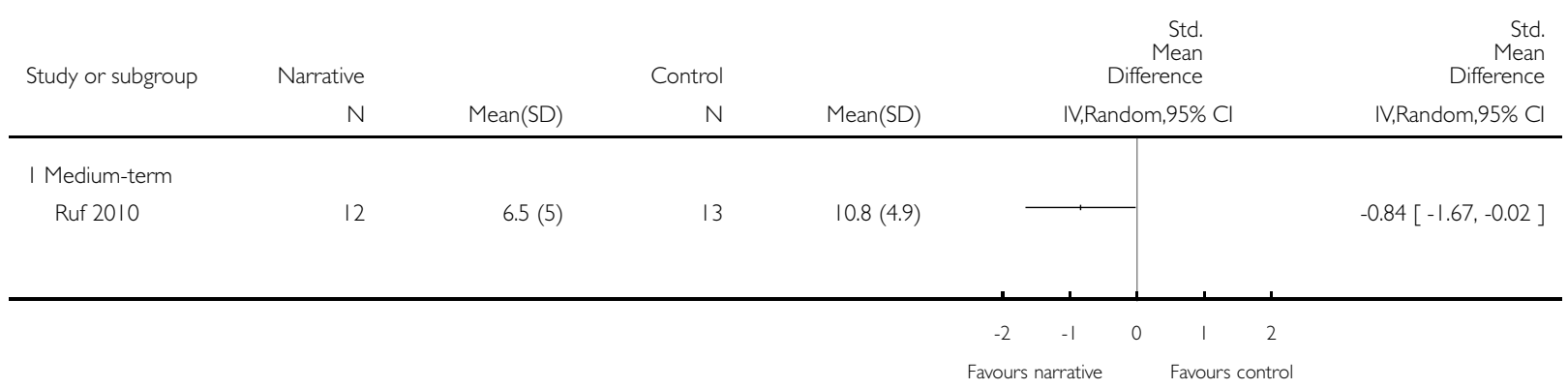




\section{Analysis 3.5. Comparison 3 Narrative versus control, Outcome 5 PTSD re-experiencing.}

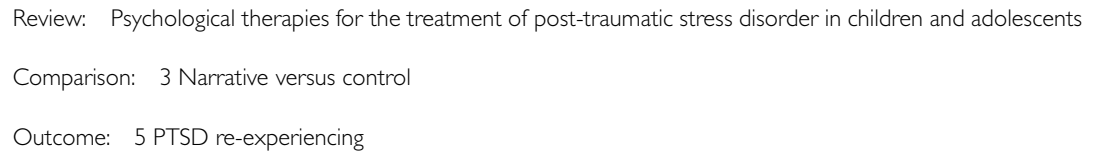

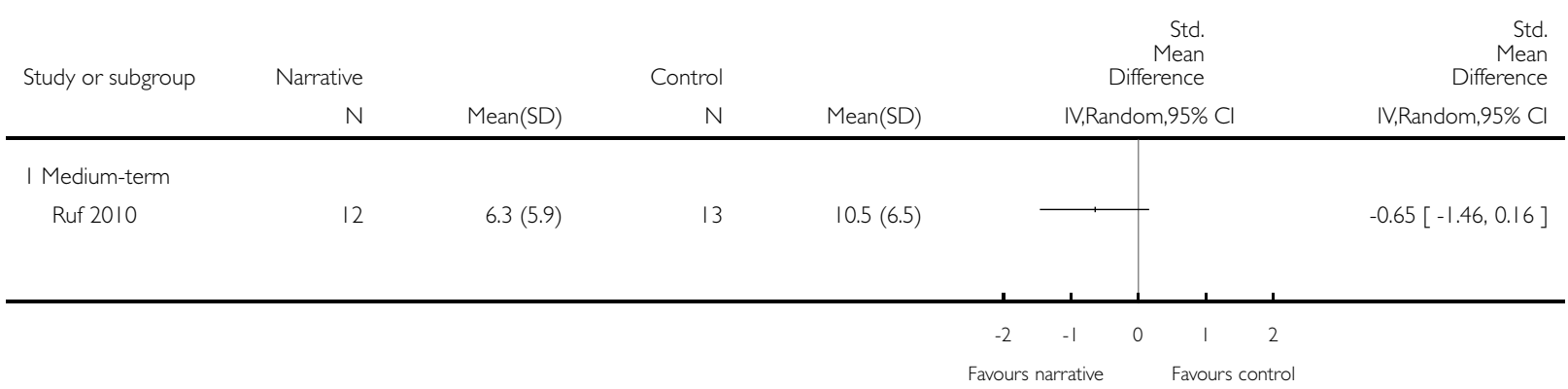

\section{Analysis 3.6. Comparison 3 Narrative versus control, Outcome 6 Depression.}

Review: Psychological therapies for the treatment of post-traumatic stress disorder in children and adolescents

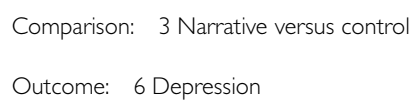

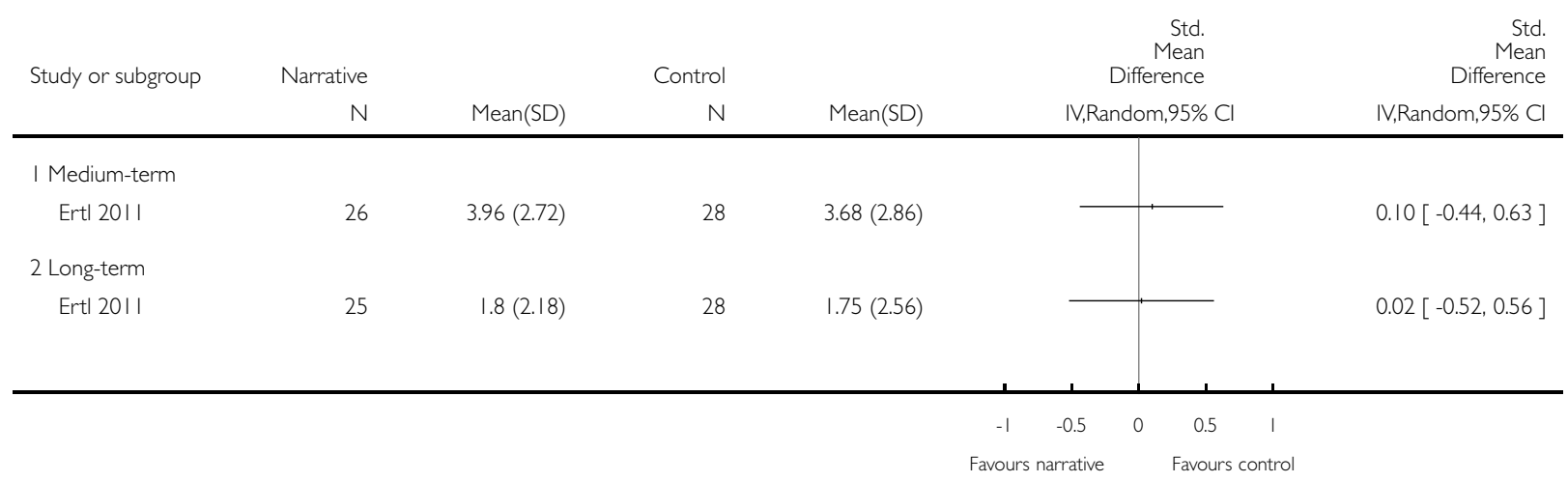




\section{Analysis 3.7. Comparison 3 Narrative versus control, Outcome 7 Loss to follow-up.}

Review: Psychological therapies for the treatment of post-traumatic stress disorder in children and adolescents

Comparison: 3 Narrative versus control

Outcome: 7 Loss to follow-up

Study or subgroup

Narrative

Control

Odds Ratio

H.Random $95 \%$

$\mathrm{n} / \mathrm{N}$

$\mathrm{n} / \mathrm{N}$

$\mathrm{Cl}$

Weight

Odds Ratio

$\mathrm{H}, \mathrm{Random}, 95 \%$

Cl

I Medium-term
Ertl 201।
Ruf 2010

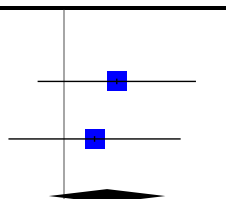

Subtotal $(95 \%$ CI $)$

42

$0 / 28$

$1 / 13$

$0 / 13$

41

Total events: 4 (Narrative), 0 (Control)

Heterogeneity: $\mathrm{Tau}^{2}=0.0 ; \mathrm{Chi}^{2}=0.14, \mathrm{df}=\mathrm{I}(\mathrm{P}=0.7 \mathrm{I}) ; \mathrm{I}^{2}=0.0 \%$

Test for overall effect: $Z=1.44(P=0.15)$

2 Long-term

Ertl 201।

$4 / 29$

$0 / 28$

Subtotal $(95 \%$ CI $)$

29

28

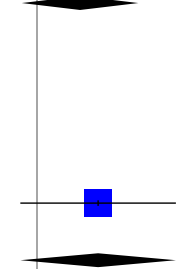

$54.5 \%$

$45.5 \%$

$100.0 \%$

$100.0 \%$

$10.06[0.52,196.10]$

Total events: 4 (Narrative), 0 (Control)

Heterogeneity: not applicable

Test for overall effect: $Z=1.52(P=0.13)$
$100.0 \%$

$10.06[0.52,196.10]$
$5.13[0.56,47.28]$

[0.37, I52.73]

$3.24[0.12,87.13]$ 


\section{Analysis 4.I. Comparison 4 EMDR versus control, Outcome I PTSD.}

Review: Psychological therapies for the treatment of post-traumatic stress disorder in children and adolescents

Comparison: 4 EMDR versus control

Outcome: I PTSD

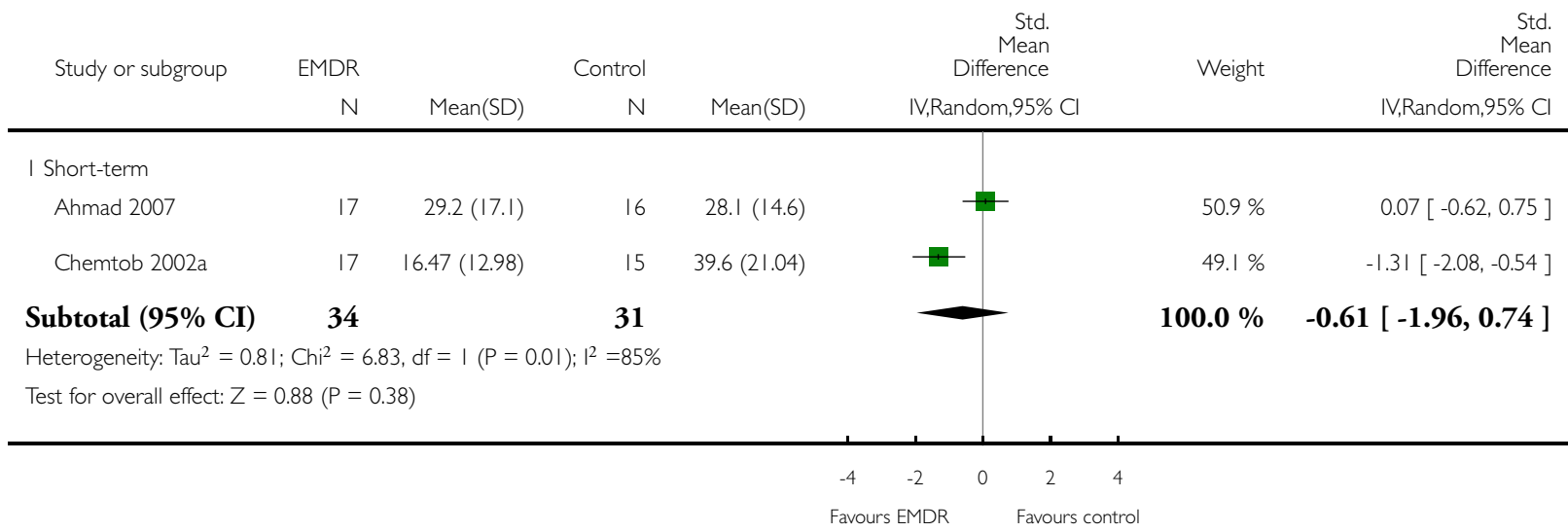

\section{Analysis 4.2. Comparison 4 EMDR versus control, Outcome 2 PTSD avoidance.}

Review: Psychological therapies for the treatment of post-traumatic stress disorder in children and adolescents

Comparison: 4 EMDR versus control

Outcome: 2 PTSD avoidance

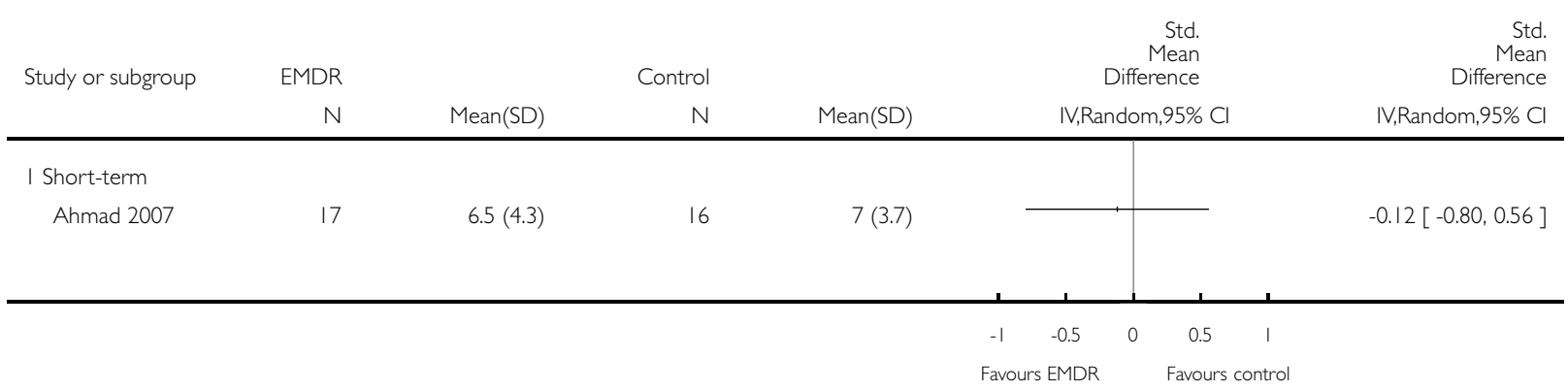




\section{Analysis 4.3. Comparison 4 EMDR versus control, Outcome 3 PTSD hyperarousal.}

Review: Psychological therapies for the treatment of post-traumatic stress disorder in children and adolescents

Comparison: 4 EMDR versus control

Outcome: 3 PTSD hyperarousal

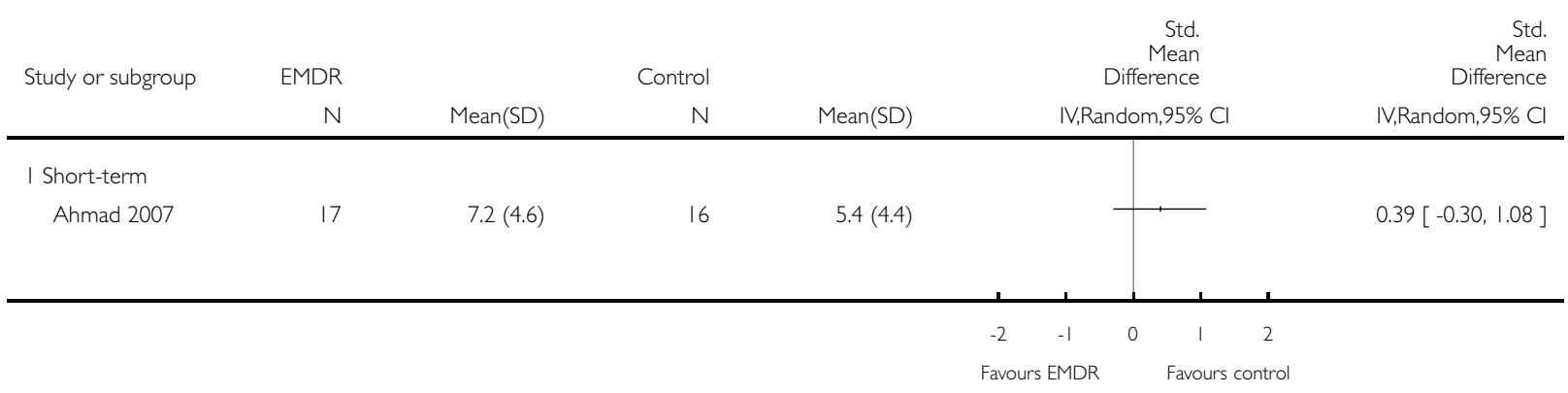

\section{Analysis 4.4. Comparison 4 EMDR versus control, Outcome 4 PTSD re-experiencing.}

Review: Psychological therapies for the treatment of post-traumatic stress disorder in children and adolescents

Comparison: 4 EMDR versus control

Outcome: 4 PTSD re-experiencing

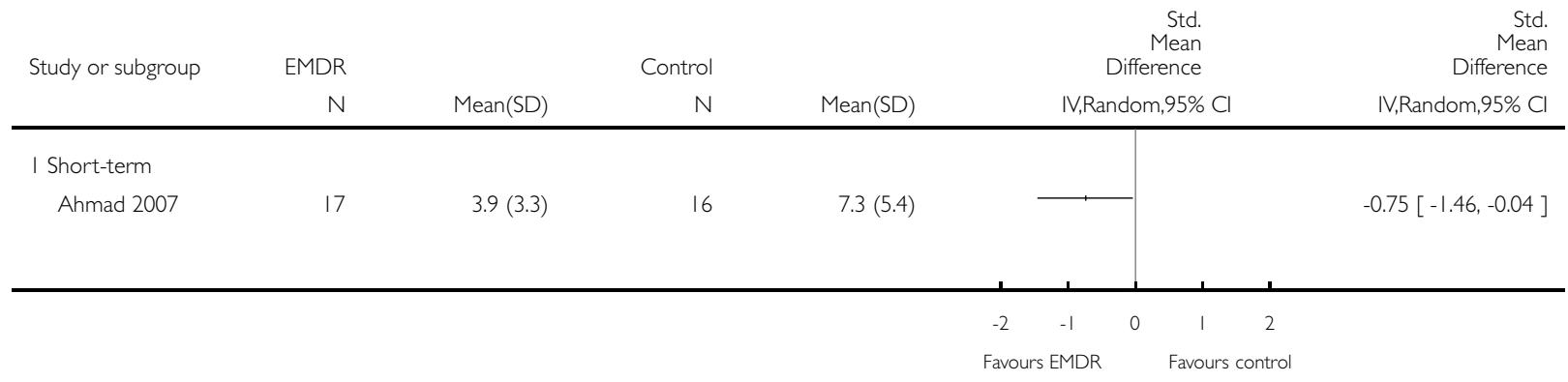




\section{Analysis 4.5. Comparison 4 EMDR versus control, Outcome 5 Anxiety.}

Review: Psychological therapies for the treatment of post-traumatic stress disorder in children and adolescents

Comparison: 4 EMDR versus control

Outcome: 5 Anxiety

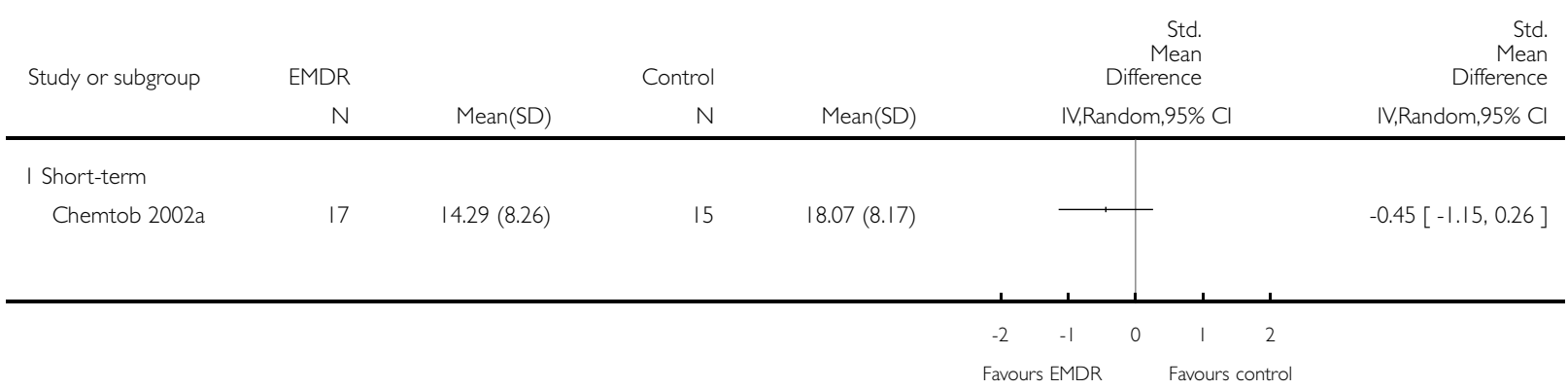

\section{Analysis 4.6. Comparison 4 EMDR versus control, Outcome 6 Depression.}

Review: Psychological therapies for the treatment of post-traumatic stress disorder in children and adolescents

Comparison: 4 EMDR versus control

Outcome: 6 Depression

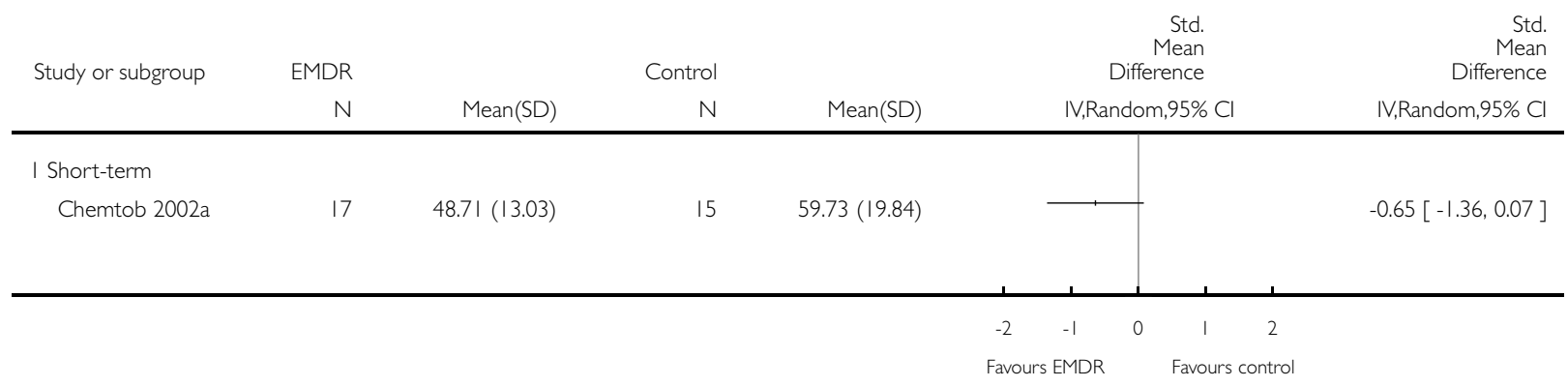




\section{Analysis 4.7. Comparison 4 EMDR versus control, Outcome 7 Loss to follow-up.}

Review: Psychological therapies for the treatment of post-traumatic stress disorder in children and adolescents

Comparison: 4 EMDR versus control

Outcome: 7 Loss to follow-up

Study or subgroup

EMDR

Control

Odds Ratio

M-

$\mathrm{n} / \mathrm{N} / \mathrm{N}$

H,Random,95\%

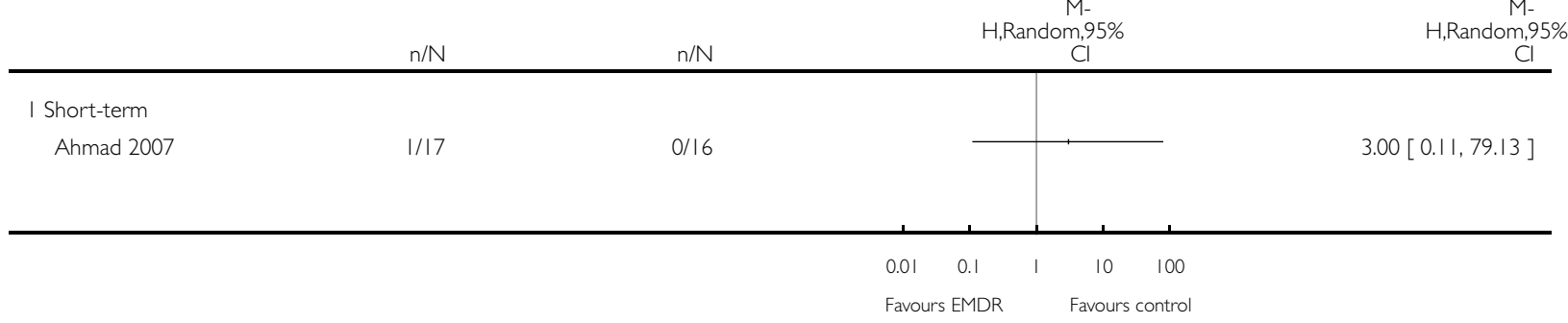

Analysis 5.I. Comparison 5 Other psychological therapies versus control, Outcome I PTSD total.

Review: Psychological therapies for the treatment of post-traumatic stress disorder in children and adolescents

Comparison: 5 Other psychological therapies versus control

Outcome: I PTSD total

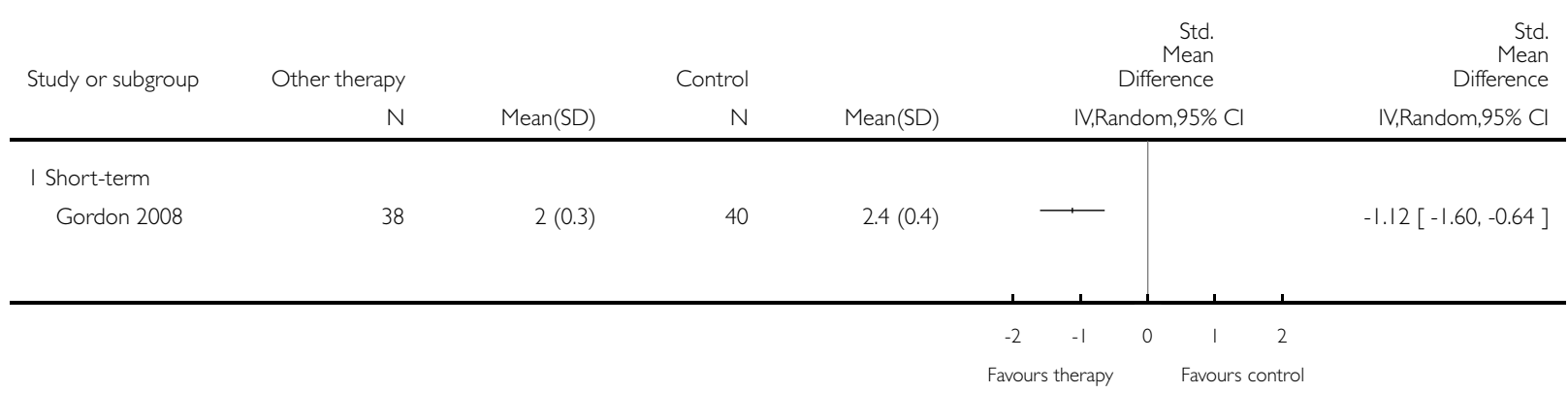




\section{Analysis 5.2. Comparison 5 Other psychological therapies versus control, Outcome 2 PTSD avoidance.}

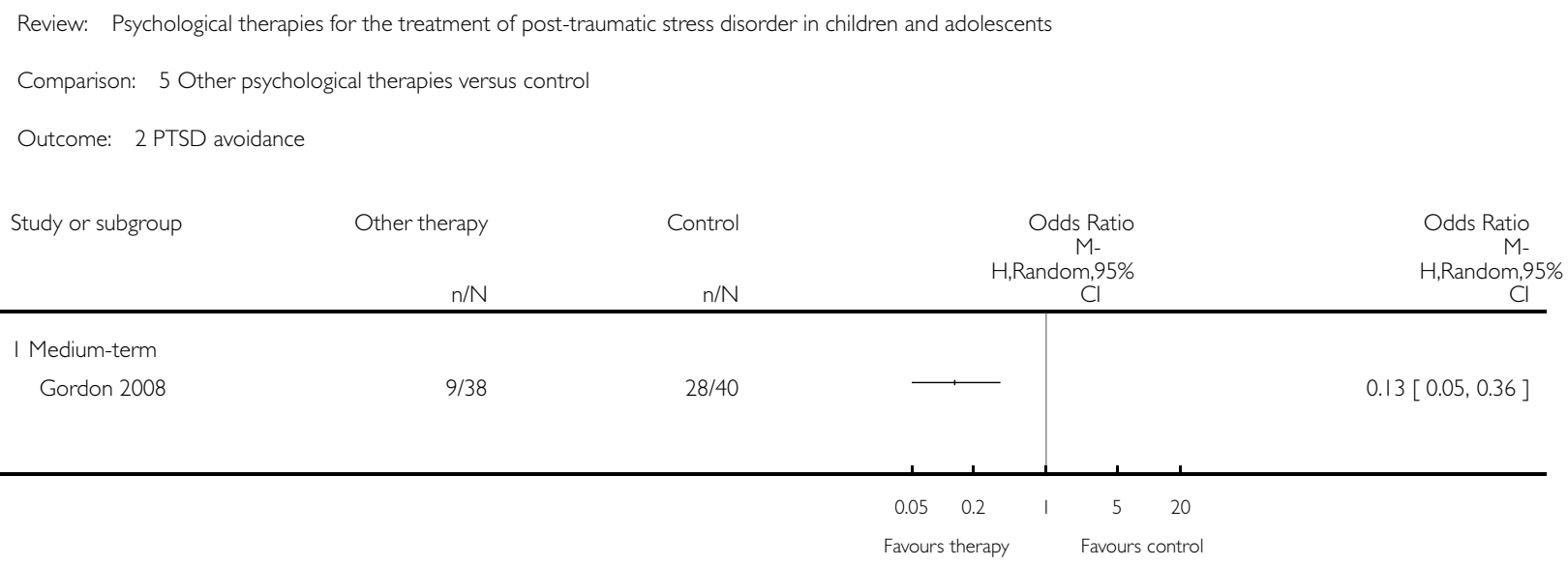

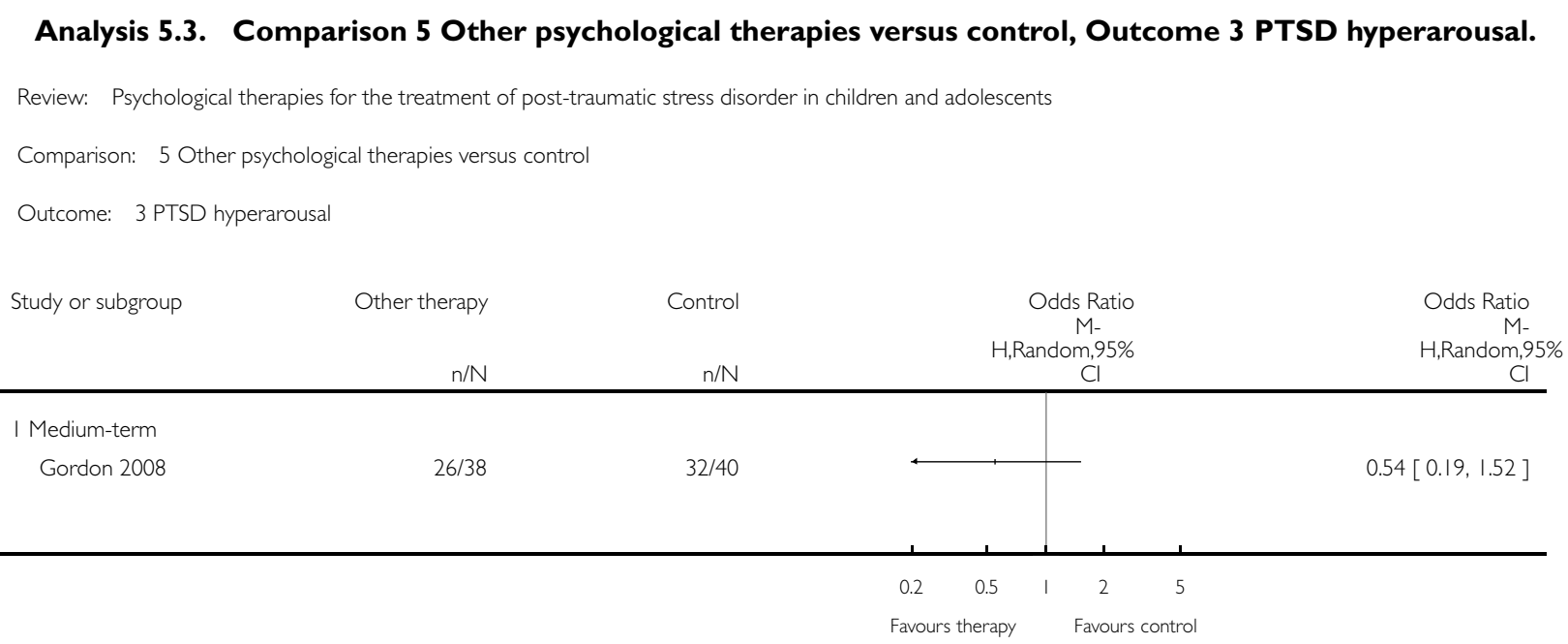


Analysis 5.4. Comparison 5 Other psychological therapies versus control, Outcome 4 PTSD reexperiencing.

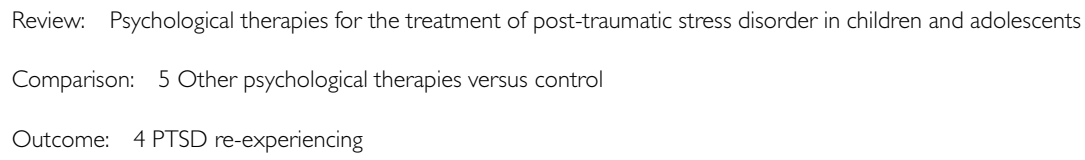

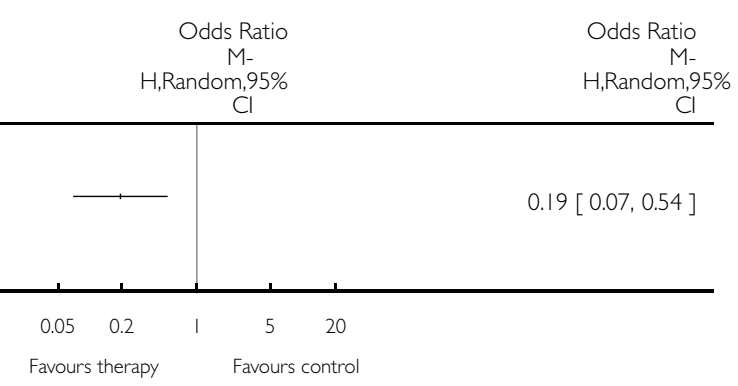

\section{Analysis 5.5. Comparison 5 Other psychological therapies versus control, Outcome 5 Depression.}

Review: Psychological therapies for the treatment of post-traumatic stress disorder in children and adolescents

Comparison: 5 Other psychological therapies versus control

Outcome: 5 Depression

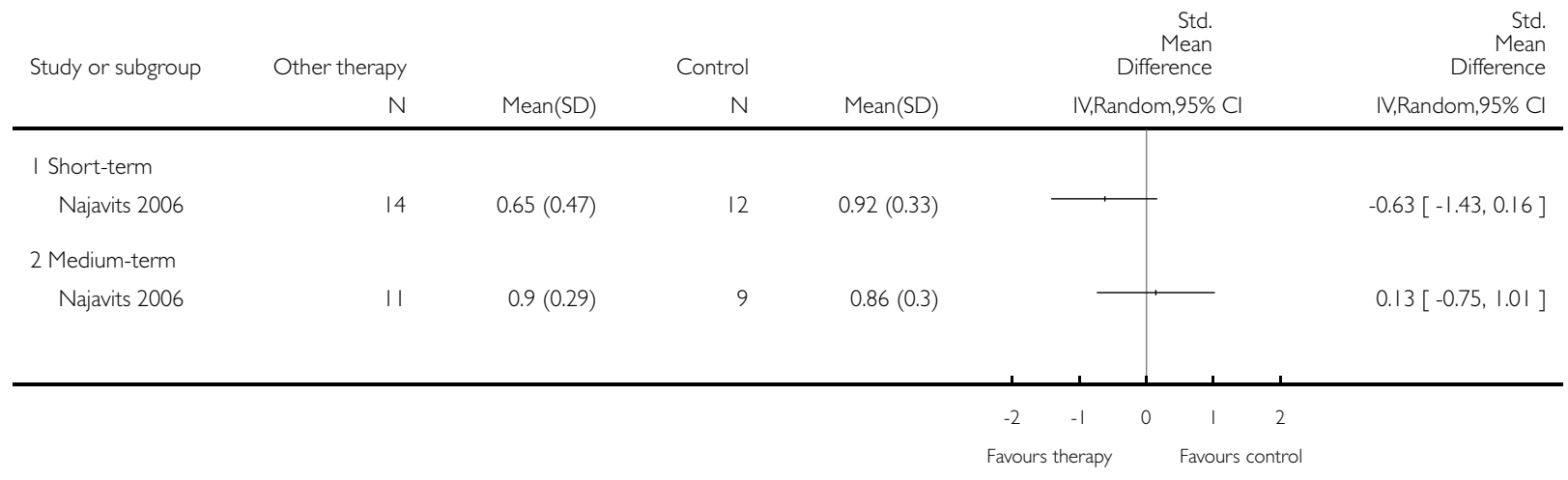




\section{Analysis 5.6. Comparison 5 Other psychological therapies versus control, Outcome 6 Loss to follow-up.}

Review: Psychological therapies for the treatment of post-traumatic stress disorder in children and adolescents

Comparison: 5 Other psychological therapies versus control

Outcome: 6 Loss to follow-up

Study or subgroup Other therapy Control

Odds Ratio

M-

Weight

Odds Ratio

$\mathrm{H}$, Random, $95 \%$

$\mathrm{n} / \mathrm{N} \quad \mathrm{n} / \mathrm{N}$

$\mathrm{Cl}$

$\mathrm{Cl}$

I Short-term

Gordon 2008

2/41

$|/ 4|$

$\longrightarrow$

56

59

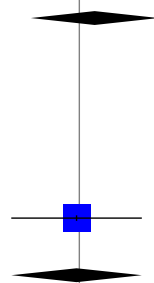

$32.2 \%$

$2.05[0.18,23.55]$

Najavits 2006

59

Total events: 6 (Other therapy), 4 (Control)

Heterogeneity: $\mathrm{Tau}^{2}=0.0 ; \mathrm{Chi}^{2}=0.15, \mathrm{df}=\mathrm{I}(\mathrm{P}=0.70) ; \mathrm{I}^{2}=0.0 \%$

Test for overall effect: $Z=0.46(P=0.65)$

2 Medium-term

Najavits 2006

Total events: 7 (Other therapy), 6 (Control)

Heterogeneity: not applicable

Test for overall effect: $Z=0.07(P=0.95)$

\begin{tabular}{ccccc}
0.05 & 0.2 & I & 5 & 20 \\
Favours therapy & & \multicolumn{3}{c}{ Favours control }
\end{tabular}

$100.0 \%$

$0.95[0.23,3.88]$
$1.14[0.21,6.16]$

$100.0 \%$

$1.38[0.35,5.52]$

$100.0 \%$

$0.95[0.23,3.88$ ] 


\section{Analysis 6.I. Comparison 6 CBT versus supportive counselling, Outcome I Improvement.}

Review: Psychological therapies for the treatment of post-traumatic stress disorder in children and adolescents

Comparison: 6 CBT versus supportive counselling

Outcome: I Improvement

\begin{tabular}{|c|c|c|c|c|c|}
\hline Study or subgroup & $\begin{array}{l}\mathrm{CBT} \\
\mathrm{n} / \mathrm{N}\end{array}$ & $\begin{array}{r}\text { Supportive } \\
\text { counselling } \\
n / N\end{array}$ & $\begin{array}{c}\text { Odds Ratio } \\
\text { M- } \\
\text { H,Random,95\% } \\
\mathrm{Cl}\end{array}$ & Weight & $\begin{array}{c}\text { Odds Ratio } \\
\text { M- } \\
\text { H,Random,95\% } \\
\text { Cl }\end{array}$ \\
\hline \multicolumn{6}{|l|}{ I Short-term } \\
\hline Cohen 2004 & $56 / 75$ & $41 / 83$ & & $76.7 \%$ & $3.02[1.54,5.93]$ \\
\hline Cohen 2011 & $24 / 32$ & $8 / 18$ & 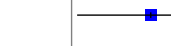 & $23.3 \%$ & $3.75[1.10,12.79]$ \\
\hline Subtotal $(95 \% \mathrm{CI})$ & 107 & 101 & & $100.0 \%$ & $3.18[1.76,5.74]$ \\
\hline \multicolumn{6}{|c|}{ Total events: 80 (CBT), 49 (Supportive counselling) } \\
\hline \multicolumn{6}{|c|}{ Heterogeneity: Tau $^{2}=0.0 ; \mathrm{Chi}^{2}=0.09, \mathrm{df}=\mathrm{I}(\mathrm{P}=0.76) ;\left.\right|^{2}=0.0 \%$} \\
\hline \multicolumn{6}{|c|}{ Test for overall effect: $Z=3.83(P=0.00013)$} \\
\hline Test for subgroup differen & applicable & & & & \\
\hline
\end{tabular}

$\begin{array}{lllllll}0.1 & 0.2 & 0.5 & 1 & 2 & 5 & 10\end{array}$

Favours counselling Favours CBT 


\section{Analysis 6.2. Comparison 6 CBT versus supportive counselling, Outcome 2 PTSD avoidance.}

Review: Psychological therapies for the treatment of post-traumatic stress disorder in children and adolescents

Comparison: 6 CBT versus supportive counselling

Outcome: 2 PTSD avoidance

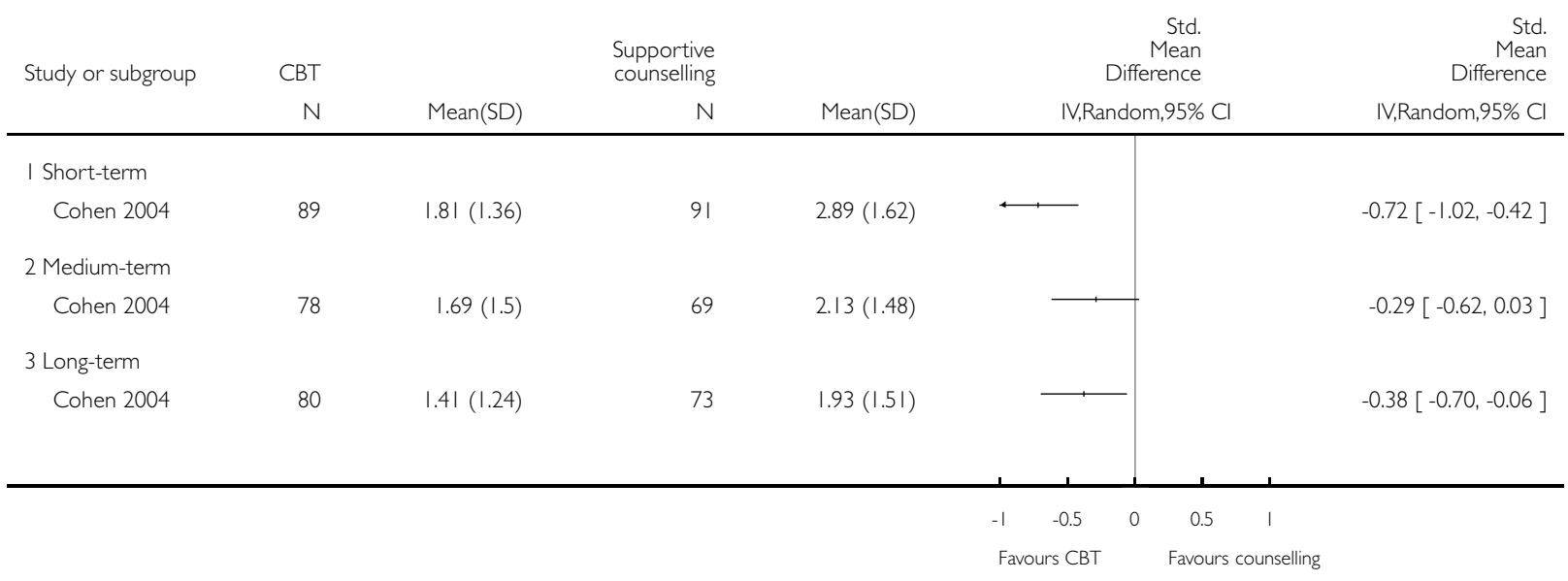

Analysis 6.3. Comparison 6 CBT versus supportive counselling, Outcome 3 PTSD hyperarousal.

Review: Psychological therapies for the treatment of post-traumatic stress disorder in children and adolescents

Comparison: 6 CBT versus supportive counselling

Outcome: 3 PTSD hyperarousal

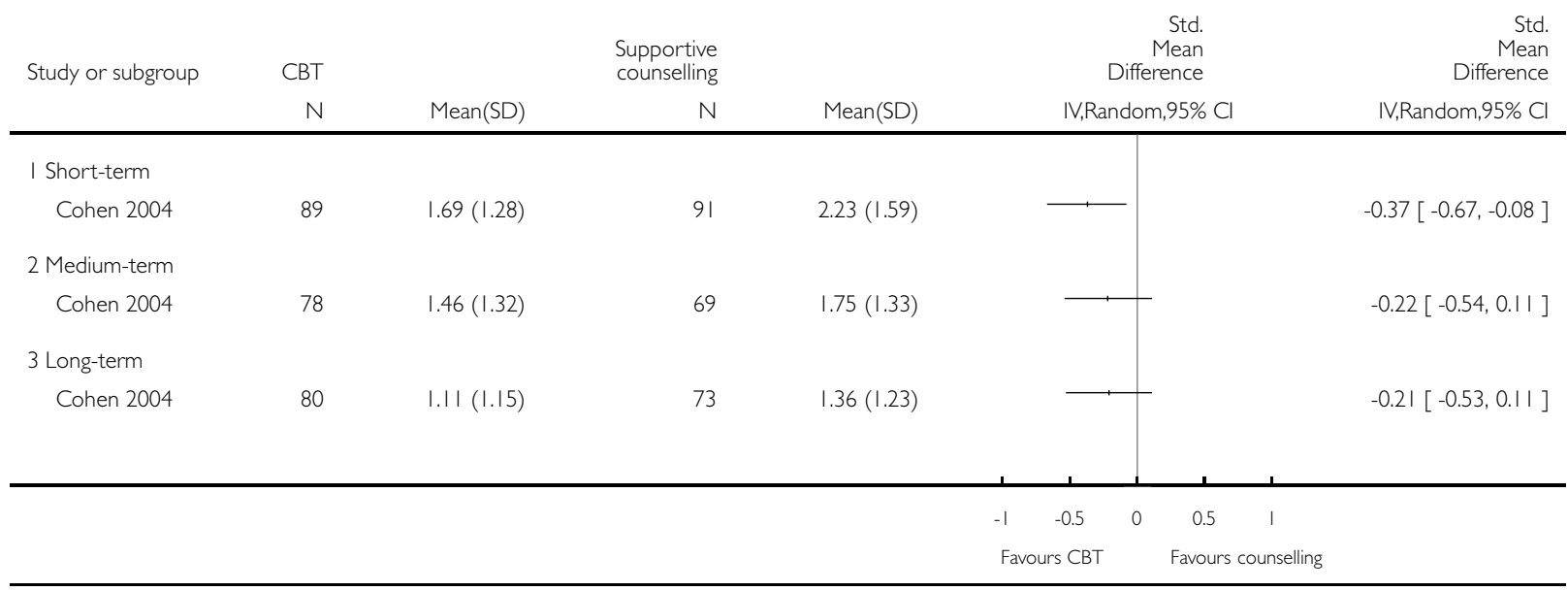

Psychological therapies for the treatment of post-traumatic stress disorder in children and adolescents (Review)

Copyright (c) 2012 The Cochrane Collaboration. Published by John Wiley \& Sons, Ltd. 


\section{Analysis 6.4. Comparison 6 CBT versus supportive counselling, Outcome 4 PTSD re-experiencing.}

Review: Psychological therapies for the treatment of post-traumatic stress disorder in children and adolescents

Comparison: 6 CBT versus supportive counselling

Outcome: 4 PTSD re-experiencing

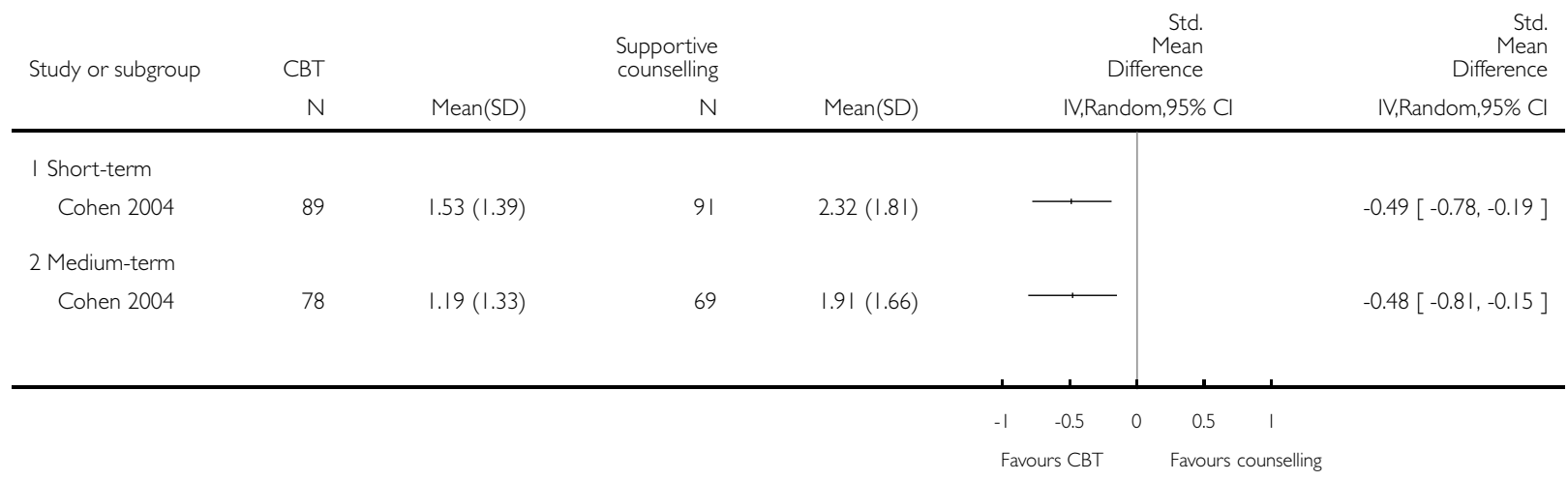

Psychological therapies for the treatment of post-traumatic stress disorder in children and adolescents (Review) 


\section{Analysis 6.5. Comparison 6 CBT versus supportive counselling, Outcome 5 Anxiety state.}

Review: Psychological therapies for the treatment of post-traumatic stress disorder in children and adolescents

Comparison: 6 CBT versus supportive counselling

Outcome: 5 Anxiety state

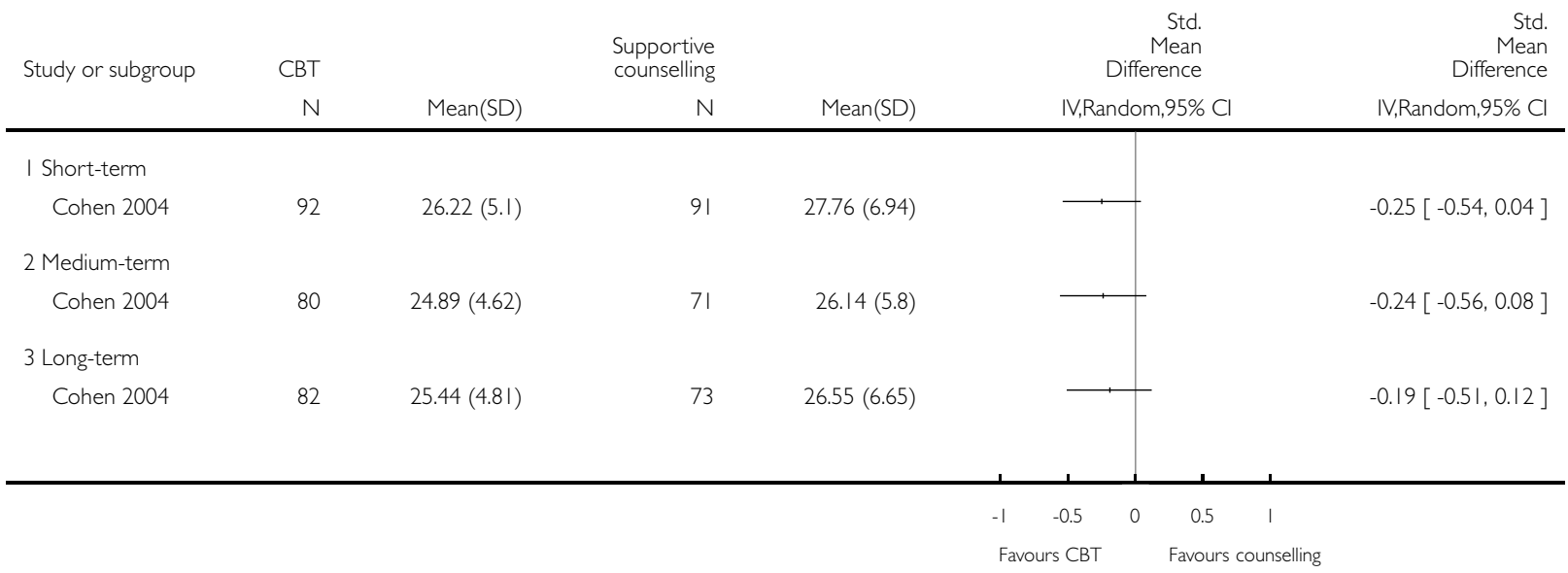




\section{Analysis 6.6. Comparison 6 CBT versus supportive counselling, Outcome 6 Anxiety trait.}

Review: Psychological therapies for the treatment of post-traumatic stress disorder in children and adolescents

Comparison: 6 CBT versus supportive counselling

Outcome: 6 Anxiety trait

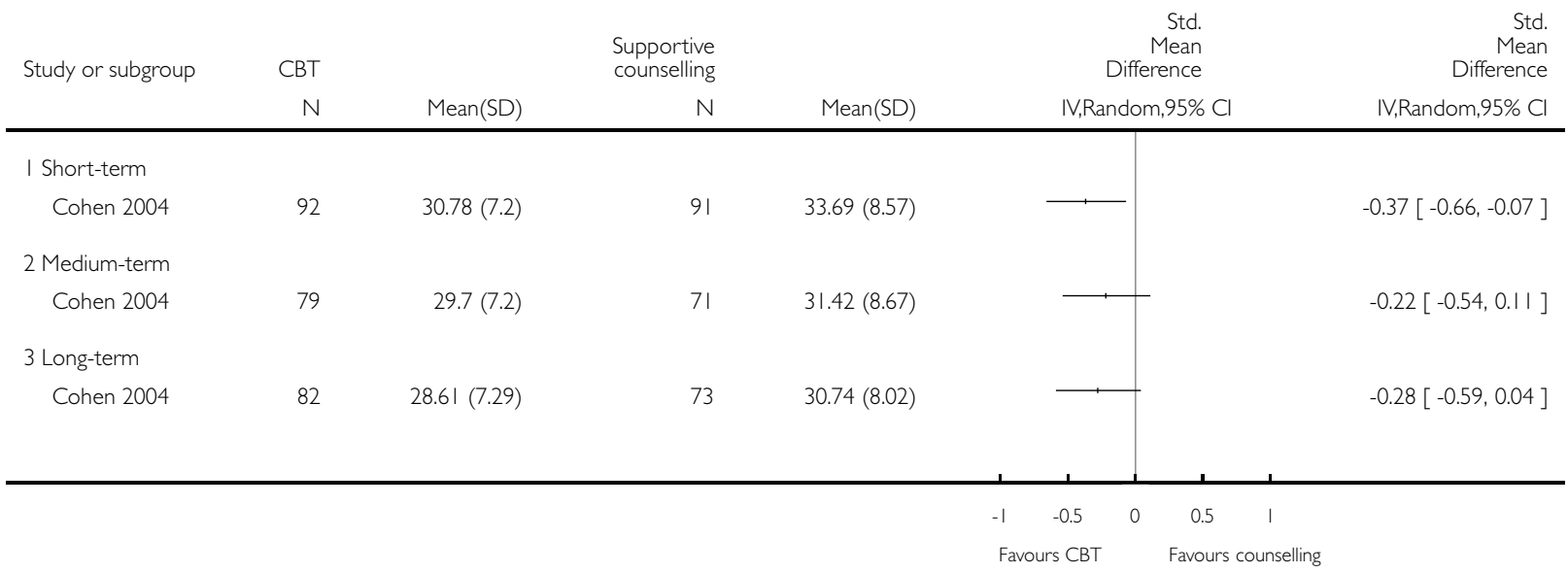

Analysis 6.7. Comparison 6 CBT versus supportive counselling, Outcome 7 Depression.

Review: Psychological therapies for the treatment of post-traumatic stress disorder in children and adolescents

Comparison: 6 CBT versus supportive counselling

Outcome: 7 Depression

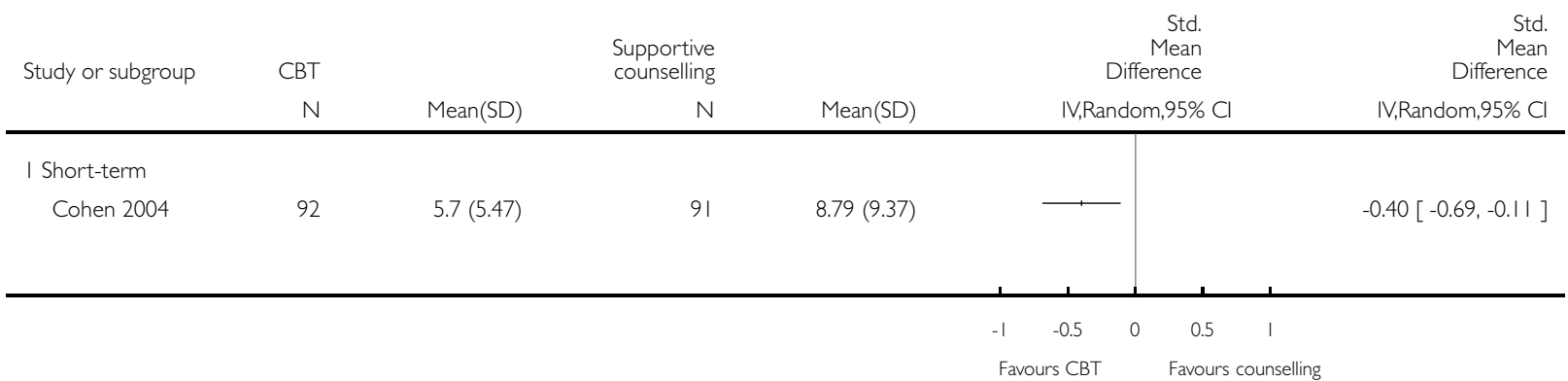




\section{Analysis 6.8. Comparison 6 CBT versus supportive counselling, Outcome 8 Behaviour.}

Review: Psychological therapies for the treatment of post-traumatic stress disorder in children and adolescents

Comparison: 6 CBT versus supportive counselling

Outcome: 8 Behaviour

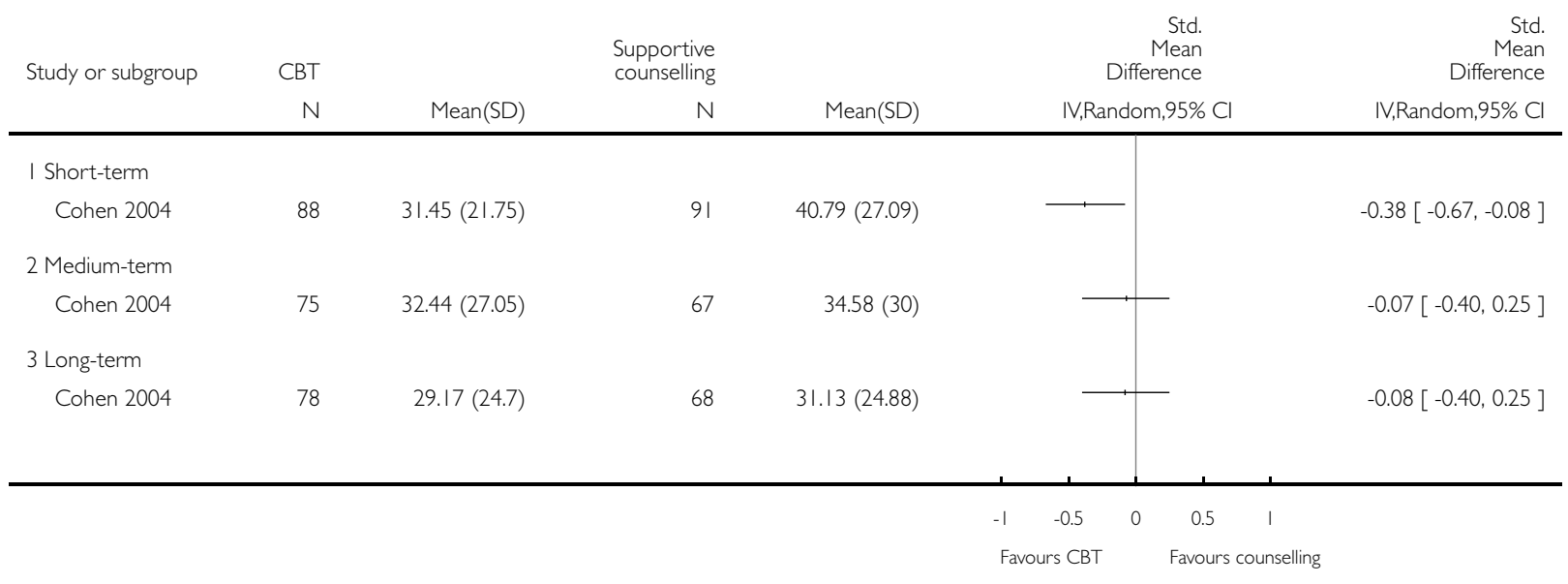




\section{Analysis 6.9. Comparison 6 CBT versus supportive counselling, Outcome 9 Loss to follow-up.}

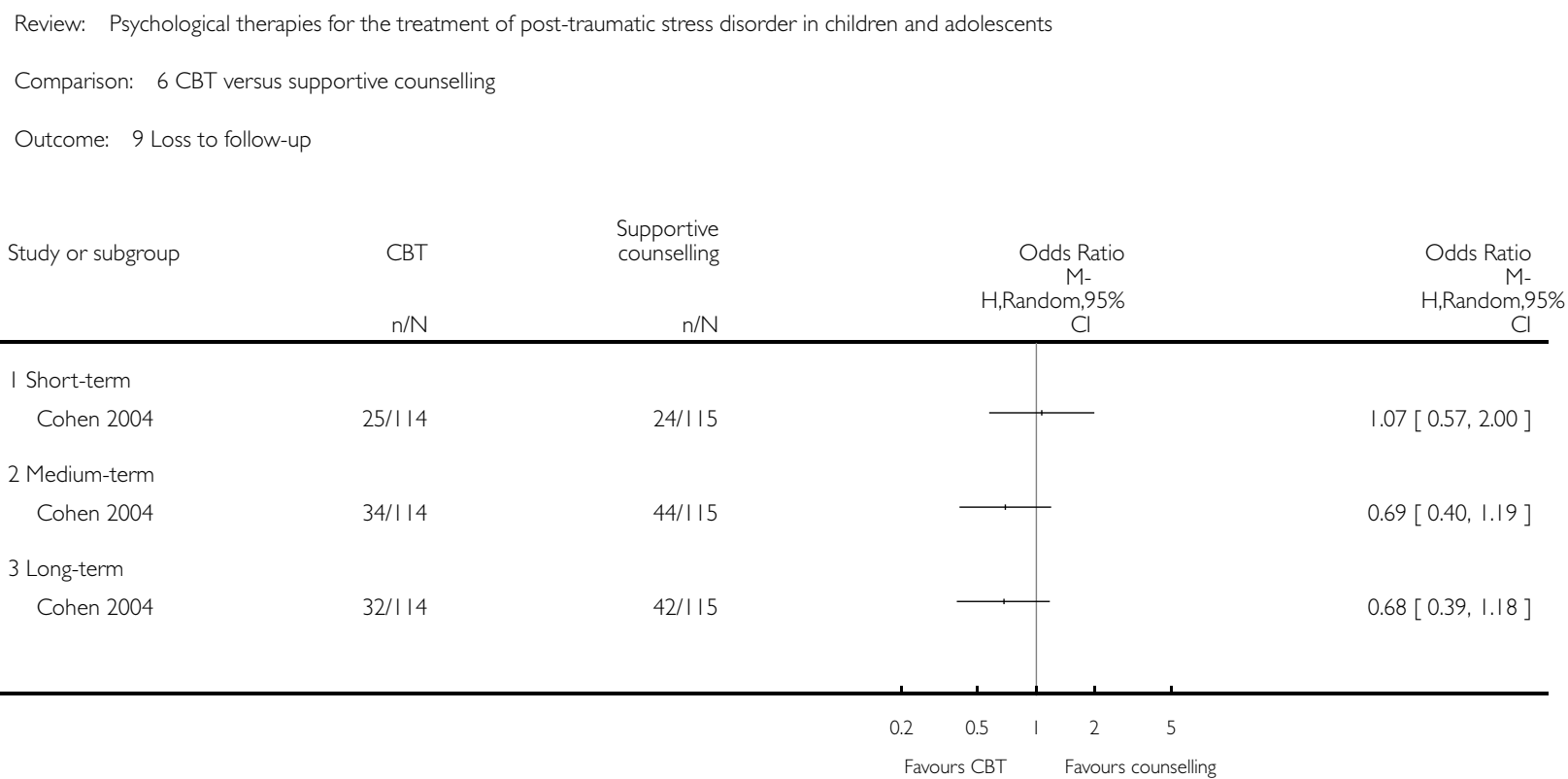

Analysis 7.I. Comparison 7 Narrative versus supportive counselling, Outcome I Improvement.

Review: Psychological therapies for the treatment of post-traumatic stress disorder in children and adolescents

Comparison: 7 Narrative versus supportive counselling

Outcome: I Improvement

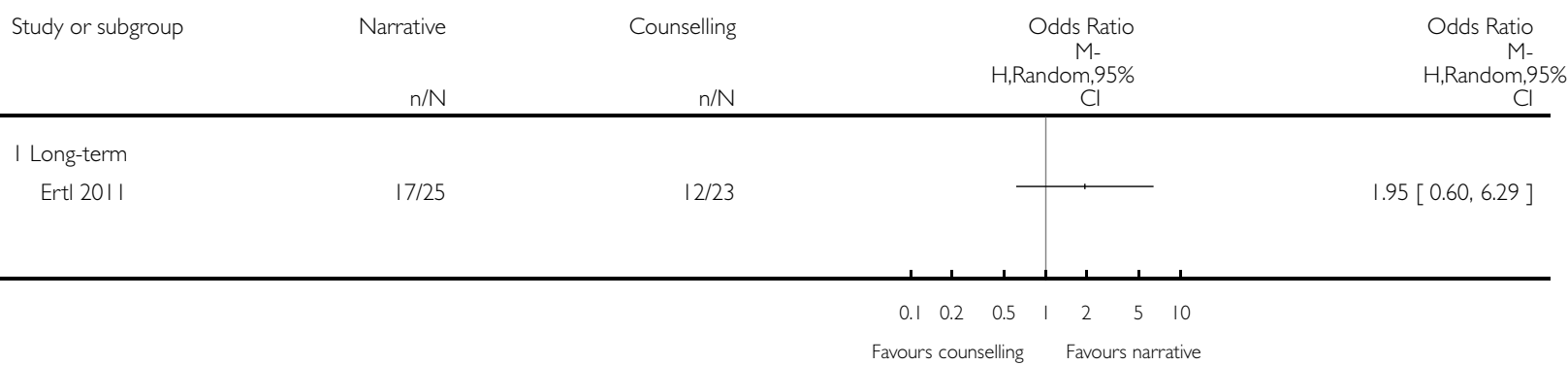




\section{Analysis 7.2. Comparison 7 Narrative versus supportive counselling, Outcome 2 PTSD total.}

Review: Psychological therapies for the treatment of post-traumatic stress disorder in children and adolescents

Comparison: 7 Narrative versus supportive counselling

Outcome: 2 PTSD total

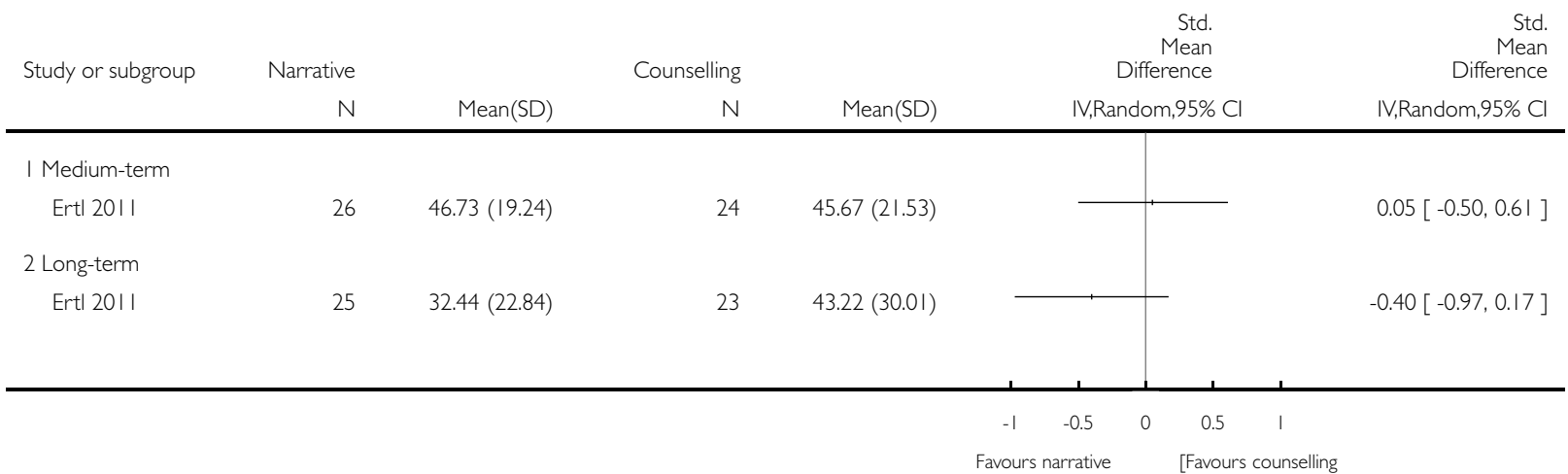

Analysis 7.3. Comparison 7 Narrative versus supportive counselling, Outcome 3 Depression.

Review: Psychological therapies for the treatment of post-traumatic stress disorder in children and adolescents

Comparison: 7 Narrative versus supportive counselling

Outcome: 3 Depression

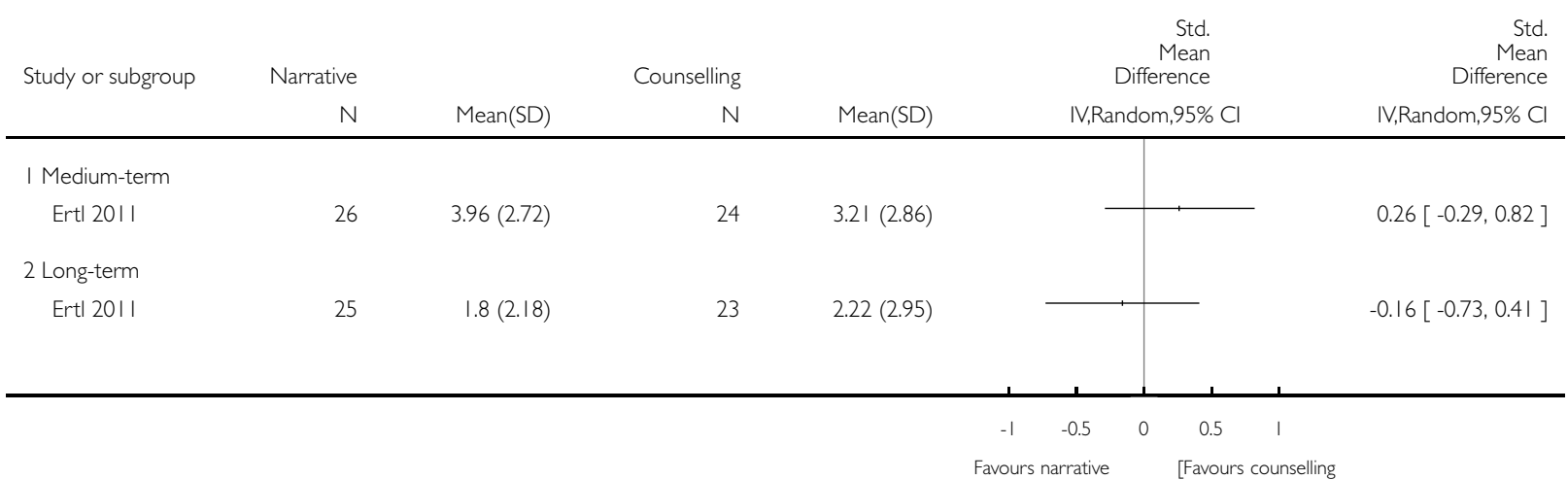




\section{Analysis 7.4. Comparison 7 Narrative versus supportive counselling, Outcome 4 Loss to follow-up.}

Review: Psychological therapies for the treatment of post-traumatic stress disorder in children and adolescents

Comparison: 7 Narrative versus supportive counselling

Outcome: 4 Loss to follow-up

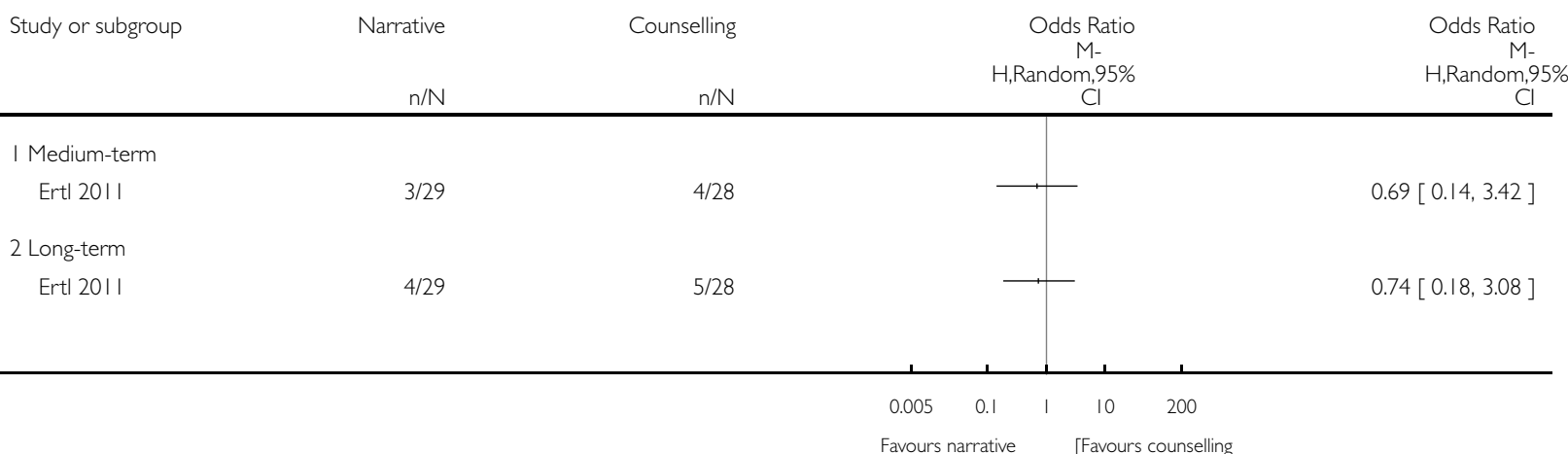




\section{Analysis 8.I. Comparison 8 Narrative versus meditation/relaxation, Outcome I Improvement.}

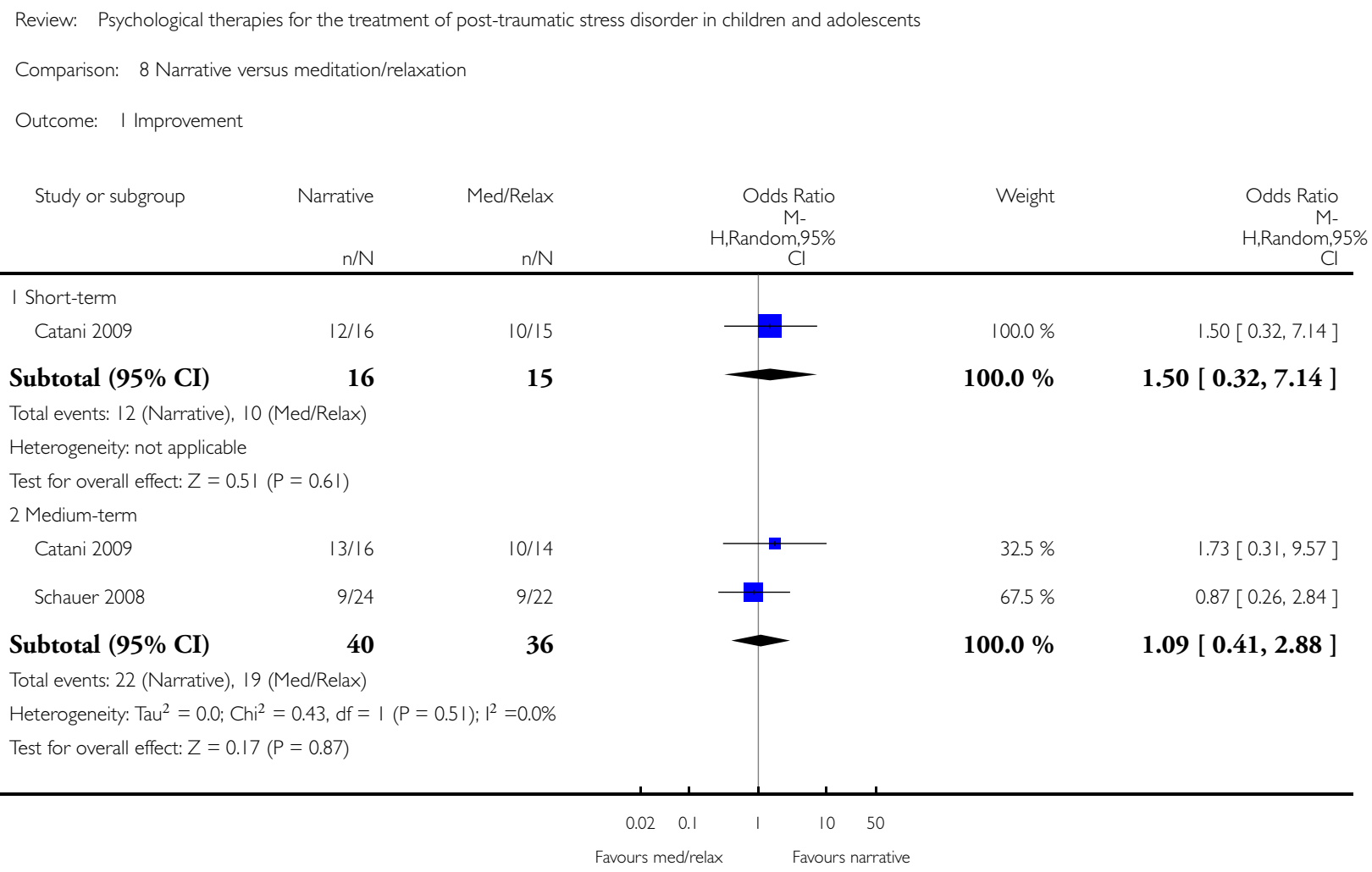




\section{Analysis 8.2. Comparison 8 Narrative versus meditation/relaxation, Outcome 2 PTSD total.}

Review: Psychological therapies for the treatment of post-traumatic stress disorder in children and adolescents

Comparison: 8 Narrative versus meditation/relaxation

Outcome: 2 PTSD total

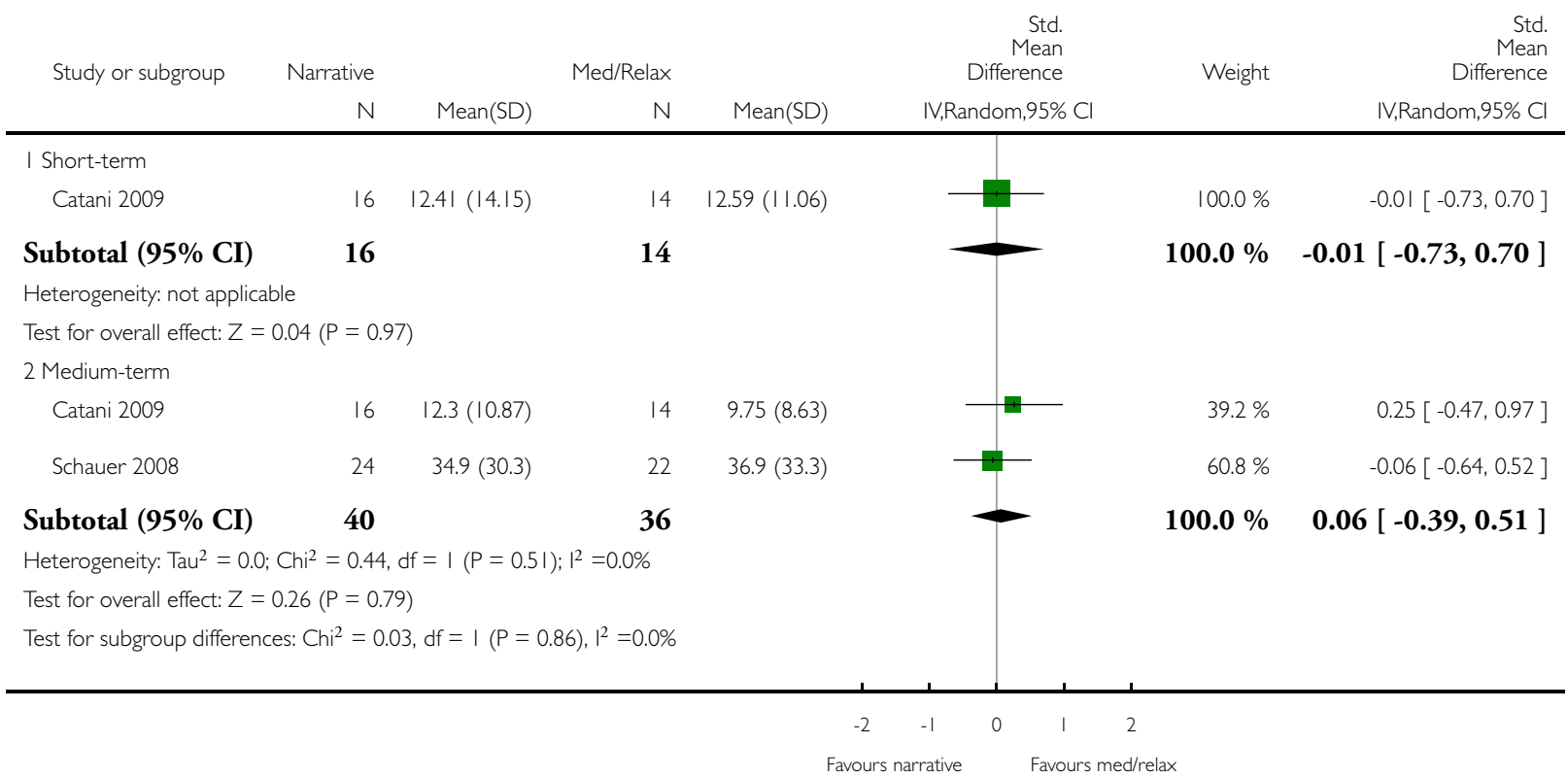




\section{Analysis 8.3. Comparison 8 Narrative versus meditation/relaxation, Outcome 3 Loss to follow-up.}

Review: Psychological therapies for the treatment of post-traumatic stress disorder in children and adolescents

Comparison: 8 Narrative versus meditation/relaxation

Outcome: 3 Loss to follow-up

Study or subgroup

Narrative

Med/Relax

Odds Ratio

M-

H.Random, $95 \%$

Weight

Odds Ratio

H,Random, $95 \%$

$\mathrm{n} / \mathrm{N}$

$\mathrm{n} / \mathrm{N}$

I Short-term

$0 / 16$

Catani 2009

16

Subtotal (95\% CI)

Total events: 0 (Narrative), 0 (Med/Relax)

Heterogeneity: not applicable

Test for overall effect: not applicable

2 Medium-term

Catani 2009

Schauer 2008

$0 / 16$

$0 / 25$

41
$0 / 15$

15

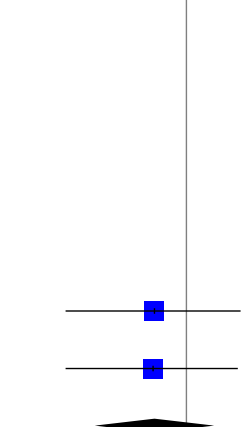

37
$1 / 15$

$1 / 22$

Subtotal (95\% CI)

Total events: 0 (Narrative), 2 (Med/Relax)

Heterogeneity: $\operatorname{Tau}^{2}=0.0 ; \mathrm{Chi}^{2}=0.00, \mathrm{df}=\mathrm{I}(\mathrm{P}=0.99) ; \mathrm{I}^{2}=0.0 \%$

Test for overall effect: $Z=1.06(P=0.29)$

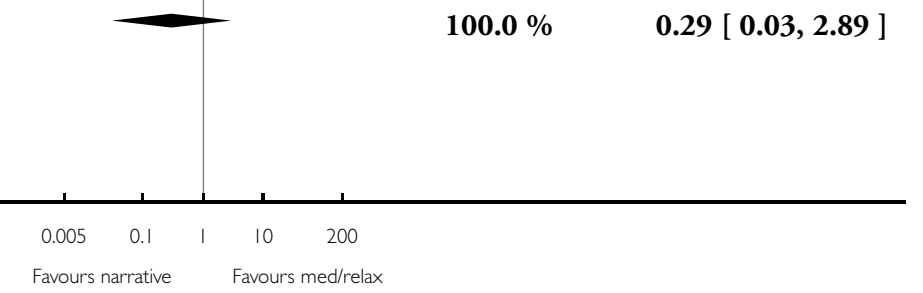


Analysis 9.1. Comparison 9 Exposure versus interpersonal therapy, Outcome I Improvement.

Review: Psychological therapies for the treatment of post-traumatic stress disorder in children and adolescents

Comparison: 9 Exposure versus interpersonal therapy

Outcome: I Improvement

Study or subgroup

Exposure

Interpersonal

Odds Ratio

H,Random,95\%

$\mathrm{n} / \mathrm{N}$

$\mathrm{n} / \mathrm{N}$

Odds Ratio

$\mathrm{H}$, Random,95\%

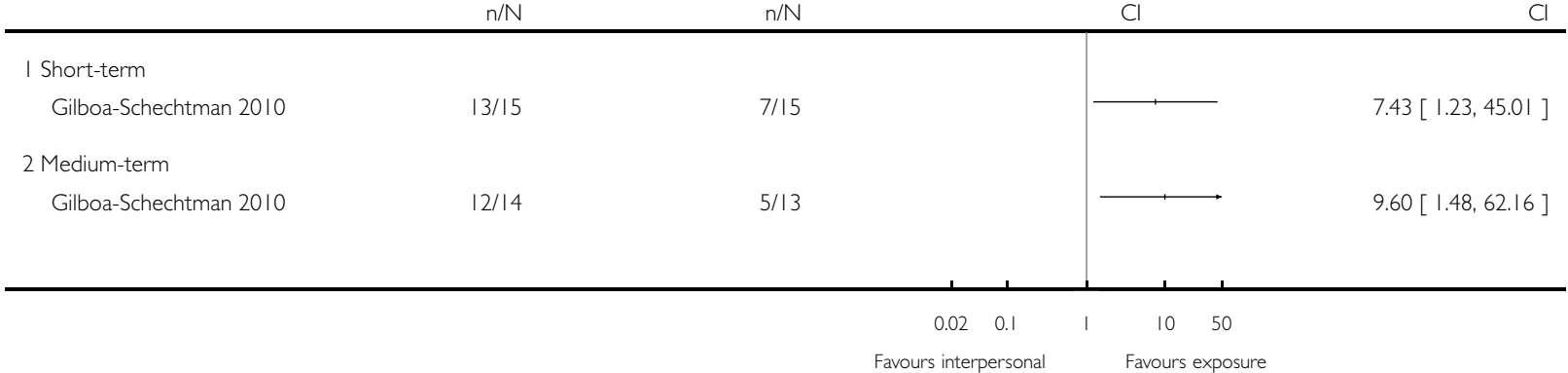

Analysis 9.2. Comparison 9 Exposure versus interpersonal therapy, Outcome 2 PTSD total.

Review: Psychological therapies for the treatment of post-traumatic stress disorder in children and adolescents

Comparison: 9 Exposure versus interpersonal therapy

Outcome: 2 PTSD total

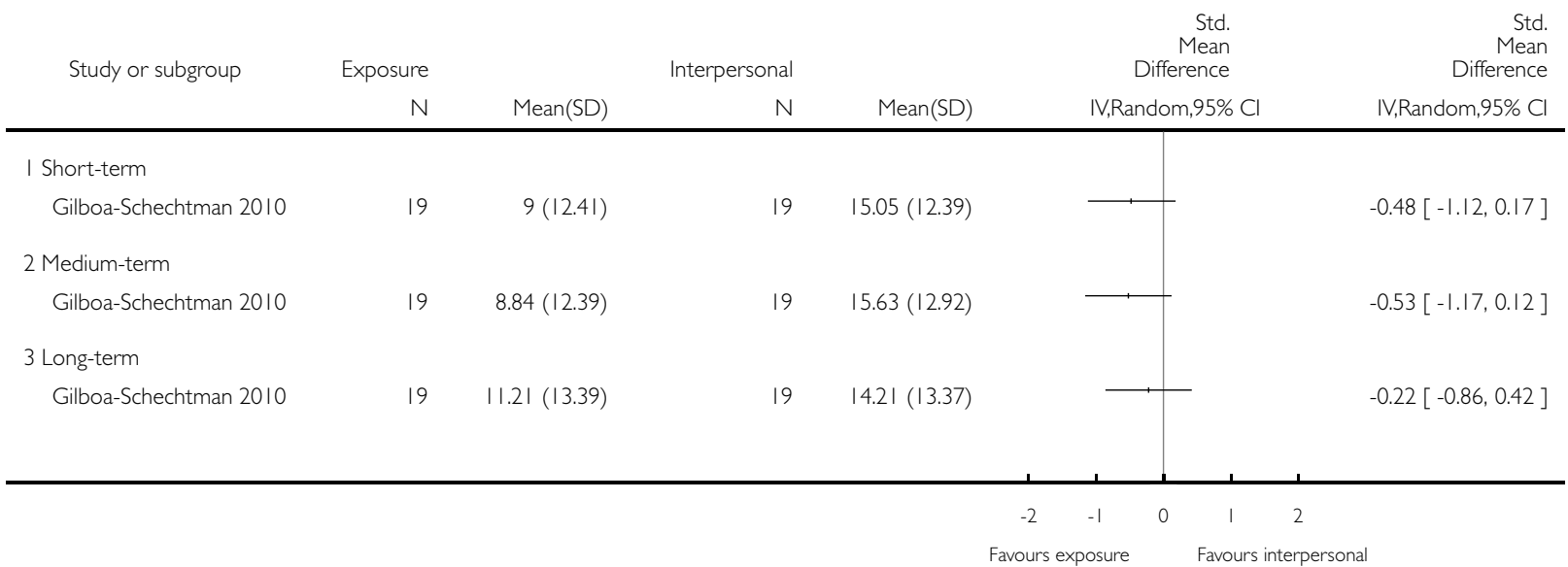

Psychological therapies for the treatment of post-traumatic stress disorder in children and adolescents (Review)

Copyright (? 2012 The Cochrane Collaboration. Published by John Wiley \& Sons, Ltd. 


\section{Analysis 9.3. Comparison 9 Exposure versus interpersonal therapy, Outcome 3 Depression.}

Review: Psychological therapies for the treatment of post-traumatic stress disorder in children and adolescents

Comparison: 9 Exposure versus interpersonal therapy

Outcome: 3 Depression

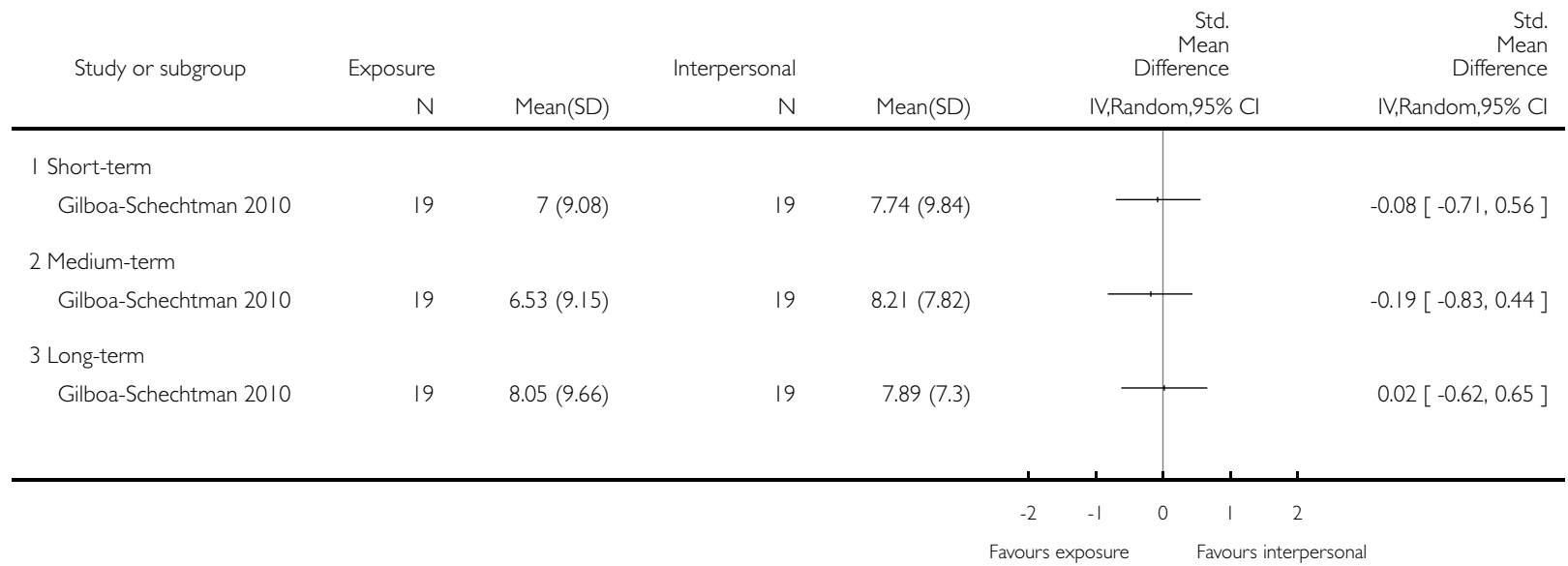

\section{Analysis 9.4. Comparison 9 Exposure versus interpersonal therapy, Outcome 4 Loss to follow-up.}

Review: Psychological therapies for the treatment of post-traumatic stress disorder in children and adolescents

Comparison: 9 Exposure versus interpersonal therapy

Outcome: 4 Loss to follow-up

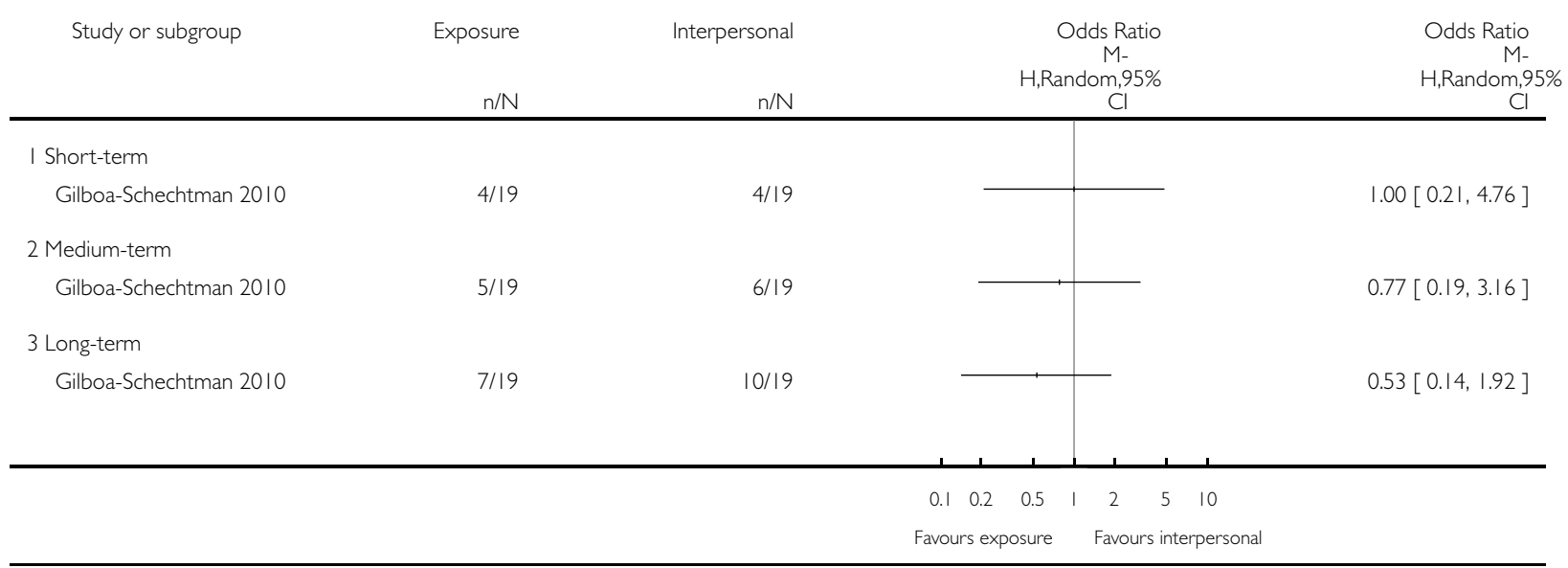

Psychological therapies for the treatment of post-traumatic stress disorder in children and adolescents (Review) 


\section{Analysis I0.I. Comparison I0 Sensitivity analysis: types of therapy, Outcome I Improvement.}

Review: Psychological therapies for the treatment of post-traumatic stress disorder in children and adolescents
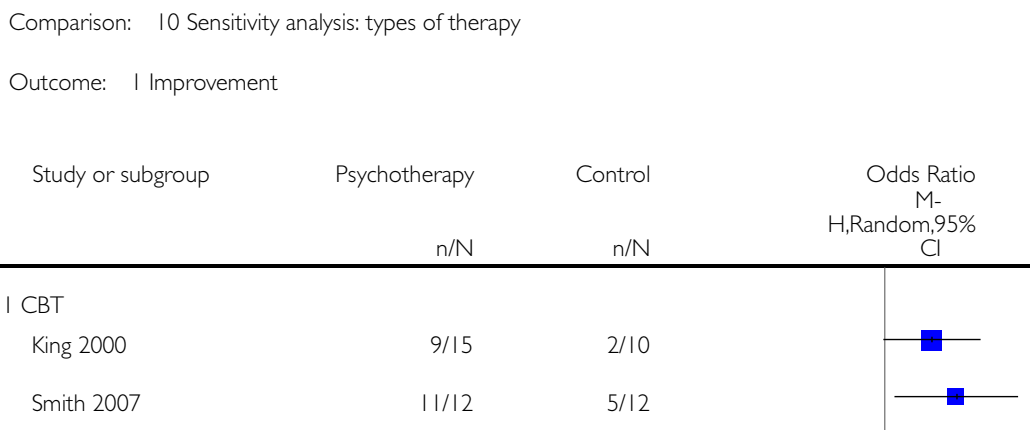

Subtotal $(\mathbf{9 5} \% \mathrm{CI})$

$27 \quad 22$

$38.6 \%$

Total events: 20 (Psychotherapy), 7 (Control)

Heterogeneity: $\mathrm{Tau}^{2}=0.0 ; \mathrm{Chi}^{2}=0.38, \mathrm{df}=\mathrm{I}(\mathrm{P}=0.54) ; \mathrm{I}^{2}=0.0 \%$

Test for overall effect: $Z=2.90(P=0.0038)$

2 Narrative

$\begin{array}{lcc}\text { Ertl 2011 } & 17 / 25 & 15 / 28 \\ \text { Ruf 2010 } & 10 / 12 & 4 / 13\end{array}$

Subtotal (95\% CI)

37

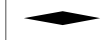

$100.0 \%$

8.64 [ 2.01, 37.14]

Total events: 27 (Psychotherapy), 19 (Control)

Heterogeneity: $\mathrm{Tau}^{2}=1.00 ; \mathrm{Ch}^{2}=2.55, \mathrm{df}=1(\mathrm{P}=0.1 \mathrm{I}) ; \mathrm{I}^{2}=61 \%$

Test for overall effect: $Z=1.51(P=0.13)$

Test for subgroup differences: $\mathrm{Chi}^{2}=0.49, \mathrm{df}=\mathrm{I}(\mathrm{P}=0.48), \mathrm{I}^{2}=0.0 \%$

41

(1)

$\%$

$59.7 \%$

$40.3 \%$

$100.0 \%$

\author{
$1.84[0.60,5.65]$ \\ I $1.25[1.65,76.85]$
}

$3.82[0.67,21.80]$ 


\section{Analysis 10.2. Comparison 10 Sensitivity analysis: types of therapy, Outcome 2 PTSD total.}

Review: Psychological therapies for the treatment of post-traumatic stress disorder in children and adolescents

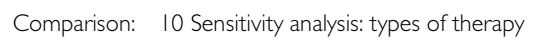

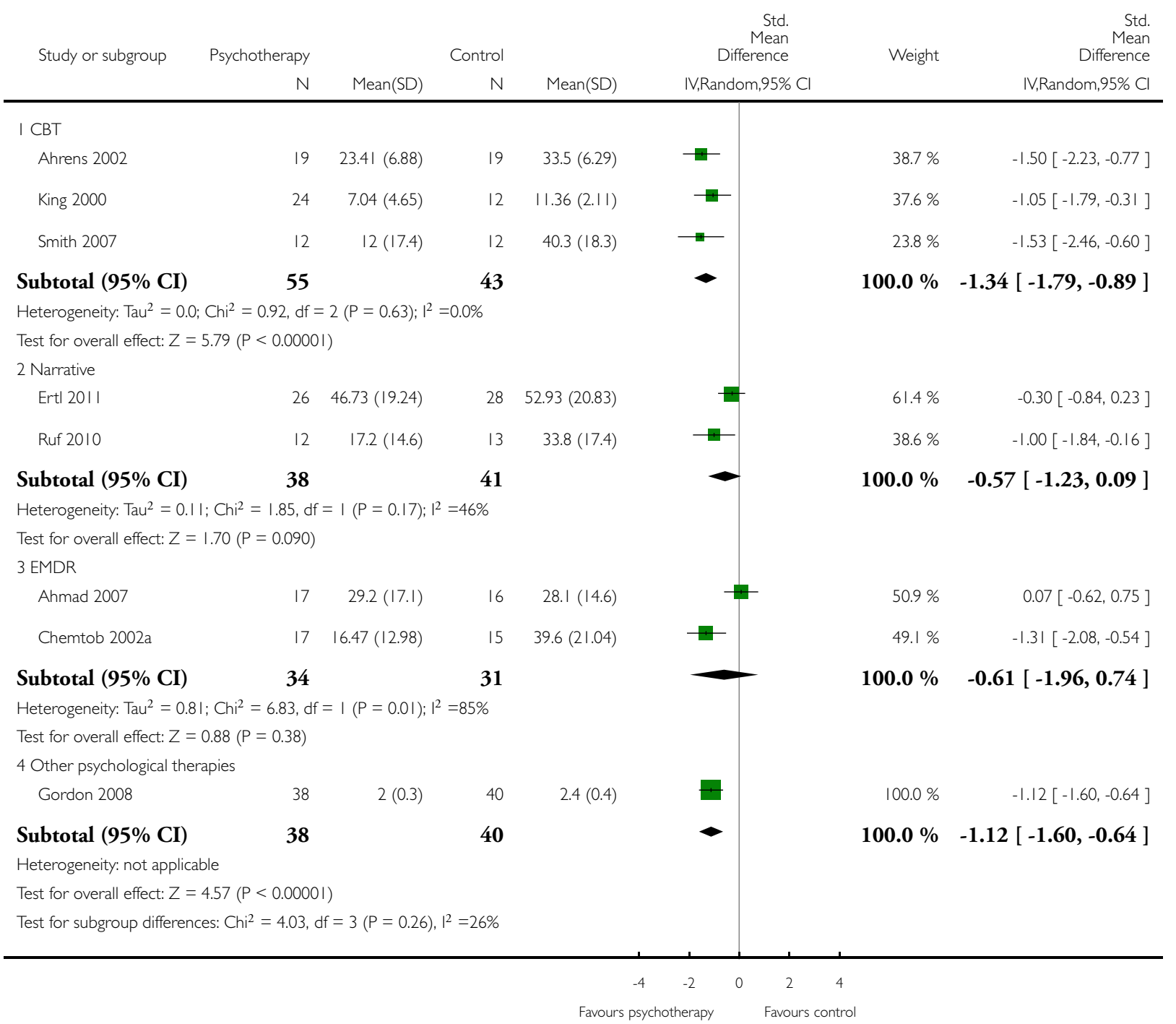




\section{Analysis II.I. Comparison II Sensitivity analysis: types of trauma, Outcome I Improvement.}

Review: Psychological therapies for the treatment of post-traumatic stress disorder in children and adolescents

Comparison: II Sensitivity analysis: types of trauma

Outcome: I Improvement

Study or subgroup Psychotherapy Control

\begin{tabular}{lll} 
& $\mathrm{n} / \mathrm{N}$ & $\mathrm{n} / \mathrm{N}$ \\
\hline $\begin{array}{c}\text { I Sexual abuse } \\
\text { King } 2000\end{array}$ & $9 / 15$ & $2 / 10$
\end{tabular}

Subtotal (95\% CI)

$15 \quad 10$

10

Odds Ratio H,Random,95\%

$\mathrm{n} / \mathrm{N}$

Cl

Weight

Odds Ratio

$\mathrm{H}, \mathrm{Random}, 95 \%$

Cl

Total events: 9 (Psychotherapy), 2 (Control)

Heterogeneity: not applicable

Test for overall effect: $Z=1.89(P=0.059)$

2 Civil/social violence

$\begin{array}{lll}\text { Ertl } 2011 & 17 / 25 \quad 15 / 28\end{array}$

$\begin{array}{lll}\text { Ruf } 2010 & 10 / 12 & 4 / 13\end{array}$

\section{Subtotal (95\% CI)}

37

41

Total events: 27 (Psychotherapy), 19 (Control)

Heterogeneity: $\mathrm{Tau}^{2}=1.00 ; \mathrm{Chi}^{2}=2.55, \mathrm{df}=1(\mathrm{P}=0.11) ; \mathrm{I}^{2}=61 \%$

Test for overall effect: $Z=1.51(P=0.13)$

3 Physical trauma

$$
\text { Smith } 2007
$$

Subtotal (95\% CI)

\section{1}

12

Total events: II (Psychotherapy), 5 (Control)

Heterogeneity: not applicable

Test for overall effect: $Z=2.28(P=0.022)$

Test for subgroup differences: $C^{2}=0.88, d f=2(P=0.65),\left.\right|^{2}=0.0 \%$

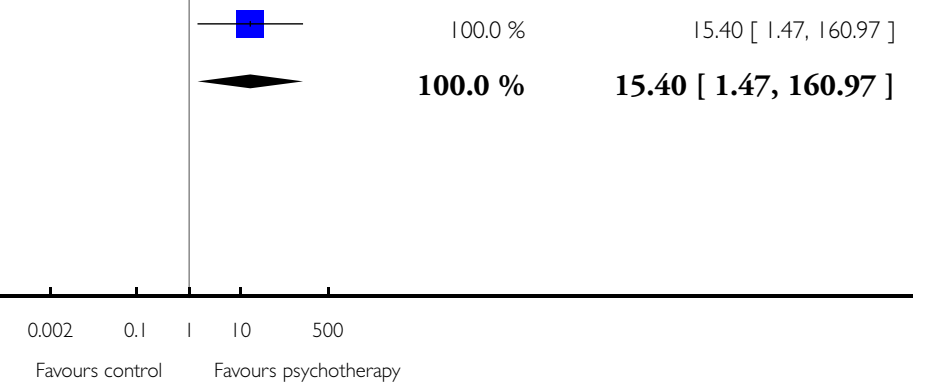




\section{Analysis II.2. Comparison I I Sensitivity analysis: types of trauma, Outcome 2 PTSD total.}

Review: Psychological therapies for the treatment of post-traumatic stress disorder in children and adolescents

Comparison: II Sensitivity analysis: types of trauma

Outcome: 2 PTSD total

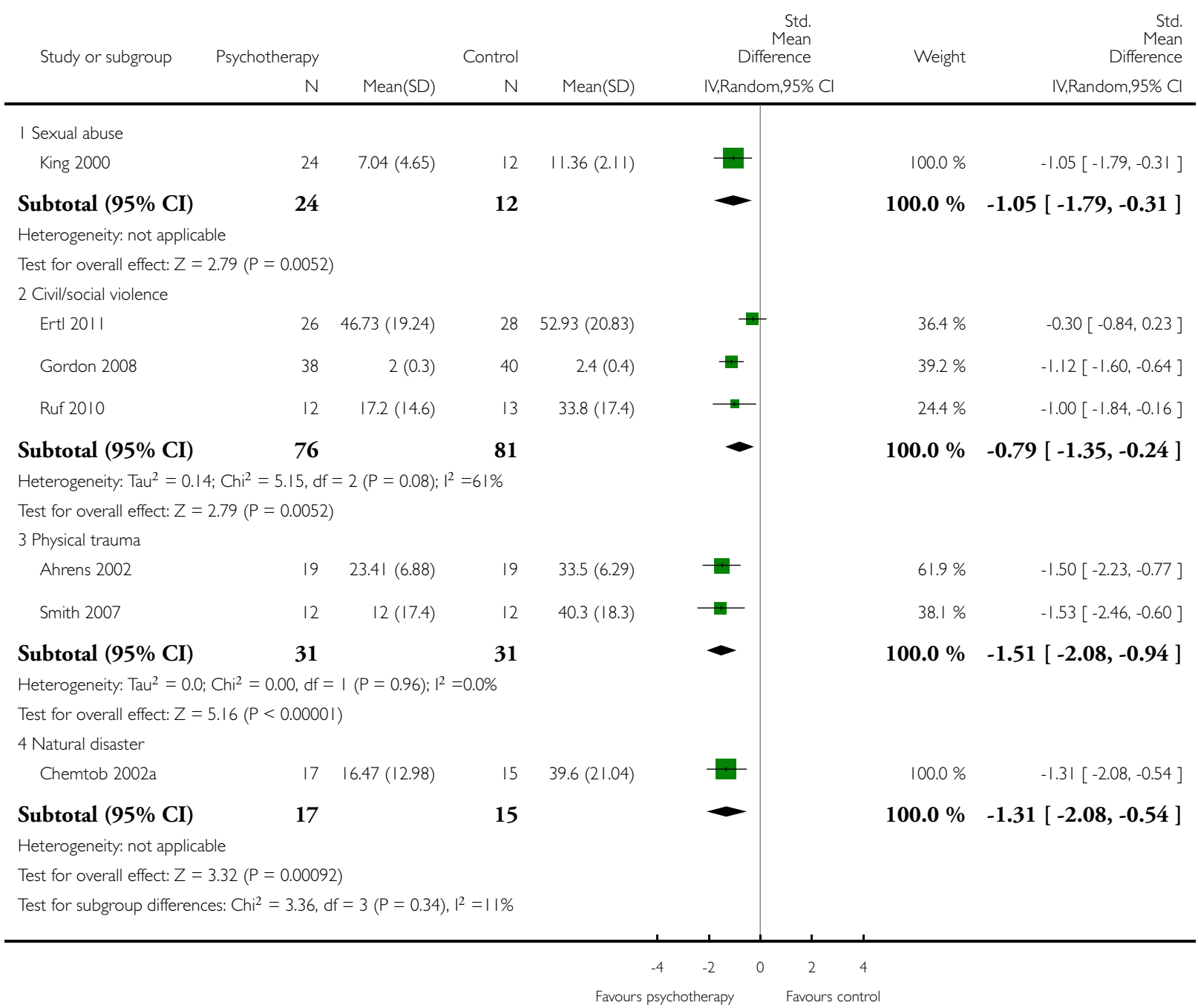




\section{Analysis I2.I. Comparison I2 Sensitivity analysis: allocation concealment, Outcome I PTSD total.}

Review: Psychological therapies for the treatment of post-traumatic stress disorder in children and adolescents

Comparison: 12 Sensitivity analysis: allocation concealment

Outcome: I PTSD total

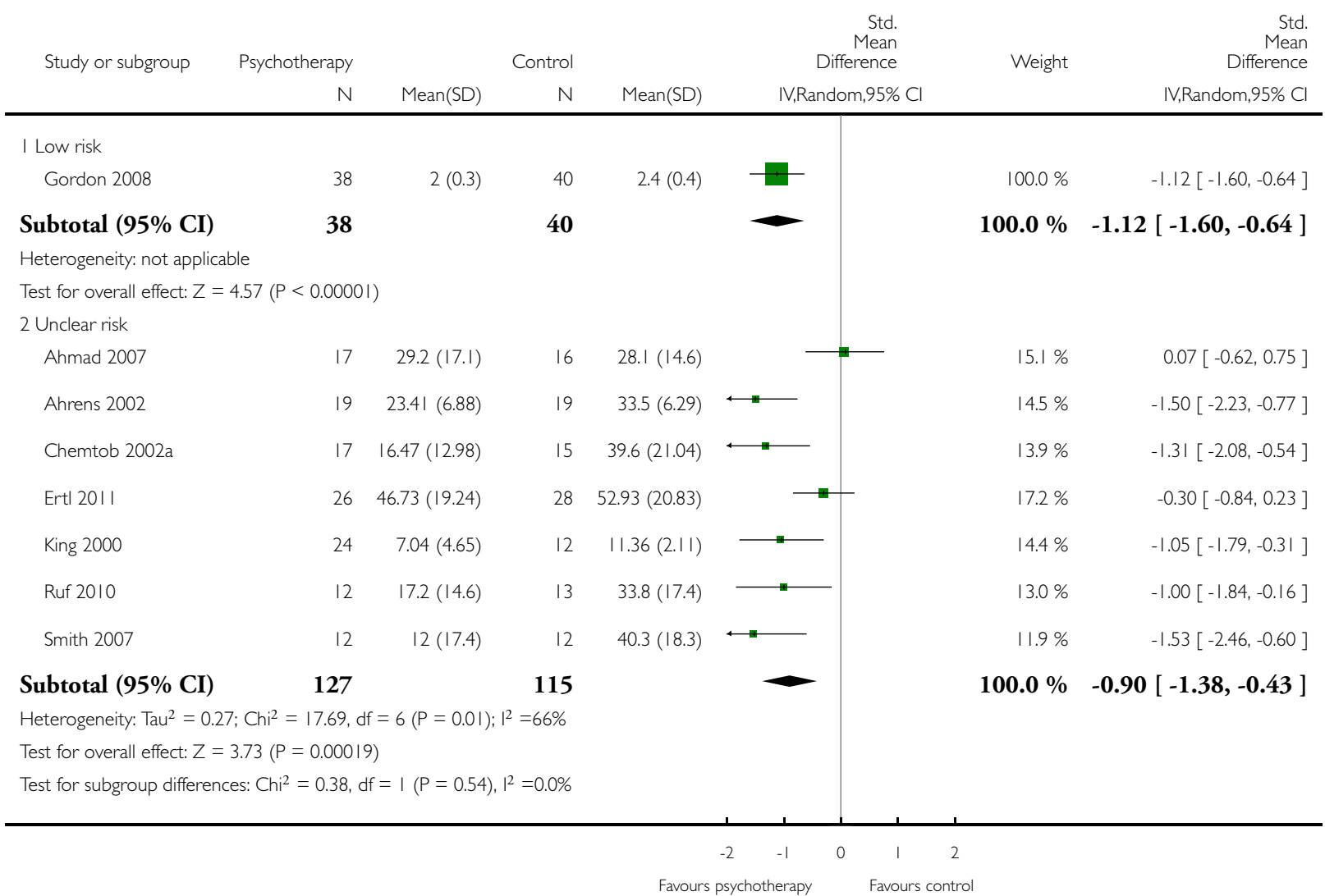




\section{Analysis 13.I. Comparison I3 Sensitivity analysis: blinding, Outcome I Improvement.}

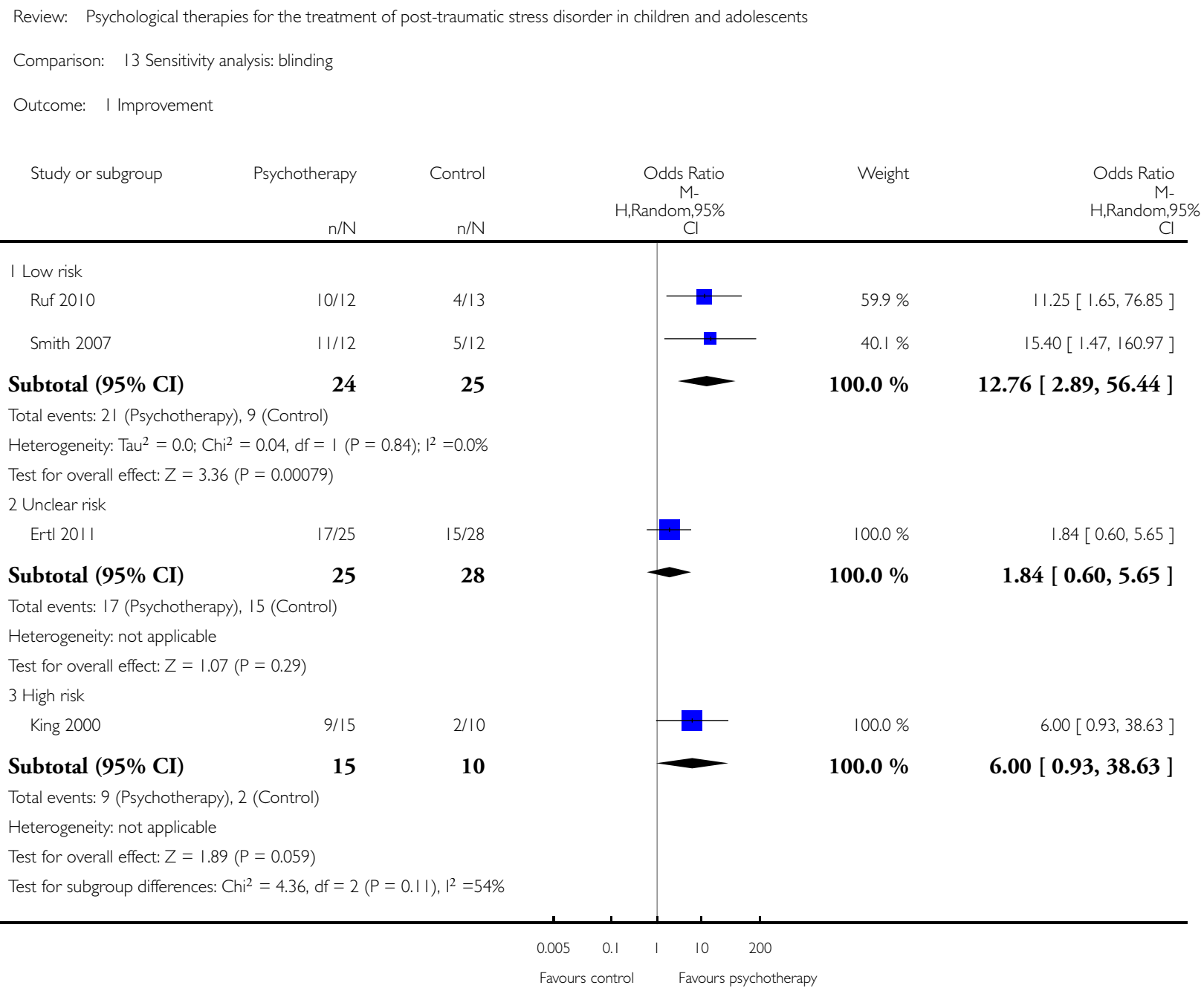




\section{Analysis 13.2. Comparison 13 Sensitivity analysis: blinding, Outcome 2 PTSD total.}

Review: Psychological therapies for the treatment of post-traumatic stress disorder in children and adolescents

Comparison: 13 Sensitivity analysis: blinding

Outcome: 2 PTSD total

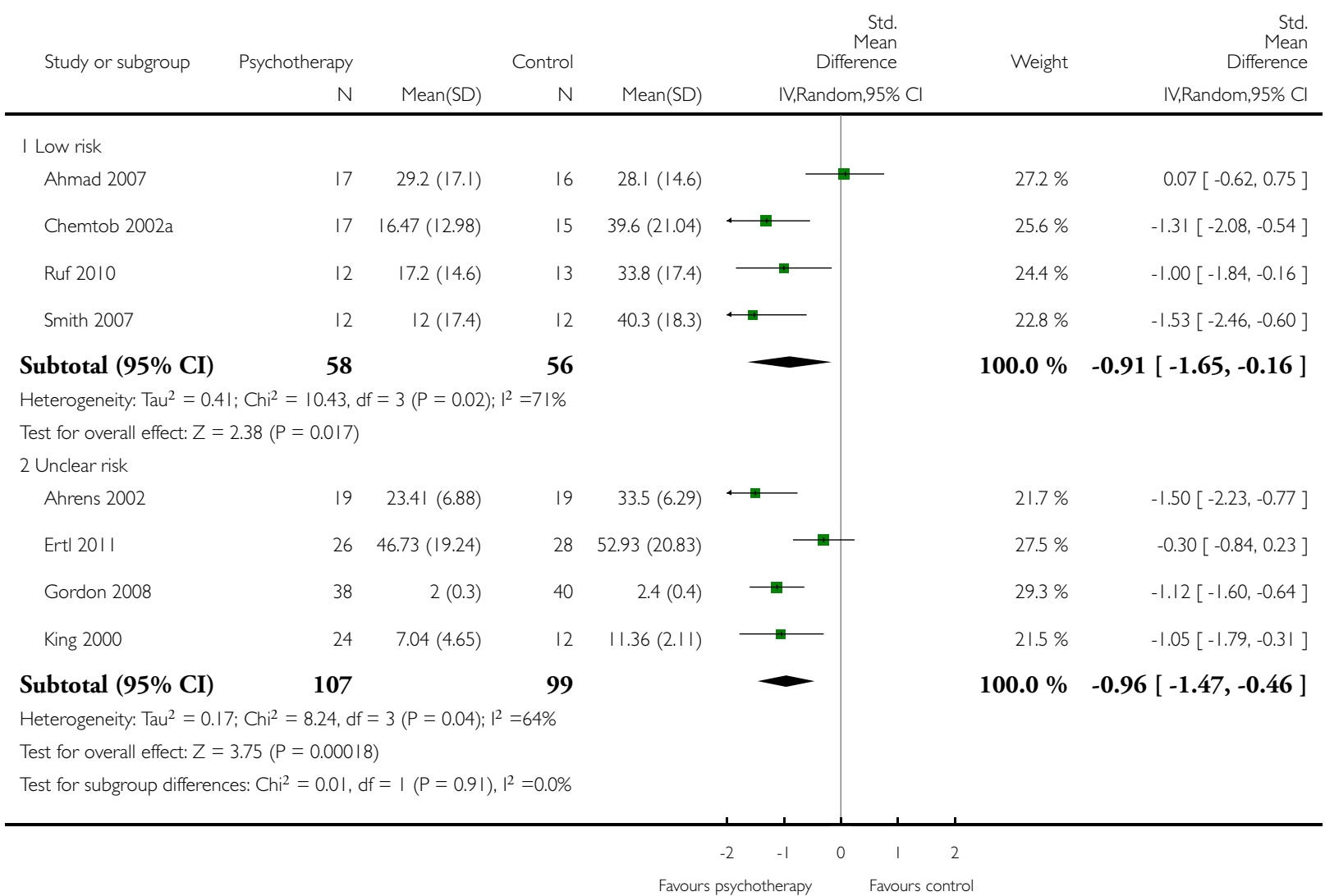


Analysis I4.I. Comparison I4 Sensitivity analysis: skewed and non-skewed data, Outcome I PTSD total.

Review: Psychological therapies for the treatment of post-traumatic stress disorder in children and adolescents

Comparison: 14 Sensitivity analysis: skewed and non-skewed data

Outcome: I PTSD total

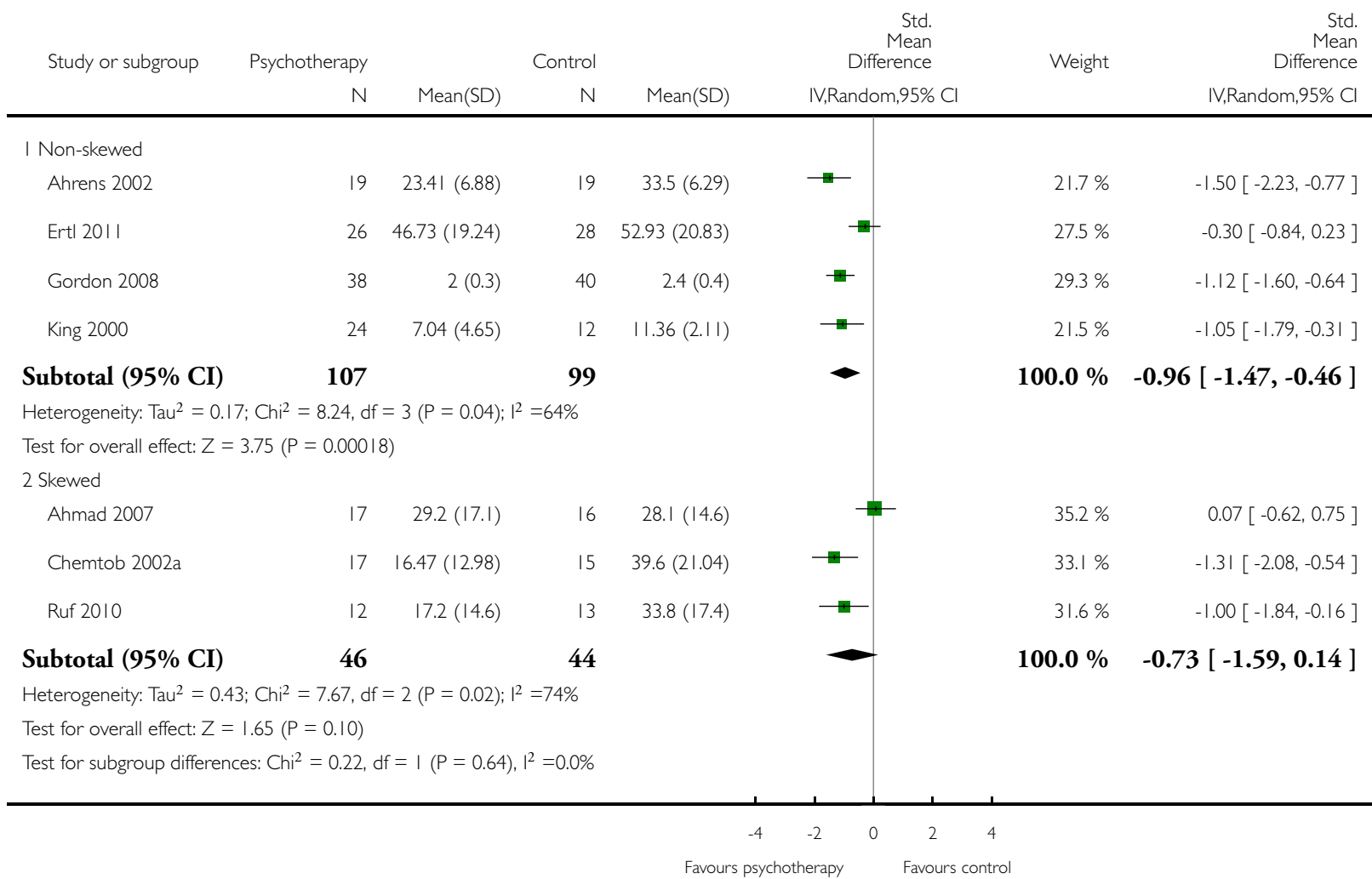




\section{Analysis I5.I. Comparison I5 ITT analysis, Outcome I Improvement.}

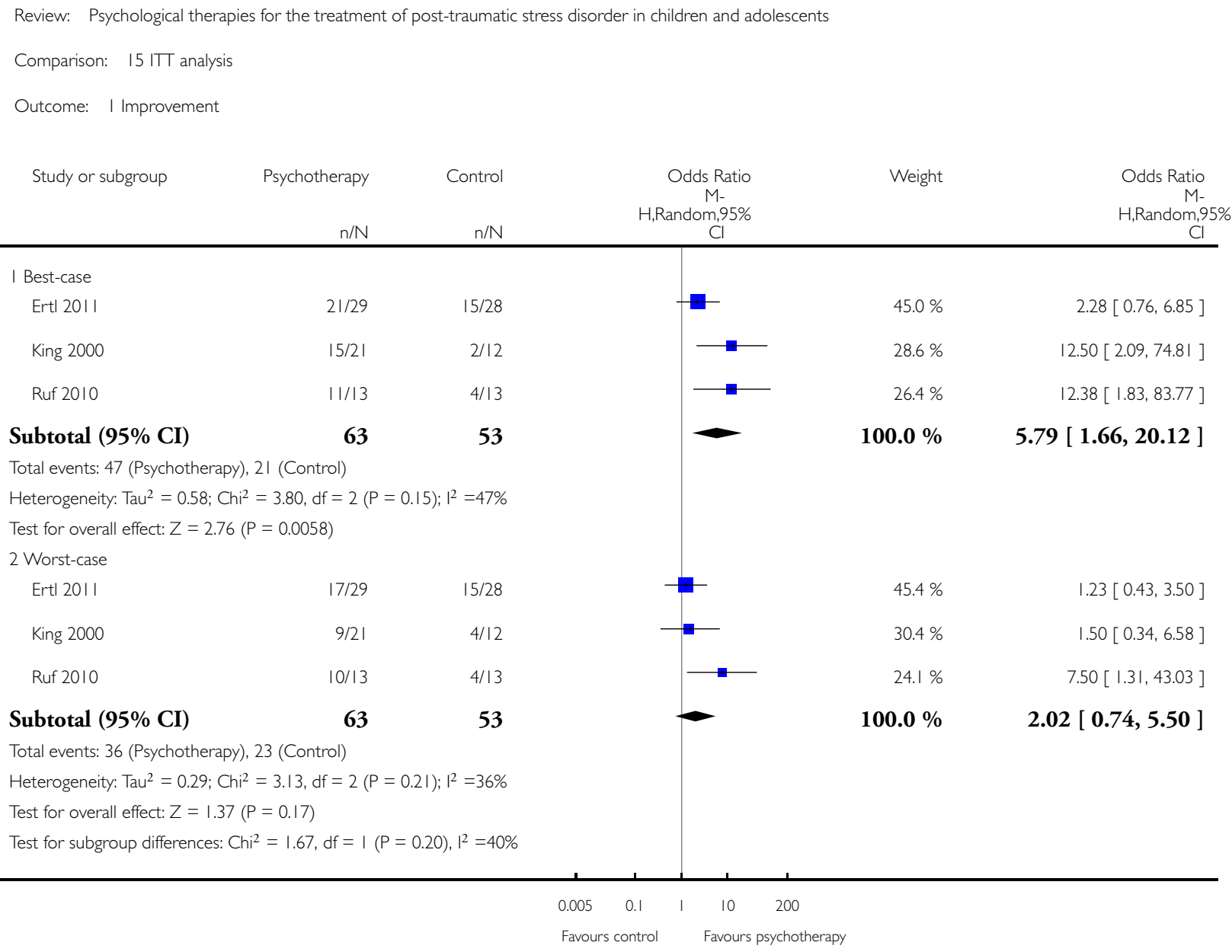

\section{H I S T O R Y}

Protocol first published: Issue 3, 2007

Review first published: Issue 12, 2012

\begin{tabular}{lll}
\hline Date & Event & Description \\
\hline 2 November 2008 & Amended & Protocol converted to new review format. \\
\hline
\end{tabular}




\section{CONTRIBUTIONSOFAUTHORS}

Donna Gillies - co-ordinating review, study selection, data extraction, data entry and analysis, writing review.

Fiona Taylor - study selection, data extraction and review critique.

Carl Gray - data extraction and review critique.

Louise O'Brien - data extraction and review critique.

Natalie D’Abrew - data extraction.

\section{DECLARATIONSOF INTEREST}

None known.

\section{SOURCES OF SUPPORT}

\section{Internal sources}

- Sydney West Area Health Service, Australia.

- The University of Western Sydney, Australia.

\section{External sources}

- No sources of support supplied

\section{DIFFERENCES BETWEEN PROTOCOLAND REVIEW}

\section{Quality criteria}

We stated in the protocol our intention to collect information for the following quality criteria. These were collected but the headings for the quality criteria have now been updated in line with the quality criteria headings in the 'Risk of bias' table.

1. Adequate allocation concealment and sequence generation

2. Clear inclusion and exclusion criteria

3. No potential confounding variables

4. Intention-to-treat analysis used

5. $<25 \%$ lost to follow-up

6. Blinded outcome assessment

\section{Skewed data}

In the protocol, it was stated that "if the standard deviation multiplied by two was greater than the mean it will not be added to the meta-analysis". However, based on statistical advice this was thought to be overly stringent. Therefore, we have included these data (and carried out a sensitivity analyses as described above) but excluded data where the standard deviation was greater than the mean.

\section{Meta-analytic model}

In the protocol for this review, it was stated that meta-analysis of binary and continuous would be calculated using a fixed-effect model but if there was significant heterogeneity, a random-effects model was to be used. However, during the editorial process, the editors concluded that it was preferable to use random-effects throughout. 


\section{Categorisation of psychological therapies}

It became apparent to us during the review process that some of the psychological therapies described in included studies were not based on any clear theoretical domain, we made the decision to include these under the heading of 'Other psychological therapies'.

\section{INDEX TERMS}

\section{Medical Subject Headings (MeSH)}

Cognitive Therapy; Psychotherapy [* methods]; Randomized Controlled Trials as Topic; Stress Disorders, Post-Traumatic [psychology; *therapy]

\section{MeSH check words}

Adolescent; Child; Child, Preschool; Female; Humans; Male 